\title{
Water Logged Mona Lisa: Who Is Mary Sue, and Why Do We Need Her?
}

\author{
by \\ J.M. Frey \\ Bachelor of Arts, Dramatic Literature (Brock University, 2005)
}

\author{
A Master's Project \\ in partial fulfillment of the requirements for the degree of \\ Masters of Communications and Culture \\ in the program of \\ Communications and Culture \\ Ryerson University and York University
}

Toronto, Ontario, Canada

2009

(c) J.M. Frey 2009 
You're floundering the waters of a flood;

The Mona Lisa and a babe float by.

Which one of these two treasures do you save?

Anne-Marie McDonald, "Good Night Desdemona (Good Morning, Juliet)" Act II, scene $i$ 


\section{Author's Declaration}

I hereby declare that I am the sole author of this thesis or dissertation.

I authorize Ryerson University to lend this thesis or dissertation to other institutions or individuals for the purpose of scholarly research.

I further authorize Ryerson University to reproduce this thesis or dissertation by photocopying or by other means, in total or in part, at the request of other institutions or individuals for the purpose of scholarly research. 


\section{Acknowledgements}

A very heart-felt thank you to Dr. Jennifer Brayton of Ryerson University, my primary supervisor and primary friend while writing this paper. Thank you also to Dr.s Stuart Murray and Steven Bailey, my committee, and those academics and authors who patiently answered my many and varied letters. Thank you to those many friends who have held my hand, read drafts, and urged me forward, including but not limited to Stephanie Lalonde, Karen Wood, and Marika Wood. And lastly, a massive thanks to my parents, my brothers, and my family, who taught me that I could do anything I wanted, as long as I worked hard enough at it.

\section{Dedication}

This is for those fan crafters who unabashedly love Mary Sues as much as I; some of you I know personally, some only online, and some of you I've yet to have the pleasure to meet (though I do lookforward to it). 


\section{Table of Contents}

\begin{tabular}{|c|c|}
\hline $0:$ Abstract & 5 \\
\hline 1: Personal Context & 6 \\
\hline $\begin{array}{l}\text { Being an anecdote of my first encounter with Mary Sue. } \\
\text { a: Being Mary Sue } \\
\text { b: My Research Question And A Quest For Answers }\end{array}$ & $\begin{array}{l}6 \\
9\end{array}$ \\
\hline 2: Literature Review & 12 \\
\hline $\begin{array}{l}\text { Being a look at the history and definition of fanthropology, and present Mary Sue research. } \\
\text { a: Definition of Fancrafting } \\
\text { b: A History of Fanthropology } \\
\text { b.i: Focus on Fanfiction } \\
\text { c: Literature on Mary Sue } \\
\text { c.i: Chaunder \& Sunder } \\
\text { c.ii: Rebecca W. Black } \\
\text { c.iii: Pat Pflieger } \\
\text { c.iv: Lelac Almagor } \\
\text { c.v: Ika Willis } \\
\end{array}$ & $\begin{array}{l}12 \\
21 \\
23 \\
24 \\
25 \\
25 \\
26 \\
27 \\
27\end{array}$ \\
\hline 3: Methodology & 29 \\
\hline $\begin{array}{l}\text { Being an explanation of my own research biases, and the methods I used to research. } \\
\text { a: Academic Sources } \\
\text { b: Content Analysis of Mary Sue Stories and Web Sites/Communities } \\
\text { c: Survey of Fan Crafters } \\
\text { d: Writing Mary Sues }\end{array}$ & $\begin{array}{l}29 \\
30 \\
31 \\
31\end{array}$ \\
\hline 4: The Social Construction of Mary Sue & 33 \\
\hline $\begin{array}{l}\text { Being an attempt at formulating an answer to the question "Who Is Mary Sue?" } \\
\text { a: Who Is Mary Sue? } \\
\text { a.i: Why She is Hated } \\
\text { a.ii: Why She is Loved } \\
\text { b: Characteristics of the Mary Sue } \\
\text { c: The Five Archetypes of Mary Sue } \\
\text { c.i: Thief of Mythos } \\
\text { c.ii: Commenter on Narrative Convention and Deconstructer of 'Inherent Truth' } \\
\text { c.iii: Literary Masturbation } \\
\text { c.iv: Forcing a Subject Position in an Otherwise Unaccommodating Text } \\
\text { c.v: Meta Sue } \\
\text { d: Why We Need Mary Sue } \\
\text { d.i: Pedagogical Applications in Narrative Structure and Story Making } \\
\text { d.ii: Self-Exploration and Expression }\end{array}$ & $\begin{array}{r}33 \\
37 \\
42 \\
44 \\
53 \\
543 \\
54 \\
54 \\
57 \\
63 \\
66 \\
67 \\
68\end{array}$ \\
\hline
\end{tabular}




\begin{tabular}{|l|r|}
\hline 5: The Project & 69 \\
\hline Being an investigation of the novels that I wrote. & 70 \\
a: Across Time & 76 \\
b: Slipstream & 86 \\
c: The Dark Side of The Glass & 91 \\
d: First Impressions & 97 \\
\hline 6: Conclusions & \\
\hline Being a summary of this project and its strengths and weaknesses. & 97 \\
a: Answering the Research Question & 99 \\
b: Weaknesses & 101 \\
c: Strengths & 111 \\
\hline 7: Bibliography and Works Cited & 111 \\
\hline 8: Appendices & 114 \\
\hline Being an assemblage of relevant documents which illustrate the precedence of Mary Sue. \\
a: The Mary Sue Checklist & 115 \\
b: "A Trekkie's Tale" by Paula Smith & 120 \\
c: "A Mary Sue Alphabet" by Irony-chan & 121 \\
d: Survey Questionnaire & $\mathrm{CD}$ \\
e: Excerpt from "Madmen and Blackflies" by JM Frey & \\
& \\
Accompanying CD: & \\
Being a CD of documents too large to print, but too important to leave out. \\
PDF versions of the complete unabridged manuscripts of "Slipstream" and its sequels (as \\
completed to date of publishing), "Across Time" and its sequel, "First Impressions", and \\
"The Dark Side Of The Glass".
\end{tabular}


Water Logged Mona Lisa: Who Is Mary Sue and Why Do We Need Her?

Masters of Communications and Culture, 2009

JM Frey

Masters of Communications and Culture, Ryerson University

\section{0: Abstract:}

Theorists suggest that participatory readers create mainstream-based texts - fan crafts - in order to address the ways they are 'hailed' by the themes and subject positions offered by a text by becoming textual re-writers (Jenkins, 1992, 2003 ; Busse \& Hellekson, 2007; Chander \& Sunder, 2007; Willis, 2007). Re-writers force their personal position or opinions into the centre by creating fanworks based in and on established media texts.

The 'Mary Sue' is a self-gratifying fan-crafting trope centered on an idealistic authorrepresentative character, a wish-fulfillment device for the re-writer that bridges the re-writer's reality and that of her favoured fiction.

This paper is a comprehensive summarizing of the 'Mary Sue' and its precedents. It asks how they can be deployed as Meta Sues to actively investigate the self or marginalized subjects in media texts. It is accompanied by four examples of my Meta Sue prose, which further illustrate my arguments. 


\section{1: $\underline{\text { Personal Context }}$}

\section{a: Being Mary Sue}

In 1990, a television program staring Geordie Johnson and Bernard Behrens, playing Count Dracula and a descendant of Dr. Abraham Van Helsing respectively, caught my attention. The program focussed on the struggles between Dracula, now a prominent international business mogul named Alexander Lucard, and Gustav Helsing, an aging, ailing vampire hunter bent on fulfilling his family legacy and wiping Dracula off the Earth. Bumbling but well-meaning Gustav was accompanied by Sophie Metternich (Mia Kirshner), Gustav's pretty young ward, and allAmerican boys Christopher (Joe Roncetti) and Max Townsend (Jacob Tierney), Gustav's nephews.

I was the wrong gender, and too young to be within the target demographic - boys, aged 10-15 - the first time the program aired. Several years later, the program went into syndicated reruns, and by then my life-long fascination with vampire mythology was already firmly entrenched thanks to a collection of short stories titled The Rivals of Dracula (1978), and the film Interview With the Vampire (1994). Dracula: the series was the distillation of everything I wanted in a television program; vampirism, clever situations, magic, and most importantly, a female character with whom I could identify fully - my age, my ethnicity, my fixation with classical music - and a handsome villain who desired her to the point of fatal obsession. Luckily, my interest in the series intersected with my discovery of its online fan communities.

The series' fanbase was relatively small, and populated with fans who predominantly wrote queer love stories about Lucard and his lackey Klaus Helsing, or coming-of-age stories about the children. I was particularly enamoured with the relationship-building in the show, and the undercurrent of sexual tension that accompanied Lucard's kills and underscored his 
interactions with his minions and enemies. In retrospect, a third important event was also occurring; I was becoming aware of myself as a sexual being. Sophie mirrored this: we were both starting to date, both did not quite understand sex, both had a strange fumbling ability to make others desire us. However, the lack of any serious investigation into sexual relationships within the program (it held a PG-13 rating and was aired on Saturday mornings) meant that I felt a distinct absence of any sort of meaningful connection on a sexual level.

I wrote a story about Elana Seward, an invented cousin of the Helsings who falls into a sexual relationship with Lucard. I wanted to explore what Sophie had with Lucard but go further, to talk about the pleasure/pain binary that the vampire produces, the BDSM${ }^{1}$ undertones of the character's relationships, the near-rape that was a vampire kill, all the things that were fascinating and dangerous and safe to fantasize about because, after all, vampires aren't real. In order to do so, Elana had to usurp Sophie's relationship with Lucard, and take it a step beyond what the show's rating allowed. Elana gives in to Lucard's demands, becomes his slave in order to save the lives of the Helsings, and over the course of several chapters accepts her own sexual identity as Lucard shapes it in a predominantly Dominante/submissive sexual relationship; I had a space to safely explore those aspects of sexuality that society often labelled taboo, and experiment without consequence.

Later that evening, Lucard tapped gently on the panel of the trap-door. After gaining permission to enter he found Elana lying on the bed, reading one of his particular favorites from the vast collection of 'Dracula' books. Quietly, he crawled onto the bed beside her. Elana gasped in surprise as Lucard wrapped one of his powerful arms around her waist, pulling her front flush against his. With the other hand his gently grabbed her book and tossed it aside. "Hello." He smiled.

"Uh...." was all she managed to say before Lucard possessively covered her lips with his own. There was a long silence and Alexander eventually released Elana's mouth. She took a deep breath and murmured something that sounded like, "Yikes..."

\footnotetext{
${ }^{1}$ Bondage sexual subculture.
} 
Lucard laughed lightly and began to nuzzle his favorite part of her anatomy, nibbling lightly at the nape of her neck. Eventually though, as she began to gasp and lean against him, Alexander broke the skin and began to once more imbibe the coppery fluid that welled up.

Elana shivered violently. Partly from the sensation of being feed off of, party from the horrific memories of the months before when he had... raped her. Being forced into a situation like this was indeed equal to rape, and Elana still suffered nightmares from it, but now it was different. She wasn't under a mind-lock, and so was perfectly able to fight back, but Elana wasn't sure she wanted to.

Lucard could shift emotions very easily and violently, he was very temperamental, and Elana was afraid of what he might do if she resisted. She didn't want to be a vampire, but she wasn't sure that that was what was happening. Besides, all that sucking felt pretty damn good... (Frey, "A Deal With Dracula", chapter 2)

I was a young teenager when I wrote it, and it was my first attempt at fiction writing. It is rife with spelling errors, cliché and melodrama, but it was an extremely important manifesto of my awakening womanhood. I do not recall at what age exactly I completed the story, but I posted a copy of it in 2000 on the online archive Fanfiction.net. I chose not to revise "A Deal With Dracula", even though I had by then acquired more technical and poetic skill. The first few reviews from readers were tentative but encouraging, praising my imagination and my clear writing style. The second half, however, were not:

Dear god, sweetheart, get ${ }^{*}$ over* yourself and your rape fantasies. If you want to write original characters like this write *original ${ }^{*}$ fiction, don't burden canon characters with her, or write them so out of character they can't be recognized just so "Elana" can be told over and over that she's the most beautiful girl ever and that they've wanted her for all time and now they will have their wicked nasty man-way with her.

Can I introduce you to someone named Mary Sue? Really, if you want to write characters like this, do it *outside* of a fandom. Fanfics are supposed to be about the characters in the series, not about you/your avatar (Adrian, reviewer, 2005).

In a review I have since deleted due to the extreme vitriol of its contents, I was brusquely informed that my disgusting story was offensive, puerile, and worst of all, badly written. The reviewer degraded me for my inability to keep the canonical characters in character, my typos, and simpering and unlikeable heroine, who was, to her great horror, a Mary Sue.

'Mary Sue'? I didn't know this term. 
The review hurt. I had been attacked on a personal and private level, hit right where I was least confident. I had invested a great deal of myself in Elana Seward, and though the writing wasn't the best example of my ability, I felt that the story still had merit. I gave up writing for a while. I contemplated deleting the story from the archive, but decided to leave it up to see what other sorts of comments I received. Some called Elana a Mary Sue, some praised the prose, and some pointed me to a community where people were openly mocking my writing, and the writing of other people who wrote Mary Sues as well.

This was before Wikipedia, so it took me several hours of reading blogs and instructive articles on fan fiction before it became clear what, exactly, had been so offensive about Elana Seward, what in her construction made her a Mary Sue. There was no universal list of character traits or plot summaries that defined what a Mary Sue was, but the concept was taking shape. I didn't understand; if I had created something unwelcome by fan readers, why were there so many positive reviews on the story? Then I was intrigued - what was it, exactly, that made them hate it? At what moment had I moved beyond Original Character into the reviled Mary Sue? Was it something traceable? Was it something I could define, grasp, pinpoint, or could stretch? Could I make a good Mary Sue? A liked Mary Sue where readers still knew her for what she was? I was on a mission. I was going to write a Mary Sue story that people enjoyed, that explored what it meant to expose oneself as I had, knowingly and with purpose.

I was, in retrospect, determining to create the first Meta Sue.

\section{b: My Research Question And A Quest For Answers}

Having been thus labelled by my readership, the question I was forced to ask myself next was 'What is a Mary Sue, exactly?' Before I could rise to my personal challenge, before I could be comfortable in the label, I wanted to understand its implications. Yet I had no definitive 
definition. I read Goodnight Desdemona (Good Moring, Juliet) (1990) by Anne Marie

MacDonald, a play whose main character Constance Ledbelly is a Mary Sue, as far as I was able to determine. I was astonished; here was a Mary Sue that was embraced by the literary community, loved by the professional critics and artists. I asked myself: 'Why Constance, and not Elana?' Why not Azilin ${ }^{2}$ or Ningen ${ }^{3}$ or other Mary Sues I had since created purposefully to test audience reaction? It was clear that a Mary Sue could be professionally written but, I wondered, could one be written by an amateur such as myself - or myself specifically - and be just as accepted, just as liked? Using Constance as a jumping off point, I began writing a Mary Sue Checklist, a manifesto document for what defined a Mary Sue. During its construction, other questions emerged: 'What characteristics define or situate a Mary Sue character? What archetypes of the Mary Sue exist? How have others defined Mary Sue in their own writings?' I wondered if Anne Marie MacDonald's triumph with Constance Ledbelly was a fluke, and if I could mimic her ability to write a Mary Sue who was still enjoyed by readers. I read Mary Sue stories obsessively, discovered Paula Smith's A Trekkie's Tale, the story from which the term 'Mary Sue' derives, but not the concept. I combed story reviews, looking for clues to why my characters were loved or hated (or both). I joined online communities both supporting and deriding Mary Sues, entered discussions, and above all of it, still questioned: What, exactly, is a Mary Sue? And how can I write one people enjoy?

I turned to academia; the field of fandom studies - fanthropology - is massive. I discovered Matt Hills, Hellekson \& Busse, and Henry Jenkins, who coined the term 'aca-fan' for

\footnotetext{
${ }^{2}$ From the stories "Spider" and "Wolf", both set in the animated series Inu Yasha. I wrote this story to try to define what separated a Mary Sue from an Original Character.

${ }^{3}$ From the stories "Ningen", "Rabusongu" and "Kado", set in the animated series Dragonball Z. I wrote this story to explore the tendency toward failing to be traumatized by traumatic events in Mary Sues; $I$ consider it a failed experiment, as the narrator was widely believed by readers to actually be in love with the villain, when I meant to convey that she was suffering from Stockholm Syndrome.
} 
those scholars like myself who study fandom from the perspective of, and as, a fan. Yet in the work of other theorists I found only paragraphs, brief one-line descriptions, nothing conclusive, nothing definitive about who Mary Sue is and why she functions the way she does. Only five essays - to be discussed in the next chapter - held any attempt at defining Mary Sue, and even then they discussed Mary Sue as a tool and not as a character archetype. It seemed that I was going to have to fill the gap and write the definitive definition myself. I was going to have to find a way to write a Mary Sue that people enjoyed reading.

To do that, I determined, I would have to discover and define what it is exactly that makes people react negatively to a Mary Sue, why they label them trivial, immature, unconscious; I would then invert the clichés, play with them in an intentional way, create a Mary Sue that could deconstruct herself while still being a viable and likable original character in a functioning narrative, and thus become intentional, analytical, conscious; in short, a Meta Sue. 


\section{2: Literature Review}

I think fan fiction is a group process. You're playing in an online sandbox and everyone is using the same toys to make their own unique sand castle. There's no dreary World building. You don't need to invent characters people can relate to. That stuff is all there. You can just jump straight into your story knowing your readers already know and enjoy your characters as much as you do.

-Korilian

\section{a: Definition of Fan Crafting}

Historically speaking, literary theory generally tends towards a specific, time-honoured interpretation of a classical work. This canonical methodology, typically from the viewpoint of the heterosexual Caucasian male, brings with it inherent binaries of understanding and meaning, which originates from, and thus reinforces, a heterosexual Caucasian male viewpoint. However, the advent of gender and feminist theory, post-structuralism, audience studies, and other such fractal theoretical models force a re-examination of both classical literary works and the canonical theoretical interpretations of said work. The work of Constance Penley (1992), Henry Jenkins (1992; 2006), Matt Hills (2002), Hellekson and Busse (2007), and Harold Bloom (1973) among many others are particularly concerned with the 're' aspect of literature interpretation, the creating-as-rewriting, though each with different creative outputs, from the written word, to restaging, comics, costuming, and visual art in all its various mediums. Among these reinterpretations is a method of working with the text known variously as fanfiction, fanficcing, or fan art. Fans create tales, art, music, videos, craft projects. etc from pieced together 'patches' of different media text literatures, theories, and lived narratives in order to force a professional and/ or copyright protected canonical work to talk about the crafter's lived life, their marginalized subject positions, and their concerns. Post-modern works, such as re-quel novels, film adaptations, novelizations, and comic adaptations are fan crafts by definition, are an answering-back to re-examinations, providing prose examples of what theorists envision. The 
difference with the professional work of art or fiction being that the creator owns the copyright and from which the creator makes a profit, and usually the text is derived from earlier works of literature that have since expired their copyrights and now fall under the category of Fair Use / Public Domain intellectual property. One such example is Gregory Maguire's novel Wicked: The Life and Times of the Wicked Witch of the West. ${ }^{4}$ based on Frank L. Baum's The Wizard of $\underline{\mathrm{Oz}}$, which examines the political consequences of the Wizard's usurpation of Oz's throne and casts the formerly Wonderful Wizard as a Caesar/Hitler-esque tyrant. Retelling these tales is very much like quilt work in that it helps readers and writers to (re)create their own identities and (re)create literatures, and the grand narratives of their own personal culture through the use of pre-existing narrative fabrics. Other examples include author P.N. Elrod's series wherein Bram Stoker's character Quincy Morris was turned into a vampire by Dracula and must regain his friends and loves (the copyright on Dracula expired in 1947 and is public domain, answering to no copyright or estate ownership) and Jane Austen has suffered an uncountable number of unauthorized sequels, retellings, and alternate histories, some even while she still lived or her family still collected copyright fees (Ray, 2006). Children's books, such as Holly Claus: the Christmas Princess by Brittney Ryan (2007) or abridgements of classical stories fall under this category, as do novelizations of films. There are many restructured retold, and recirculated fairy tales beyond Maguire's award winning novels, and classic movies, novels, and straight plays are often reworked into musicals or new films. These can all be conceivably labelled fan fiction in all ways except that these writers receive a wage. Fan work, on the other hand, is created based on or with previously copyrighted intellectual property, without the explicit consent of the copyright holder, and without profit. In some cases, fan work actually works on a deficit, as fans

\footnotetext{
${ }^{4}$ And it's sequels Son of a Witch and Lion Among Men, as well as the Broadway musical adaptation Wicked, which refocuses the story in Maguire's book onto the broken friendship of the witches of the West, Elphaba, and North, Galinda.
} 
spend their own money to create fan work that they are not remunerated for either out of respect for the copyright holder or fear of legal retribution, or, and this is the more usual case, out of the love for the text and the recipients, their fellow fans.

Harold Bloom argues that great literature must always struggle with the tension between originality and our expansive creative history as humans, trying to find a balance between the burden of inherited stories and creativity, what he calls the "Anxiety of Influence" (Bloom, 1973). Fan, however, embrace this burden; the patches that they select from the fabric of canon texts are chosen particularly for the information, morals, clichés, tropes, and allusions already woven into the weave of the material. This gives them the ability, like quilters, to world-build and narrative-build, to tell a story, without having to struggle with the more difficult aspects of originality or creativity. They can focus instead on the message or entertainment. To use another allegory, they are like children playing with letter blocks to spell words; the work of crafting the letters and writing the alphabet is taken care of for them, so they can concentrate instead on spelling out their messages. They give creators - both professional and amateur alike - the ability to demarginalize their own voices and experiences, deconstruct the paradigms of classical theoretical interpretation, and destroy the walls between amateur, the professional, and the academy by utilizing commonly known literature, theory, and media texts to tell personal narratives that have the ability to change the way the author and her subject position are viewed.

Every day, thousands of amateur authors and traditional/media artists create uncountable numbers of such pre-, se- and re-quels in the form of art, videos, costumes, and literature, based on their preferred media texts, such as comic books or graphic novels, movies, television programs, and books. These creations - what I term fan crafts due to their not-for-profit and 
hand-made-gift qualities - are direct challenges to the time-honoured interpretations and the concept of copyrighting intellectual property, art.

This subversive faction of viewers/readers do not limit their interaction with mainstream media texts to mere consumption. This group of reader/consumers is referred to by cultural communications theorist Henry Jenkins as 'participatory readers'. Several cultural theorists have suggested that these consumers create mainstream-based texts - fan fictions - in order to address the ways they are 'hailed' by the subjects and subject positions offered by a text (Jenkins, 1992, 2003 ; Busse \& Hellekson, 2007; Chander \& Sunder, 2007; Willis, 2007). Other scholars have called this 'participatory readerships' (Matt Hills, 2002; Jenkins 2004,2006) or 'textual poaching' (Jenkins, 1992), 'active consumership', 'remixing' or 'blending cultural artefacts' (Lankshear \& Knobel, 2006) and 'derivative texts' (Black 2008). I however, personally prefer the term fan crafting. 'Poaching' has a whiff of the illegal hanging about it, and the rest still put the emphasis on the consumption of and subservience to a text, rather than on the creative output on the part of the fans. Crafting, however, connotes a labour undertaken with the intention of gifting away the results, and with a nod to pulling together items from elsewhere (think of Arts and Crafts time in preschool with egg cartons and glitter pens, or quilting with a variety of fabric squares) to make a new and cohesive whole, a product that speaks of and to the creator, intensely personal and yet meant for public consumption. Fan crafting will therefore be the term that I employ throughout this text.

Fan crafts are stories written, videos mixed, music remixed, art created, replica costumes or clothing and toys knit or sewn, in short, any creative product created by fans and based on intellectual properties to which they do not own the rights, for the consumption and enjoyment of other fans with no profit garnered on the part of the creators. Fans are fragmenting "elements of 
pop culture and then redistributing them in new forms that are imbued with meanings that are grounded in the lived realities and social worlds of the fans" (Black 14). The quality of these products differs wildly, as anyone with the tools, inclination, enough time, and an imagination can create and share their creations with little to no cultural gate-keeping involved in a vetting process prior to publication online. Fan crafts are hybrids, not definable by the traditional genres by which art and literature are commonly divided. Black writes that

though such texts are derivative in the sense that they depict available images of popular culture, I argue that the fans producing these fictions are far from being 'mindless consumers' and reproducers of existing media, as they actively engage with, re-work, and appropriate the ideological messages and materials of the original text... [they] draw on available media to engage in a wide range of innovative and sophisticated literate practices, such as creating robust characterizations, developing new histories for characters, and /or generating alternate settings and plotlines that are not present in the original media (Black xiii).

Writer Natasha Walter admits that "fan fiction is generally derided as a semi-literate, usually pornographic genre providing nothing but in-jokes for geeks" (Walter). However, Walter also says that in re-writing, re-contextualizing, by playing in and with, "by putting in the sexuality, the humour and the irony that the original tales often lack, these writers can change the way some readers see the works, and not always negatively... Indeed," she presses, evoking images of children weaving together stories while they play in their rooms,

when it comes to fan fiction, the Internet is giving us back something like an oral society, in which people can retell the stories that are most important to them and, in so doing, change them... they remind us that the power of these fantasy worlds are not built just on profit and loss, but on imagination responding to imagination (ibid). 
Many consider fan fiction a manifestation of "the human impulse to discuss contrary ideas or a book or movie or TV show and to take the next step to imagine a further adventure" (Shelly). Jenkins describes fans as creators who "play with the rough spots of the text - its narrative gaps, its excess details, its loose ends and contradictions - in order to find openings for [their] elaborations of its world and speculations about characters" $(1992,74)$. Or, to put a more pithy spin on it, fan crafter Springwoof says, in examining an unsatisfying ending to the Stargate: Atlantis episode 'Vegas': "I can so change the ending! I'm a fan-ficcer, that's what we do" (Springwoof). Willis highlights the necessity of creating space for queer interpretations within dominantly heterosexual texts. $(2007,155)$ Through such space-making and recirculations, fan fiction creates an opening in the canon in which a dialogue about the subjects absent from the canon can be addressed. In closely reading, in forcing a re-examination of canon through various fractal and fannish theories, and in critiquing the elements of a canonical offering, fans are able to point out gaps in subject and subject positions in canon. Essayist Deborah Kaplan posits that a "large part of the fannish experience lies in analyzing the source texts of fandom. Fans interpret these texts through discussion and formal analysis, but ... artwork and vids ${ }^{5}$ all contribute to a shared understanding of the source text" (Kaplan, 136).

Due to fan fiction's limited base of canons to plunder, fan fiction can initially be assumed a "limited genre, restricted in possibilities by the need to work with already existing characters and settings" (Kaplan, 151).

But by taking advantage of the narrative games inherent in the interplay between reader knowledge and fan fiction creation, fan authors find the potential for empowering dialogue in what initially seems to be a restricted form of creation (ibid) .

\footnotetext{
s Abbreviation for "fanvids" - music videos made by fans from video clips or images from a text, set to music that in some way communicates a message, story, or theme.
} 
That is, any story can be told through/by the manipulation of a source text, despite the seeming narrowness of having to work within a pre-established canon. The only limit of re-interpretation of the text is imagination. Canonical universes can be crossed over, or their histories re-written to create alternate version of the events and characters. Extra original characters or events can be added, or others canonically present removed. Genres can be shifted and focal themes interchanged. Any alteration, or new subject position the author can invent can be played out upon the canonical characters and their world.

Fan crafting oft times acts as a sort of communal apprenticeship for new creators, as the very works-in-progress nature of posting art on the Internet allows for a continual revisions processes and thus improvement. Many professional artists and authors can cite their time working within the exacting area of re-creating another's detailed worlds and characters and proffering them up to critics of the most minute and invested nature as a sort of training-wheels period in their own careers.

It is especially important to highlight that these fan fiction authors are connecting, interpreting themselves and their world through popular cultural properties typically categorized as 'low culture'. Fan crafting "documents a group insistent on making meaning from materials others have characterized as trivial and worthless," (Jenkins, 1992, 3) within both classical and popular culture. To that end, fan crafting has the potential to limitlessly address potentially limitless issues, points-of-view, and themes. "Undaunted by traditional conceptions of literary and intellectual property, fans raid mass culture, claiming its materials for their own use, reworking them as the basis for their own cultural creations and social interactions" (Jenkins, $1992,18)$ and it doesn't stop there. Texts accumulate new meaning when seen through the filter 
of a fan craft, and vice versa. As Chapman and Truman so eloquently put it: "fan fiction is literary karaoke. Why resist that anonymous urge to sing along?"

In the professional field of writing alone, there are hundreds of examples of fan crafters: "in the $19^{\text {th }}$ century, the Bronte sisters wrote fan fiction about the Duke of Wellington" (Chapman \& Truman). Even earlier than that, oral narratives were altered or added to with each successive telling, before the advent of print. Shakespeare cannibalized popular tales and histories of his day to create his own plays, and "Geraldine Brook's March the imagined adventures of the absent father in Little Women, took the National Book Award" in 2007" (Chapman \& Truman). In 2006 the Great Ormond Street Hospital, copyright holder for J.M. Barrie's classic Peter Pan, authorized the sequel Peter Pan in Scarlet (Cross). The genesis of fan crafting as it is known today was in the 1930 s when adult, primarily North American fans with disposable incomes worked together via mail to produce hard copy and bound magazines of fan fiction and fan art (Jenkins 1992; Black 2008; Thomas 2005), though fan crafting did not gain

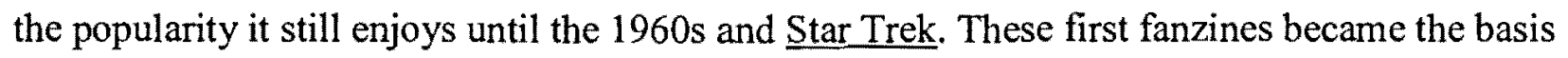
for the online fan fiction and art archives and fanzines when the "movement of the Internet to the public realm in the mid-19990s ... changed the very nature of Fandom" (Brayton 2006). First, the well of source texts has expanded to include not only Star Trek in its various incarnations, but literally thousands of other television series, movies, books, songs, bands, celebrities, and comics. Secondly, as medium with the means of distributing fan crafts for no more cost than the price of gaining access, and possessing the ability to archive not only prose and photographs, but art, comics, videos, and music, the Internet became the favoured method of communication and connection between fans (Brayton 2006). Hard-copy fanzines dropped in popularity and techsavvy adolescents surged into fan crafting and the majority of fan crafters shifted towards "a 
range of culturally diverse canons that are composed of multiple languages and posted largely by fans between the ages of thirteen and eighteen" (Black 14). Black explains that "the Internet has had a profound effect on the scope of the genre, as it has enabled large numbers of fans from across the globe to meet online and share and take part in substantive discussion of fictions produced online by their peers" (Black xiv). Black goes on to point out that the fan crafting is now a "ubiquitous literacy phenomenon that is difficult to overlook" (Black xiv) and has the potential to affect the shape of current pedagogy in regards to the way that tech-savvy youth engage with texts, analyze and deconstruct them, find and make meaning, and express themselves creatively. Information and communications technology advancements have "led to the development of literacy and social practices that traverse accustomed national, cultural, linguistic, temporal, and producer-consumer boundaries... [they] have facilitated the global dispersion of a range of fan-produced, cultural and intellectual products via circulation in online communities" (Black 2). These advances have been the backbone, and the functioning reason for forming said communities, as "the contours of a media and culture landscape that are in constant flux as a result of new information and communication technologies that allow" (Black 1) for this traversal.

Writer Natasha Walter says that in re-writing, re-contextualizing, by playing and "by putting in the sexuality, the humour and the irony that the original tales often lack, these writers can change the way some readers see the works, and not always negatively" (Walter). As Henry Jenkins has so famously and eloquently stated, "fan fiction is a way of the culture repairing the damage done in a system where contemporary myths are owned by corporations, rather than the folk" (Jenkins, 1992). While I don't entirely support the thrust of Jenkin's anti-corporation sentimentality, I support Jenkins' harkening back to a time when stories were oral, told to 
communities, belonging to no one specific author with a copyright or intellectual properties claim, to a time when cooperative storytelling was the norm (Annon. in Wedding 2; Black). Jenkins in essence advocates for a 'secondary orality', a "more deliberate and self-conscious orality, based permanently on the use of writing and print" (Ong 136).

Most importantly, fan crafting allows previously marginalized voices to take centre stage. Theorist Ika Willis explains that "it is through writing fan fiction that a fan can, firstly, make - space for her own desires in a text which may not at first sight provide the resources to sustain them; and, secondly, recirculate the reoriented text among other fans without attempting to close the text on the 'truth' of her reading" (Willis 155). Through such space-making and recirculations, fan fiction creates an opening in the canon in which a dialogue about the subjects absent from the canon can be addressed, to include all that which the canonical author either intentionally or not discluded ${ }^{6}$. In closely reading, in forcing a re-examination of canon through various fractal and fannish theories, and in critiquing the elements of a canonical offering, fans are able to point out gaps in subject and subject positions in canon. In fan crafts, these issues are confronted, addressed, worked with, and written through. Fan crafting,

as a sharing, as a making legible of these difficult negotiations between subjectivity and textuality, these complicated subject/text/world relations, is a way of reassuring each other that we have what Barthes calls the 'immoral right' to make and circulate meanings... as a fan fiction writer, feel I have (despite copyright law, despite being aware that there are writers who experience fan fiction written about their work as a painful effacement of their investment in the text) a right to the stories I tell, a right which is granted in part by my readerly implication in a text, a right which has something to do with pleasure (Willis 167-8).

\footnotetext{
${ }^{6}$ This isn't, however, to suggest that everyone in fandom gets along and de-marginalizes themselves together. Tensions from within fan communities and across groups may work to further marginalize some, put them at odds with one another, or silence them completely.
} 


\section{b: A History of Fanthropology}

While fandom studies - the study of the interaction between media texts and celebrities and their fans, and how exactly fans engage with said texts and celebrities - could conceivably be called a subgenre of audience studies, I maintain that it deserves particular scrutiny and attention aside from the audience study paradigm. While still connected through a historical precedence of theoretical literature, both relying on Lacan (1977), Fiske (1989; 1992), Lasswell (1953), Morley (1992), and other such great thinkers of the twentieth century, fandom studies acknowledges the contributions of these thinkers and then steps beyond them. Audience studies and fanthopology, while yoked by similar subject matter, and a shared history in the study of consumer reaction, are two separate beasts. Fanthropology focuses on the more complex intersections above and beyond the passive consumption that concerns Audience studies, and towards structuring active consumers who construct self identity and a community through the use of media texts and the derivatives of such texts. While the subjects of Audience studies consume, and sometimes regurgitate, the subjects of fanthropology consume, process, and subsume that which they've consumed into expressions of self through creative means. Participatory readers 'mine' the text for 'gems' - characters, plots, ideas, and mores - and uses these gems to create or to define; they weave elements of the mainstream text into their own creations, becoming textual re-writers. While the audience in Audience Studies admires the diamonds, the audience in fanthropology admires them, pulls them out of the wall, and works them into a new mounting of their own creation.

The definitive seminal text in regards to fanthropological research in an ethnographic sense is inarguably Henry Jenkins' celebrated Textual Poachers (1992), but research into the genre from within the structure of Audience Studies - particularly in cultural, communication, 
media, and literature fields - Feminism, and Ethical / Legal theory stretch back to the mid1980s. Joanna Russ (1985), Patricia Frazier Lamb (1986), Diana L. Veith (1986), and Camille Bacon-Smith (1992) focussed primarily on slash $^{7}$ fanfiction as a form of female-written erotica for females that privileges women's desires and projects feminine romantic sensibilities onto otherwise purely masculine and inaccessible (or dominating / threatening) male characters. Constance Penley (1991) proposed that slash was a means of subverting the traditional male dominance over technology and sex. Jenkins, a male in a previously female dominated field, and a fan in a previously academic dominated investigation, determined to break the stereotype of passive consumer fans, socially alienated and awkward, taken in by corporate hype and desperate to "get a life" (1992).

Jenkins opened up the study of fandom into other modes of theoretical engagement and proved the topic worthy of study and its objects as worthy of respect. Much of the work done in the 'fanthropological' field has been primarily situated within the theoretical and methodological contexts of critical theory, subjective constructionism and auto-ethnography. Positivist methods are rare in this field - the use of focus groups and surveys have shifted from content analysis and data-mining in favour of ethnographic and anthropological readings of the results. The first few landmark works in this field act in dialogue with one another - Henry Jenkins' first call to participatory academic fandom arms, Textual Poachers: Television Fans \& Participatory Culture (1994) responded to by Matt Hill's Fan Cultures (2002), and Jenkins's replies in several important texts - Convergence Culture: Where Old and New Media Collide (2006), and The Wow Climax: Tracing the Emotional Impact of Popular Culture (2006) - but most important is

\footnotetext{
${ }^{7}$ A genre of fan crafting in which two male characters are paired in queer relationship. The term 'slash' comes from the ' $\%$ " symbol which is used to separate the characters names when indicating the pairing. Subgenres include 'PWP' ('porn without plot' or 'Plot? What plot?'), curtain!fic, in which the pair are featured in domestic situations. The sister genre is 'femslash.'
} 
Fans, Gamers, and Bloggers: Media Consumers in a Digital Age (2006) wherein an actual conversation between Jenkins and Hills is published as a transcript. This dialogue revolves mainly around the establishment of media fandom studies as a) a legitimate subgenre of audience studies separate from the earlier literature that maintained that fans were little more than hysterical 'fanatics' and b) that academics themselves could speak from the positions of both academics and fans without 'tainting' the observational processes. For both Jenkins and Hills auto-ethnography constituted not only a research method, but a means through which to legitimize fandom experience and pull it out of the realm of observational sociology. Their main arguments run the line of why fandom is worthy of academic inquiry and a de-hystericizing and demystifying of fandom subculture; a pulling back of the veil to reveal the normalcy of the social groups and activities that constitute fandom, while rejecting the forced value judgements and 'freakifying' of fans and their hobbies, replacing 'religious' with 'religiosity' and 'fanatic' with 'participatory reader'.

Fan crafting has been positioned by academics as a form of reclaiming the oral narrative and folk story style of storytelling that the ability to write and duplicate the written word has marginalized in society. The sheer amount of fan crafts available for perusal or participation online makes fan crafting a highly visible and culturally relevant sociological topic. There is simply too much of it, too many people doing it, for it to be ignored. In recent years, more than one newspaper or columnist has attempted to wrangle the definition down to a graspable concept for the public (Jergensen; Chapman \& Trueman), and even the New York Magazine has tried to shed light on the activities and stunning skills of these underground communities ${ }^{8}$ (Hill, 2007). But, Scholar Rebecca W. Black, author of Adolescents and Online Fan Fiction, states in her

\footnotetext{
${ }^{8}$ New York Times author Logan Hill interviewed a fan crafter known as Luminosity, who is widely recognized as inhabiting the upper echelon of talent as a creator of remix music videos.
} 
forward, "the boundaries of fan fiction are porous, and definitions may vary" (Black 10); even within her very recent publication there are terms that $I$, as a fan crafter of over a decade, disagree with in her proffered definition, and the terms utilized by myself and those fan crafters I interviewed varied.

I have personally chosen to focus on the writing aspect of fan crafting in creating my MA project. My own talents and skills tends towards literature, rather than art - either digital or traditional medium - and as such I feel it the best suited to convey the subtleties of my intentions.

\section{c: Literature on Mary Sue}

While many fandom researchers allude to the existence of the Self-Insert character in their texts, rarely does the phenomenon merit more than a single line or a paragraph explaining what a Mary Sue is and even less (if any at all) to its worth as an expression of self-discovery and exploration, or as a literary trope. There is almost no direct academic inquiry into those fan crafters whose primary form of engagement with fandom and fan communities is within the Mary Sue genre. My own particular research is unique because I am attempting to compile a definitive definition of just what a Mary Sue is and what she means to her creators and the readers who engage her. Then I am utilizing that information to deploy a new breed of the Mary Sue, a self-aware, self-conscious functioning character who is both a Mary Sue by the traditional definition, but also is either aware of herself as a Mary Sue $e^{9}$ or has an author who is aware of her status as a Mary Sue ${ }^{10}$, and plays against the negative stereotypical tropes of Mary Sues to create an entertaining, solid narrative that educates the reader on the Mary Sue and, one hopes, encourages them to create their own Meta Sue stories. Meta Sue gives authors a chance to

\footnotetext{
${ }^{9}$ As Marie is in my story 'Slipstream', discussed in chapter 5.

${ }^{10}$ As Mary is in my story 'The Dark Side Of The Glass', or Vega in 'Across Time', both discussed in chapter 5.
} 
seriously engage in self exploration and investigation into narrative structure without the negative reader reaction that most Mary Sues garner because of the awareness inherent in the character archetype.

Below are the five important essays on the topic, the major themes of their research, and their relationship to my own.

The first is Anupam Chaunder \& Madhavi Sunder, Everyone's a Superhero: A Cultural Theory of "Mary Sue": Fan Fiction as Fair Use (2007). One of the few articles to directly name Mary Sue in its titles, this essay is nevertheless more interested in the presence of Mary Sue to encode a fan craft as eligible under 'fair use' laws as a legal remix. The lawyer authors do not linger on the whys and wherefores of the Mary Sue archetype itself, and instead focus on legal the potential repercussions of fan crafting and how they may be considered legal through the inclusion of a Mary Sue. While an interesting concept, it does not help me to define what a Mary Sue is, beyond that she is an original character inserted into a media text that is otherwise the copyrighted property of another. Next is Rebecca W. Black's book Adolescents and Online Fan Fiction (2008) ${ }^{11}$. While not specifically devoted to Mary Sues, the personal reflections of scholar Black, and her investigation of several teenage, female fan ficcers provides important insight to how fan fiction is used as a tool of self-exploration by young women. In her preface, Black recollects her own introduction to fan fiction in her youth (a story similar to her subject's, as well as nearly parallel to my own), and while not actually mentioning the term Mary Sue, refers to the

\footnotetext{
11 The limit of fandom studies (and cybercultural research overall) is that generalizations cannot really be made of who does what as fan crafters, but can only be made of the specific group being studied. Black's subjects are specific to her research, adolescent females between the ages of 13 and 18, and therefore not representative of the diversity of Mary Sue writers. Suethors may be male or female, of any age. However, Mary Sue research in general (Willis, Pflieger, Almagor, and Jenkins in particular) assumes that the Suethor demographic matches Black's. I follow this same assumption based on my own interactions with Suethors online, however maintain that Suethors outside of this demographic do exist, though possibly as exceptional cases (myself and Scribe, for example, who both write Mary Sues in order to comment upon Mary Sues). More research is required. Also, I suggest that above the assumed age demographic, there is a tendency to shift towards a more self-aware and /or meta-version of Mary Sue (see chapter 4).
} 
self-representative avatars and plots that she used to write. Using fan fiction in general - and for me, Mary Sues in specific - as a method of safely exploring self, creative writing, social interaction online, and in the case of her subjects, English as a Second Language is the overarching theme of Black's work and has influenced my own understanding of why Suethors write as they do.

Pat Pflieger's Too Good To Be True: 150 Years of Mary Sue (2001) essay traces the beginnings of the archetype to Victorian children's stories published in such magazines as Robert Merry's Museum or Youth's Companion, and centered on good, kind, perfect little girls who awe their Indian Captors or punish their negligent Mothers by dying poetically in a perfect Christian manner. She defines some aspects of the Mary Sue, but not all, and not completely without vagueness. She suggests that reader derision of Mary Sues stems from embarrassment on the part of the reader; embarrassment at the blatant self-exposure of desires and wishes that the Mary Sue is for the Suethor, sympathetic embarrassment at the lack of creative writing skill, and embarrassment on the part of the read at remembering one's own Mary Sues. She defines the difference between in-canon Mary Sues and Suethor created Mary Sues (that is, characters in a media text that behave like Mary Sues, such as Wesley Crusher in Star Trek: The Next Generation, or Agent Riley Finn in Buffy: The Vampire Slayer), and likens Mary Sue to the heroine placeholder character prevalent in romance fiction. The Mary Sue, however, is a failed placeholder, due to her excessive moreness; more beautiful, more talented, more real than Harlequin heroines, the Mary Sue cannot possibly stand in for the reader because she is not nebulous enough. Pflieger's discussion of placeholders and embarrassment served to finish fleshing out the Mary Sue Checklist, my defining definition of what makes a Mary Sue, as well as clarify the archetypes of Mary Sues which I have endeavoured to archive. Pflieger draws upon 
texts and theories that I had not considered previously, and expanded my understanding of why Mary Sues are so hated.

Next, Lelac Almagor's paper The Mary Sue Project (2006) discusses her use of the Mary Sue as an educational tool. She outlines the aims of her Mary Sue Project: to teach students about narrative structure and character development by forcing them to splinter a narrative by inserting themselves, and the results: that students were forced into self-exploration in order to create a character that is a reflection of their own wishes and desires, and yet can still be an effective member of the story's ensemble cast. Almagor's essay also aided in shedding light on why the Mary Sue's characteristics must be as they are - why they must be everyone's friends or why they must be desired - and helped in completing the final stages of the Mary Sue Checklist.

Lastly, the most influential essay is Ika Willis', Keeping Promises to Queer Children: Making Room (for Mary Sue) at Hogwarts (2007). Long before I read Willis' essay ${ }^{12}$, my previous study of Mary Sues, especially of Constance Ledbelly and the Mary Sues written by a fan crafter named Scribe ${ }^{13}$, led me to believe that the primary meta-literature achievement of the Mary Sue was to force a subject position that had previously been marginalized by a text back into the centre. Constance is an academic, a woman with free agency, and possibly a lesbian in a traditional Shakespearian Moor or Venetian culture, where women are chattel, weak, or victimized. Scribe discusses what it means to be what she terms a 'queen sized woman' in a text where the women featured are primarily athletically slim or anorexic-thin, and reinforces the positives of being comfortable with one's body size by making the canonical characters attracted to larger ladies. In Willis' case, she discusses how Mary Sues and Slash genre fan crafts have the ability to force discussions of queerness into J.K. Rowling's predominantly heterosexual

\footnotetext{
${ }^{12}$ Or had the pleasure of making her acquaintance at an academic conference in Wales in 2008.

${ }^{13} \mathrm{http}: / / \mathrm{www}$.angelfire.com/grrl/scribescribbles/
} 
wizarding world ${ }^{14}$. This was a direct reflection of my own belief that the Mary Sue's primary duty could be to question notions of marginalization and exclusion within media texts, and has served as the largest basis of support for my own research and conclusions.

${ }^{14}$ The paper in publication before Rowling's announcement that Albus Dumbledore was gay. 


\section{3: Methodology}

When I was 13, (30 years ago) I filled a bunch of notebooks with a multiple Mary Sue story (I included friends, for all our entertainment) involving the Beatles. I totally forgot I did this until just a few months ago. If I could retrieve those notebooks from whatever landfill they currently live in, I would probably be mortified and/or laugh until I died.

$$
\text { -Cat_Latin }
$$

A significant amount of primary research makes up the bulk of my study. Sources ranged from first-hand experience as a Suethor, to content analysis of those Mary Sue stories and communities I have been reading or involved in for the better part of a decade and a half, as well as drawn from academic inquiries into fandom in general, and where they exist, into Mary Sues in particular. Lastly, a survey was distributed both in 2005 and 2009 to solicit Mary Sue readers' and writers' opinions, and their answers have contributed towards an understanding of why Suethors choose to knowingly write Mary Sues, and how they have reacted when confronted with accusations that their characters are Mary Sues.

\section{a: Academic Sources}

Before engaging in any sort of study involving human subjects, I researched the seminal and canonical Fanthropology texts and researchers - Henry Jenkins, Matt Hills, Hellekson \& Busse, Brooker \& Jermyn, Tuloch, etc. - and the history and biases of Audience Reception research. These texts helped to situate my theories firmly among those whose research is already considered foundational, and allowed me to speculate beyond fan crafting in general towards Mary Sues in specific. Drawing upon Fanthopological researchers and texts, I identified the gap of knowledge surrounding the Mary Sue and found the girders of theory with which I was able to begin to traverse that crevasse. The particular essays of the Mary Sue theorists mentioned above - Chaunder \& Sunder, Pflieger, Black, Almagor and Willis - enabled a further understanding, 
from the theoretical perspective, of the past investigations into Mary Sues and served as the bolts of my bridge, the strong sticking points of research.

\section{b: Content Analysis of Mary Sue Stories and Web Sites/Communities}

Much of the work done in the 'fanthropological' field has been primarily situated within the theoretical and methodological contexts of critical theory and subjective constructionism. Focus groups and surveys have lost most positivistic elements, such as content analysis and datamining, in favour of ethnographic and anthropological readings of the results. Jenkins explains that in the early days of fan studies, there was an "attempt to pull back from the fan community at the end of such writing and say, right, now we can arrive at the truth that the fans don't yet recognize about their own political activity" (Jenkins, 1992). This was a positivistic approach to social research - observing from behind the proverbial one-way mirror, without direct obvious interaction with the fans and indeed had its place at the start of the fanthropological field, as sort of 'oh, hey, what are they doing over there? That's kinda cool.' However, this method carries the danger of falling back onto an 'us/them' dichotomy, and the 'get a life, fans' attitude could give rise to contention from the subjects of a study, especially if the subjects, like fan crafters, are performing an activity which as the potential to carry legal ramifications.

It was therefore my greatest concern to proceed with caution when interacting with fans, being clear that while I, too, was a Suethor, I was also gathering data for my research. Most fellow Suethors and community members were open to my presence, even opening up more to my questions due to my position as researcher, which gave me great insight into why people write Mary Sues. Over my research period, I have read likely hundreds of Mary Sue stories, or discussion forums, or questionnaires, participated in tutorials and panels at fantasy and science fiction conventions, and used this firsthand knowledge to compile both the archetype list and 
checklist, but also to further my understanding of why, on a theoretical level, Suethors write Mary Sues. To continue the metaphor of bridge building, these studies served to create the walkway which I traversed, the solid basis of understanding supported by the girders of theory.

\section{c: Survey of Fan Crafters}

In distributing a survey of seventeen questions ${ }^{15}$ over the Internet, and on the Mary Sue communities and websites with which I had become acquainted through my content analysis phase, I was able to better determine the variety of personal reasons for which Suethors write. Most answers reinforced the preconceived notions I had about personal motivation for writing Mary Sues, and some forced me to return to my research and revise my assumptions on why Mary Sues were loved or hated. Sixteen of the questions engendered direct responses about personal preferences in regards to fan crafting and Mary Sues, however, the second last question asked for an explanation of the subject's chosen screen name; I asked this question in order to determine how personally the user was connected to their online identity, and identity which is, in essence, a style of the Mary Sue itself. People's responses were generally open and I feel, honest, and gave me an insight into the personalities they attempt to convey via their online identities, their fan craft work, and therefore, under which Mary Sue archetypal heading they would fall, thus affecting my interpretation of their answers through the filter of that archetype.

\section{d: Writing Mary Sues}

However, the best way to learn is to do, and therefore I embarked upon my Masters Project: creating four Mary Sue stories whose central protagonists each represent one of the Five archetypes of the Mary Sue (every story carries the fifth), whose plot and characteristics follow the checklist, and which led me, in the process, towards a greater understanding of the creative process that goes into creating Mary Sues, in understanding potential of the Mary Sue in a meta-

\footnotetext{
${ }^{15}$ See appendix $F$ for a list of the questions.
} 
literature context, and the appeal of wish-fulfillment, and the adulation or derision that the character offers for readers and writers. I forced a space for myself and my work where theory and practice could converge. In writing Mary Sue stories with the checklist and archetypes as a guide, I was able to complete the definition of what made a Mary Sue, speaking from an autoethnographic viewpoint, and answer my decade long question, 'What makes a Mary Sue?' 


\section{4: The Social Construction of Mary Sue}

\section{a: Who Is Mary Sue?}

I think Mary Sues are an important part of a writer's evolution. Usually, they are written very badly, and they get a lot of baggage and wish-fulfillment out of the way so that the writer can get on with the business of storytelling. Beyond that, the other reason I don't read them as a general rule, is that it's rarely fun to watch someone else masturbate. IMO, a couple of famous original-story Mary Sues: Anne Rice's Sleeping Beauty series, and Jean Auel's Clan of the Cavebear series.

$$
\text { -- Cat_Latin }
$$

Lawyers Chunder \& Sunder state that "semiotic democracy requires the ability to resignify the artefacts of popular culture to contest their authoritative meaning" (601). Fan crafters will tell you that they began crafting because the text with which they are engaged is lacking something which they desire, be it in plot, character, or the way the text engages with liminal issues and subject positions. A majority of fancrafts set in the $\underline{\text { Stargate franchises reflects }}$ the series' lack of domesticity, romantic relationships, and glimpses into the personal lives and histories of the characters. Fundamentally comedic texts, such as the series The Simpsons or the BBC Drama Merlin, are treated in fancrafts with seriousness and an eye towards the darker elements of life, the revelation of secrets, betrayals, or traumatic incidents. The fan crafts of darker texts, such as the movie Jumper or the CSI franchise programs, focus on the humour and lightness that the series' tone precludes, on practical jokes, lazy Sunday mornings, or hilarious misunderstandings.

Mary Sues exist because the originating text lacks a subject or subject position with which a particular viewer can identify comfortably. She is the "subaltern critique, challenging the stereotypes of the original" (Chander \& Sunder 597). Be it as general as the series lacking a character of a race or ethnicity that the viewer can associated him/herself with happily (that is to say, without discomfort or internal conflict at how said race or ethnicity is deployed), or as 
specific as 'someone exactly like me'. Or in the case of Mary Sues, 'someone exactly as I wish I was'. The fan crafter therefore writes herself ${ }^{16}$ into the text, or a self-representative avatar character, "a beautiful, brilliant, beloved teenaged newcomer who bears an uncanny resemblance to the author" in a story "which often plunge[s] past the niceties of plot and purpose in order to get to the wish-fulfillment" (Almagor 664).

Derided as an exercise in narcissism by most fan crafters, a Mary Sue is a "pejorative term for a fictional character who is portrayed in an overly idealized way and lacks noteworthy flaws, or has unreasonably romanticized flaws" (Wikipedia ${ }^{17}$, "MS"), and who features centrally in a fan craft. The Mary Sue is an author-representative character created by the fan crafter and inserted into a familiar fandom in a story of their own devising; the Mary Sue represents the author in the world, and is a wish-fulfilment device for the fan crafter who wishes to partake of the canonical universe. Jenkins explains that Mary Sue stories are a method of personalizing a canon which is otherwise out of reach (1992) and Black calls them the inclusion of strong female characters to occupy the vacuum left by an insufficient cast (2008). The writers of fan crafts "work to efface the gap that separates the realm of their own experience and the fictional space of their favourite programs" (Jenkins, 1992, 173) and Mary Sue stories utilize idealized images of the writers as young, attractive, intelligent people who interact with the program and its canonical characters.

\footnotetext{
${ }^{16}$ The majority of Mary Sue authors are female. In rare cases is the Suethor male, and in rare cases is the Mary Sue character male (called conversely a Marty Stu or a Larry Lou). Sometimes female authors choose to write male Mary Sues and vice versa. However, by and large Suethors are female and I will therefore be referring to Suethors with the female pronouns.

${ }^{17}$ As Wikipedia is an open content platform without - as Andrew Keen (2007) calls them - cultural gatekeepers in the form of professional and society accredited editors, fact-checkers, or writers, I would not normally consider it a valid source for an academic investigation. However, as the Mary Sue is largely an Internet phenomenon defined by a collective society and with a definition in constant flux, and the information collected on it appears largely solely on the Internet, I maintain that Wikipedia constitutes a reasonable source for a social definition of the Mary Sue. Or as I have used it, as a starting point for research avenues.
} 
The term 'Mary Sue' was coined by fan fiction author Paula Smith in "1973 for her parody story 'A Trekkies Tale ${ }^{18}$... the main character was Lieutenant Mary Sue ('the youngest Lieutenant in the fleet - only fifteen and a half years old'.) The story poked fun at what Smith considered to be unrealistic wish-fantasy characters appearing in Star Trek fan fiction of the period" (Wikipedia, "MS"; also Pflieger). The term encapsulates an understanding of an "original (non-canon) female character who had a romantic liaison with an established canon character, particularly if she possessed unrealistic or unlikely (and often exotic) traits above and beyond those expected of a character in that particular series, or a conventional author surrogate" (Wikipedia, "MS"). In recent years, with the advent of Internet fan fiction communities and archives, the term has expanded to include references to any "author surrogate character or highly idealized character that plays a major role in the plot, especially those who upstage the canon characters and occupy the spotlight" (Wikipedia, "MS").

The Mary Sue can be more poetically described as "horrible, wonderful, self-fulfilling things; we think how nice it would be to have all the attention, be the focus of every war, just happen to have the inside magic/power/song/DNA necessary to win the day, make all the friends, have all the love-relationships, and be the hero of every story" (Trin). The Mary Sue usually is involved in a romantic relationship with the author's favourite character, and physically resembles the author, or the way the author wished she looked. Her name is usually similar to the author's. The Mary Sue either already exists within the world but was heretofore unrecognized by the characters or is a 'regular person' from 'the real world' who somehow 'falls' into the fan fiction/canon reality. One fan crafter explains that "unless it's a parody, the author is often writing a Mary Sue unconsciously, and so warps the world in frankly boring ways to make it conform to their wish-verse world view. Generally this is at the expense of character

${ }^{18} \mathrm{http}: / /$ www.fortunecity.com/rivendell/dark/1000/marysue.html/ Appendix B 
development, interesting plot devices, or any kind of adherence to the logic of the world" (Katekat1010). Seshat, Keeper of the Library ${ }^{19}$ further explains that a Mary Sue is an original character in fan fiction who [is] TOO perfect. These are usually heroines (hence the term 'Mary Sue'), who step in without warning or true back-story (or a very implausible or overly-used one), sweep one or more established protagonists off their feet (usually making them act completely out of character), and then proceed to save the day in truly remarkable and dramatic ways that leave the established characters gaping in admiration and amazement (Seshat).

In short a Mary Sue is more: "more charming, more belligerent, more understanding, more beautiful, more graceful, more eccentric, more spiritual, more klutsy. She has better hair, better clothes, better weapons, better brains, better sex, and better karma than anyone else... she is singular; she is impossible to ignore" (Pflieger 2-3). The Mary Sue fan craft almost inevitably features a romantic pairing outside of that of the Mary Sue and her author's favourite character. This 'other' romance is usually between two different main characters in the series, and often is a plot device utilized by the Suethor to 'get the competition out of the way'; that is, remove from the romantic equation the partner that the Mary Sue would be competing with for the romantic interest of her favourite character in the canonical universe of the fan fiction. However, in a twist unique to Mary Sue fan fiction, this 'other' romantic pairing is sometimes constructed as queer. This 'other' slash or femslash relationship is usually propagated by the Suethor regardless of evidence of the character's canonical sexual preferences and usually, therefore, makes the character act in ways that he or she would not otherwise. For example, in Scribe's popular Mary Sue fic, $\underline{\text { Stranger in a Strange Land }}{ }^{20}$, based on Sam Raimi's Xena: Warrior Princess, the character Ares is made to be sexually attracted to Joxer in order to free

\footnotetext{
${ }^{19} \mathrm{http} / / \mathrm{www} . g e o c i t i e s . c o m /$ sheshat/fanficl

${ }^{20} \mathrm{http} / / \mathrm{www}$.angelfire.com/grrl/scribescribbles/strangercontents.htm
} 
Scribe's Mary Sue to pursue Joxer's triplet brother Jett; in Ann Marie MacDonald's play Good Night Desdemona (Good Morning, Juliet), Romeo and Tybalt, and Desdemona and Juliet/Constance engage in queer relationships - or at least experimentation - due to the presence and interference of MacDonald's Mary Sue Constance Ledbelly (MacDonald 84, III ix).

\section{a.i: Why She is Hated}

Sues also tend to be, as Mary Poppins Queen of the Sues once said, 'practically perfect in every way,' and such characters are, for me, boring to read about. Sues make no mistakes, they can do everything, they're beautiful, they get whoever they're interested in - who would want to read about that? Oh, that's right: the author. --beccastareyes

The term 'flaming' denotes a comment, review, piece of feedback (as well as doubling as a noun and being the person who creates the above) which is purposefully insulting, critical, and mean $^{21}$. Some have likened it to cyber-bullying (Parry), acknowledging the inherent anonymity of the Internet and using it to personal advantage, treating fellow users like faceless avatars on whom all kinds of abuse can be heaped without personal repercussions. Mary Sues, as representations of the Suethor which form first a chain link fence between the reader and the object of their desire, and secondly as forwarding their Suethor as superior to the reader, are understandably the "the most reviled character type in media fan fiction" (Pflieger 1) and the recipients of a large amount of flames. While the Suethor's desire to become part of an "interesting world full of interesting people whom she watches weekly and thinks about daily" (Pflieger 1), from the reader's point of view the Mary Sue is self-indulgent, uninteresting, and a failed attempt at a creating universally reader-representative avatar. Mary Sue "gets in the way of what many fans consider the 'real' relationship [in the media text] and/or outshines the 'real' characters" (Pflieger 1).

${ }^{21}$ The reviewer who first alerted me to the existence of Mary Sues was a flamer. 
In the romantic novel genre, "readers of romance fiction aren't identifying with the heroine of the work; their real focus is on the hero, with the heroine holding open a spot in the novel into which the (usually female) reader can slip mentally" (Pflieger 1). Presumably, a Mary Sue is meant to function in the same way for readers, a placeholder for the Suethor and potentially, ideally, for the reader as well, but often because Mary Sue is such a precise recreation of a single Suethor's particular wish-fulfilment fantasy that she is not a functioning place holder. Instead Mary Sue acts as a barring mechanism for the very readers the Suethor hopes to attract. LJ user Floraisatosca notes that, when it comes to fan crafting in general and Mary Sues in specific she has

a 'have your fun and let other people have theirs' attitude... whether the fun in question is crossover crack pairings or wish-fulfillment OCs. Although I'm more irritable about issues like 'turning previously independent characters into shadows or distortions of their former selves to better set off the Sue.' The stories that claim to be solely populated with canon characters but turn every cast member into an outlet for the writer's issues and interests irritate me more than obvious Sues (floriatosca in were_lemur 3).

Not every reader, however, is as magnanimous. The marginalization of these Mary Sue stories has to do with the centralization of Mary Sue herself within them, and also with the fact that a Mary Sue is, in essence a writer's proto-version of a believable original character, a character with whom 'write what you know' and 'imbue your characters with a bit of yourself - common writer advice - has run rampant. The Mary Sue is a fan crafter's "baby steps in writing", and Suethors and readers alike dislike her so intensely "not simply because Mary Sue is such a startling insight into the wishes and dreams of another person, but because she is 'like a security blanket - once kids outgrow them they're embarrassed by the whole concept of ever having used one' " (Crites in Pflieger 9). Mary Sues have "too big a core of reality. A beginning writer hasn't 
figured out... how to just take little pieces of herself and grow them into life like characters" (Pflieger 10). Mary Sue is just too real to exist in fiction. It is embarrassing to see another fan crafter make the same mistakes the reader, has in the past, but also forces a recollection of the reader's own Mary Sues.

LJ user Korllian, like many fan crafters, admits to having written Mary Sues in the past, characters who are "basically me, only prettier, more talented and closely connected to the hero," but feels the need to justify her admittance with the caveat: "I was very young" (Korllian, survey). The Mary Sue flamers who "seem to be the most vicious ... are those in the 16-20 age bracket $^{22}$, who [have] just realized what they were publishing for the last few years and feel the need to share their revelations with everyone else, loudly" (lilacsigil on were_lemer 3). However, $\mathrm{LJ}$ user were_lemur notes that

disavowing representations of embarrassing younger selves, even being angry at them, is part of growing up. And who hasn't felt embarrassed by something they said when they were younger? Especially if they put their embarrassingly personal stuff up on the Internet where everyone can read it... But then I found the sporking ${ }^{23}$ communities and while they were funny, they seemed a lot more personal. And after the first few months, they seemed less funny and more just plain mean. As if instead of taking their frustration with the Mary Sues and creating something funny (in much the way that fan fic does to source material) they just want to mock. (were_lemur 3 ).

Canonical media characters have just as much potential to be Mary Sues; Star Trek: The Next

Generation's Welsey Crusher has been widely inferred to be Roddenberry's Mary Sue (and was removed from the series quickly and according to rule $\# 17$ on the Checklist); executive producer

\footnotetext{
${ }^{22}$ The actual composition of Suethurs is currently unknown outside of limited research. This is therefore an internalization of a stereotype of Mary Sue authors rather than what might actually be occurring in Mary Sue writing. Flamers and sporkers seem to buy into this assumed image of the Mary Sue authors' demographic.

${ }^{23}$ A term referring to online communities who make a point of finding and pointing out the flaws in fancrafts, usually in a mean-spirited way. This is called 'sporking' because that particular utensil is the one they'd rather stick in their eyes than read more of whatever genre of fancraft they are mocking. The irony being that to continue sporking, they must continue to read more of what they spork.
} 
David Fury on Buffy: the Vampire Slayer was widely suspected to be recreated as Agent Riley Finn, and even Frodo Baggins has been suspected of being J.R.R. Tolkien's avatar; likewise Jason White, the son of Superman and Lois Lane in the film Superman Returns has been likened to director Bryan Singer's Mary Sue, that Peter Pan's title character was meant to stand in for J.M Barrie, that producer Sydney Cecil Newman imbued the Doctor in Doctor Who with all his best traits (Frey, 2008, "WD?"). Even one-off characters in television programs that must perish to clear the way for next week's disposable character are often called Mary Sues if the plot of the episode revolves around their existence or the surrounding canon characters act in a manner different to their typical portrayal around the new character.

Reader also dislike Mary Sues due to the 'not my kink' reaction. While the Mary Sue exists to fulfill the wishes of one Suethor, the wishes being fulfilled may not be attractive or even resonate with any of its readers, whether sexual or not. Perhaps they might even be repulsive. Vulgar Weed, in the Fanthropology LJ community, writes that, "for one thing, they are usually the writer's self-insertion fantasy... which doesn't necessarily do anything for me as a reader. It's sort of the Not My Kink phenomenon on a very personal level... Why would I care about someone else's [fantasy]? I read fanfic because I love the characters in the original source material. I want to read about them, not some random person's idealized version of themselves taking centre stage narcissistically" (vulgarweed). Mary Sues, both the characters and narratives are therefore commonly perceived as being pointless, un-stimulating, unappealing, and uninteresting to anyone but the Suethor. LJ user velvet_mace explains that the problem with a Mary Sue is, "as exciting and wonderful as my Sues are, they just don't resonate with anyone other than me. Same thing goes for other people's Sues. They are like in-jokes, and 'you had to be there' stories. Once they leave your head they lose all their magic" (velvet_mace in were_lemur 
4). What is attractive, stimulating, interesting, or desired by one Suethor may not be interesting, and may even be off putting, to any other reader, even another Suethor. Lastly, LJ user calas_galadhon likens the Mary Sue fan craft to a chain link fence which separates the reader from the characters and plots they enjoy from the media text, but allows for viewing the Mary Sue bogart them. Fan crafts are meant to offer up crafts based on a community's shared object of desire - be it an actor, a character, or a media text's universe - a "communal activity with space for each member's/viewer's thoughts and impressions" (calas_galadhon 1). However, the Mary Sue

interrupts the ebb and flow of the comm[unity] - she takes away that voyeuristic, erotic appeal by shoving not only a woman, but one of our own [a fancrafter] (because we can't begrudge real people their girlfriends/wives/lovers/daughters/etc) in between the rest of the community and the shared object of our affection. The M[ary] S[ue] artificially elevates that particular person so that we're forced to watch her fantasy play out instead of indulge our own (calas_galadhon 2).

Essentially, she explains, the Mary Sue creator isn't following the rules of the sandbox and sharing. Fan crafting in general offers the active consumers of a media text the ability to indulge in fantasy, pulling inspiration from each other's crafts and the text, in turn motivating, moving, and inspiring other crafters in a cycle where "the fan not only analyzes the text, but also must constantly renegotiate her analysis" (Hellekson \& Busse 6), what they call the 'works in progress' model of meaning making. However, in offering an unappealing placeholder in the Mary Sue character, the Suethor is failing to follow the established, if unspoken, rules of the fan community, where offered crafts are meant to aid in everyone's enjoyment of the media text, placing themselves into the text in only an invisible and non-disruptive manner. 
a.ii: Why She is Loved

Honestly, I've given up bashing Sues. It's a phase, everyone needs to do it. They'll get over it and move on.

-- muccamukk in were_lemur.

Conversely, there are those fan crafters - myself among them - who believe that creating

Mary Sues is a vital phase in the growth, both personal and creative, of a budding fan crafter and that Mary Sues, when deployed consciously and purposefully, have the ability to speak to issues and topics that may otherwise be inaccessible in the canon text and / or other forms of fan crafting. Many crafters admit to having begun writing Mary Sue stories (though they may not have been aware that it was a Mary Sue story they were creating) when they first began their journey into fan crafting. Mary Sues are often many reader's "favourite ways of reading for pleasure. [One] want[s] badly to imagine myself at Hogwarts, to Sort [ones]self into a House and talk back to the protagonists and make up [their] own spells" (Almagor 664). The only difference being that some turn these fantasies into Mary Sue texts, and others simply use them as a method of "involve[ing] themselves so intimately in stories, take them personally, inhabit them - and read more critically as a result" (Almagor 665). Those fan crafters who, despite all scorn, continue to produce Mary Sues, do it because they love their fandoms and their fantasies, and get enough positive feedback from the stories to continue them, as an attempt to make a theoretical or ideological statement (see chapter 3), or as a way to rekindle their passion about a particular fandom, that is, for the sake of nostalgia. A trend online sees the Mary Sue making a reemergence on fan craft archives, only this time written by aware, mature writers. This recognizing a Mary Sue for what she is and writing her as one anyway highlights "the nostalgia factor - [it] may be why Mary Sue is coming out of the fan fiction closet. While many readers still gnash their teeth, many writers are having fun with her" (Pflieger 10). Scribe, in her 
introduction to the Make Mine Mary Sue Mailing List Community, says that "we all know Mary Sue/Marty Stu... but you only THINK you know hi/r. Welcome to the new era of Mary Sue. I believe that the author can insert him/herself into a fiction in a manner that will amuse, or entertain. Mary Sue doesn't have to be hateful, and even if she is--*bleep* 'em if they can't take a joke!" (Scribe, MMMSML). These tales are outright labelled as Mary Sues, and in "so labelling the story is essentially a defence mechanism, especially for the new-fan. The fan gets to have her cake and also eat it, inviting the reader to laugh along with her, since she knows the reader will be laughing anyway" (Pflieger 11). Theorist Mark Crispin Miller calls this 'prophylactic irony', an attempt to iron-ize an otherwise painful term in order to protect oneself from the harm that it can cause, where one "preempts derision by itself evincing endless irony ... protecting... from mockery by doing all the mocking, thereby posing as an ally to the incredulous spectator" (1988). These self-admitted Mary Suethors ${ }^{24}$

are not new fans; they are old enough to be nostalgic about her, and what she meant to them when they first began to write... often she was their very first original character... and she took them on mental adventures that they remember fondly... We created her, and, true heroine that she is, she has recreated us (Pflieger 11).

Another interesting trend in current storytelling has been a move towards using the basic tenants of self-aware fan crafting in order to create an original story. Children's author Cornelia Funke, in her Inkheart trilogy, tells a reverse-Mary Sue story, in which a character from a book invented for the story crawl out of the books and into the real world. In Adrienne Kress' Alex and the Ironic Gentlemen, the author pauses in the prose to directly address the reader and the concerns the reader may be having as they process the story; a technique likewise utilized by fantasy writer Terry Prachett, and most likely influenced by him. In Paul Glennon's Bookweird, a

${ }^{24}$ Like myself, Scribe, Trin-san, Paula Smith, and many more than I could possibly hope to name here. 
young boy accidently ingests the page of a Redwall-esque book before bed and wakes up inside of the plot, engaged in a battle with talking rodentia. Professional authors are either, like Lelac Almagor and Paul Smith, acutely aware of the Mary Sue archetype and are exploiting it, or have indulged in the same wish fulfillment fantasy of early Suethors, and have created a far more literal place-holder character for themselves and the readers than usually found in professional fiction.

\section{b: Characteristics of the Mary Sue}

The outcome of my academic research and the data acquired by both the content analyses and the results of the surveys suggests, as I hypothesized, that there were underlying similarities between Mary Sues regardless of the age, gender, social or ethnic position of the Suethor. In compiling and examining these characteristics, we can begin to understand to what purpose Suethor's write, make estimates about the motivations of Suethors, and understand how the Mary Sue acts as a method of self-exploration. I have compiled these characteristics into what I nick-named the Mary Sue Checklist.

They are as follows:

In order of common Plot Chronology Occurrence ${ }^{25}$

1) The Mary Sue character exists for the Suethor's wish fulfillment. The Sue looks like the author wishes she looked, acts like the way she wishes she could, says what the author wishes she could say, and creates an environment within the canon in which things that the Suethor wishes would have happened in the canon, does. The Mary Sue is

\footnotetext{
${ }^{25}$ And drawn from such a myriad of fan crafts, essays, online forum discussions and blog entries since 1991 that I could not even begin to hope to properly cite all of them. Unless otherwise directly noted, that this information came from somewhere and somewhen and have accumulated like strata, piling and weighing down the coal until a diamond kernel of understanding has emerged. I have ordered it in the pattern in which they commonly appear within the plot.
} 
sometimes the gender or sexual orientation which the author wishes (s)he was, or feels is fashionable.

The Mary Sue is the Id, as according to Freud $(1920 ; 1923)$, let loose to run rampant, to hedonistically enjoy a fictional world with no fear of repercussion; she is an avatar who experiences the sexual interaction with fictional beings that the author can never access; she is the putty that fills the gaps that separate the writer's own reality with that of their favourite fiction (Jenkins, 2007, 173).

2) There is a sense or tone of whimsy and /or self depreciation in the text. Most Mary Sue characters are written to be "competent. But not too competent; she's still a little girl inside, and there's a sense that at least some of what she accomplishes is done by accident or luck" (Pflieger 11). Suethors experimenting with wish fulfilment don't often also experiment in agency and therefore introduce chance to further the plot, which lends an air of the narrative pressing forward despite the Mary Sue character, rather than because of it.

3) The Mary Sue's appearance, personality, and even scent are often divulged in detail within the exposition of the story; Mary Sues often have physical traits that are a biological impossibility, such as eyes that are violet or shift colour, pointed ears, the limbs or ears of an animal, or hair colour that is not within the normal spectrum of shades.

As the Mary Sue is often the first example of attempting to create an original character for many authors, they feel it necessary to load exposition and description into the text at the earliest opportunity. As professional writers rarely describe their own characters so blatantly, this is considered a mark of an amateur and a turn off for most readers. However, due to the nature of media text making, the characters in a particular text are usually also extremely engaging, 
intelligent, interesting, brave, beautiful and talented. A Mary Sue, therefore, must be more perfect than the characters in order to win their affection, admiration, and interest (Pflieger 10), and thus must be described so thoroughly in order to compare to the canonical characters and / or overshadow them.

4) The Mary Sue often was given a name with a hidden or relevant meaning, or that simply "sounds cool", with no regard for ethnic tradition or likelihood.

Often this is an attempt to mask that the Suethor is writing about an idealized form of herself by fitting the character with an idealized form of her own name, or a name with a significant meaning which they feel describes themselves, with no regard for the ethnic tradition / genesis of the name itself.

5) The Mary Sue is a character either previously unrecognized by the fandom's central protagonists and antagonists before the commencement of the story, or drops in from 'reality' into the fandom.

The origin of the Mary Sue character depends on the role she is to play in the story. If she is to act as meta-commenter, to be wish fulfillment for the Suethor's desire to see specific events or pairings occurring in the source text, then often she arrives from our own 'real' reality to influence the events and characters of the canon text. If she is meant to engage in a relationship with the characters and become an integral part of the ensemble cast, then she is often introduced as having existed in the source text all along, the far flung relation or long-lost-something to one of the canonical characters, a previously unseen or ignored co-worker, or a special consultant / agent / student / etc transferred in or visiting.

6) The Mary Sue's abilities / magical powers / skills / talents not only outdo the canonical characters (even if, or especially if, the canonical characters are the most powerful / 
talented / skilled at this particular ability) but often eclipse them. The Mary Sue directly copies the skill and is better at it. The Mary Sue is adept at any sort of fighting or magic wielded by the canonical characters, often surpassing the canonical characters in ability with little to no practice or previous experience.

To be a functioning and useful part of the canonical world, the Mary Sue must have the abilities to earn the respect and endorsement of the canonical characters. Without any sort of power - and any sort of power useful to the characters, therefore similar or exceptional - the Mary Sue is relegated to the position of innocent and useless bystander, and therefore cannot engage with her desired character or fulfill her particular wish.

7) The Mary Sue is immediately accepted into the canonical character's inner circle of friends and confidants, no matter how unsociable or closely guarded said circle of friends is in the canon.

7.5) If the Mary Sue is related to a major character that is not the romantic interest, then said relation is often used as a haphazard excuse to introduce the Sue to the canonical • characters/ future romantic interest.

If the Mary Sue does not gain entrance, there can be no relationship, and therefore no plot, and thus no story. Mary Sue stories focus on relationships more than plot; therefore, while a long and complicated narrative in which the Mary Sue gains the friendship, trust, and eventual acceptance of the canon characters could be written, the Suethor bypasses this approach and imposes the friendship in order to move swiftly to the relationship portion of the narrative.

8) The Mary Sue acquires friends or romantic interests / partners among the canon characters, blocking or disrupting the canonical friendships, partnerships and romantic relationships within the canon. 
Mary Sues exist so the Suethor can figure centrally in the most important relationships - platonic or romantic - and therefore characters who are canonically linked must be severed or blocked from each other by Mary Sue's mere presence in order to facilitate the wish fulfilment that my research suggests is the Suethor's primary motivation.

9) The surrounding canon characters are made to act out of character by the Mary Sue's presence.

Pflieger points out that this is called, by most fan craft readers, "character rape" (Pflieger 6), and occurs because character's personalities have developed in relation to only those characters that exist within the show. In adding an unknown quantity, the chemistry of the ensemble must change. Some mistakes in out-of-character instances, however, could also be traced back to the Suethor's neophyte writer status, in that she has yet to master the subtly of writing that allows a character to remain in character, even when written by an outside party like a fan crafter.

10) The Mary Sue robs the strong female characters of their rational agency, turning them irrational, unintelligent, and unpleasant.

Again, this could be traced to the Suethor's newness to crafting, but also to the inclination for competitiveness. Strong, capable female characters threaten the Mary Sue's agency and her necessity for existing in the story. The Mary Sue's importance, and place in her beloved's heart, is put in jeopardy by the presence of capable canonical female characters. They must therefore be removed or made undesirable. Suethors may also be living in situation where other women are assumed to be potential competition, or bullying is present. A real-world feeling of persecution or competitiveness (whether from peers, parental or media pressure, etc.) may translate into the story, and the existence of a character that could challenge a Mary Sue's ability to form 
relationships with the desired characters / romantic target therefore becomes a threat and must be neutralized via changing their characterization.

11) The Mary Sue is sexually attractive to all canon characters, regardless of their sexual orientation or availability.

It is assumed that the age at which most Suethors are beginning to write Mary Sues is also the age wherein personal confidence and self exploration begins, as well as the blossoming realization of sexuality and the power women can hold over sexual partners in regards to sex and attraction. The Suethor uses the Mary Sue story to experiment and understand the power they have as young women over other sexual beings, and to comprehend their own sexual urges and fetishes by playing them out in a fictionalized -and therefore safe - space. If the Suethor is a mature writer, then the story tends to serve as a safe space to indulge in and develop sexual fantasies, to create a space wherein their subject position is regarded as sexually desirable, or as a means of boosting morale or celebrating the self.

12) The Mary Sue is often ardently desired by the villain despite there being no advantage or reason for the villain to want said Mary Sue.

Again, the Suethor is experimenting with her own sexual or intellectual attractiveness, and in most media texts, the villain seeks to defeat the hero by taking away or destroying everything that the hero relies upon for stability and happiness. That includes the Mary Sue, in a Mary Sue story, so the villain must desire her, too.

13) The Mary Sue is often the reason for the main conflict in the plot, whether inadvertently or as a central figure. Any special destiny, quest, or plot arc possessed by the central character of the canon is often usurped by the Mary Sue.

The Mary Sue has often been called the 'black hole of plot' or the 'thief of mythos' 
(see chapter 4); for example, if Harry Potter is the child spoken of in the prophecy, then the Mary Sue is the real child the prophecy means. As the plot of a media text surrounds a canonical character, the Mary Sue must usurp that plot in order to be included in the sphere of her desired character's relations. Otherwise, Mary Sue has no reason for interacting with them.

14) The Mary Sue is witty and snarky, and no matter how lame said witticisms are, the canonical characters akin the Sue's sense of humour to that which is quite practiced and enjoyable.

This often goes back to the Mary Sue's neophyte writer status. Media texts often possess their own particular forms of dialogue and humour structure, which the Suethor (or all fan crafters for that matter) isn't always able to replicate successfully.

15) The Mary Sue is often able to shift shapes, or has a friend or magical pet that can shift shapes.

As noted above, most young Suethors are at a stage in their lives where their bodies, minds, understanding, emotional relationships, and life patterns are shifting due to puberty, sexual awakening, educational expansion, etc. Relying on a constant, imaginary friend may be a holdover from younger childhood fantasies, or it may also be an unconscious signifier of the turmoil that such changes cause within the Suethors. Such creatures often accompany canonical heroes, especially in the fantasy literature aimed at the Suethor demographic - Harry Potter has Hedwig, SailorMoon has Luna - and therefore the Mary Sue must have one also, and one that, like the Mary Sue herself, is more.

16) As the Mary Sue is the author's avatar, the Mary Sue enters the world of canon with the same understanding of character, plot, and universe as the Suethor; the Mary Sue therefore has incredible insight into the lives and workings, the desires and dreams and 
fears, of the characters with which she is interacting and often serves as a conduit for advice that the Suethor wishes to impart on the characters. The Mary Sue 'understands everything'. The advice considered, the canon characters behaviour often is altered to accommodate the Suethor's desired changes.

17) The Mary Sue has a tragic past that precedes the story, or something traumatic and mentally scarring occurs mid-story that they 'get over' cheerily, suffering neither posttraumatic stress, Stockholm syndrome, or other disorders or phobias brought on by their past experiences. Any scars or marks that result from the trauma are 'cool', or are interesting places or shapes, and are often aesthetically tasteful (that is, attractive and minimal rather than ugly and disfiguring). Sues are rarely ashamed by said scars or marks, or associate them only lightly with the trauma.

17.5) Mary Sues mope, brood, or pout, but only for as long as it takes for the canonical characters to distract her. Long-term guilt or pain is rare in a Sue.

While the hurt/comfort ${ }^{26}$ genre of fan crafting is popular, it is rare to see in a Mary Sue story. Most Suethors are interested in the acts - especially the sexually violent acts - as methods of exploring personal fetishes, blooming sexuality, and imagined experiences, without concern for the fall out. As the Mary Sue is the Id, it is unconcerned with suffering and emotional strife, and as these things are undesirable in real life, they are made to cease to exist in the Mary Sue realm.

18) The Mary Sue is the centre of the plot, the key player in any battle, and is the only one who can 'save the day' by virtue of her wonderfulness.

\footnotetext{
${ }^{26}$ The majority of the plot occurs around an injury or illness that is inflicted on one character and their subsequent comfort and recovery. The other characters must care for the injured character, thus provoking an emotional revelation, a catharsis for the readers, and usually the achievement of character expressing their feelings for one another - previously hidden or un-acted upon - and ending the story are paired off, usually romantically but sometimes in a platonic, but deep, friendship.
} 
18.5) And in doing so, the Mary Sue 'ties up loose ends', filling in plot holes from canon, getting characters who the Suethor believes are romantically destined for one another together, or forces an ending to the major plot arc from canon in a satisfying (to the Suethor) and happy way.

Paula Smith notes that "the truest mark of a Mary Sue is not how she's described or what she does, but the effect the sheer fact of her existence in the story has on the other characters in the story" (Smith 1996). Pat Pflieger adds, "In these stories, Mary Sue is the centre of the known universe" (Pflieger 6). For example, in my 2003 fan fiction Harry Potter and the New Neighbour, my Mary Sue Anathemia Oldwyn uses her vampiric powers to force Peter Pettigrew to confess to the murder of the Potters, thus clearing Sirius Black's name and freeing him from Azkaban Prison.

19) Somehow the Mary Sue character 'saves the day' in unlikely ways that leave the canon characters stunned and amazed, often at the cost of her own life / health / magic powers / happiness / love / ability to stay with the characters or in the fandom. If Mary Sue must be more than the canonical characters in order to maintain her relationship with them, then the method in which she saves the day must also be more.

20) Yet somehow there is a happily ever after wherein the Sue and the Love Interest are reunited, often affirming their relationship through marriage and procreation, therefore supporting the patriarchal hegemony that a powerful female character like a Mary Sue could otherwise challenge.

20.5) Unless the Mary Sue dies, in which case her death is tragic, meaningful, beautiful, and offers the characters that the Suethor is most directly interested from the canon a lesson / morale / memento to take with them. 
Pflieger explains that there are many practical reasons for the Mary Sue to perish: like the many deaths of the women-of-the-week in canonical series, "it clears the decks for next week"; "there is the angst value"; the way that nobility in death (or of death) has fascinated writers for centuries (Pflieger 8). Most importantly, she says, "death keeps Mary Sue memorable to those who really interest the author [the characters], fixing her in their minds as in amber, at the peak of her loveliness and strength and nobility and virtue" (Pflieger 8-9). Being dead also means that Mary Sue can never grow un-lovely, cannot ever make mistakes, bungle, prove herself incompetent, and otherwise ruin the perfection of her actions (Pliefer 9). It also spares the love interest characters from having to actually have a relationship with her, sparing them a messy breakup or divorce, or falling out of love (Pflieger 9). It also undoes the trauma of the events a Mary Sue may have had to suffer through, and also allows the Suethor to feel content that while she has exposed her fantasies to the world, she has effectively closed them off from her own psyche by eliminating the chief avatar of said desires. The wish has been experienced, explored, satisfied, seduction has been practiced without the need for the natural consequences of it (sex, pregnancy, and/or commitment, whichever is scariest to the Suethor) and fulfilled and now can be neatly filed away with the deletion of the evidence.

\section{c: The Five Archetypes of Mary Sue}

\section{c.i: Thief of Mythos}

Mary Sues exist to help the Suethor take up a 'hero' mantle, whether she strips it from a previously existing hero or creates a new mantle for herself. In this way, Suethors are "able to draw from available sources to create fictions that served as a way for them to give voice to themselves and issues related to relationships, family, sexuality, and friendship" (Black 16). It is 
required for the Mary Sue to usurp the major destiny or plot of the hero in order to be worthy to make the acquaintance of the characters with whom the Suethor seeks an interaction.

\section{c.ii: Commenter on Narrative Convention and Deconstructer of 'Inherent Truth'}

Mary Sue has the rare ability to be an outside observer of the media text as well as an inside participant. This point of view offers the Mary Sue the ability to analyze the structure of the narrative or the characters and offer advice via the story or critique the construction of the media text. These dramatic characters and stories, the "first principals" of Eagleton's article on deconstructing literary binaries (me author; you consumer, and nothing in between), in being altered and/or regarded from a different perspective by the fan fiction author and their work are therefore shown as constructions and thus not essential truths from the canonical author's proverbial mouth. The Mary Sue has the ability to bypass the author and break down the binary between producer/consumer; artist/audience; writer/reader. The reader can call into question those cultural 'truths' that seem to be inherent in the text but are actually constructions stemming from a hegemonic perspective; being a rewriter offers the fan crafter the outside perspective that the creator cannot achieve.

\section{c.iii: Literary Masturbation}

Paula Smith explains that Mary Sue stories are often written by young women who are just beginning to explore their newly found sexuality (1996). The Mary Sue (as $\operatorname{Id}^{27}$ ) is the perfect vehicle for experimentation without consequence. The Mary Sue literally personifies "love and admiration of heroes" (Crites, 1996): the Mary Sue attempts to achieve the regard of

\footnotetext{
${ }^{27}$ For though the Id is subconscious and the wish-fulfillment aspect is conscious, it is the Id that dictates how the wishes are fulfilled, thus revealing and acting upon subconscious desires.
} 
the hero, and the hero himself is the "template of what we [the readers] admire" (Pflieger 10). Thus, the Mary Sue is a Suethor's way of learning to want, to achieve, to accept those goals and experiences that they are just beginning to understand in real life. Live Journal user were_lemur makes a distinction between those Mary Sues that people write and post on the Internet, and those who figure in her fantasy life, those which she dubs 'Head!Sues ${ }^{28}$, which fan crafters refrain from writing stories about. She defends the Mary Sue tradition on the grounds that she herself engages in Mary Sue styled role play in her own fantasy (were_lemur 1). What follows on the journal is a discussion via a comments forum in which a large number of users comment that they too have Mary Sue fantasies, often sexual, and occasionally they do indeed write them down, though rarely post them on the Internet. It leads to a general consensus that having Mary Sue fantasies can lead to healthy sexual fantasy life, but also, "on those occasions when [one] feels overwhelmed and out-of-control, a bit of 'yes I am awesome and funny and desirable and vitally important in the grand scheme of things' can be a good thing" (were lemur 1).

Suethors can act out that rape fantasy, that rentboy!kink, the dark drama that earns actors Geminis and Emmys, that make certain scenes in shows horrible and fascinating and gut wrenching to watch, and re-watch and re-watch because humans in moments of extreme emotion are fascinating creatures. Suethors can do all of this and not suffer for it. Mary Sues are also able to have those friends we want, explore what kind of intimacy makes us weak-kneed or run screaming, and lets Suethos test the sense of humour they would like to develop. When I realized that every Mary Sue I wrote entered or was forcefully entered into a sexual situation wherein issues of consent were present, where BDSM was featured, or where it was out-and-out rape, I

\footnotetext{
${ }^{28}$ Following a popular labelling pattern among fan crafters in which a descriptor is attached to a character or concept via an exclamation point in order to define which aspect of a character or descriptor is the focus. For example; kid!fic, fan fiction about the characters as or with children, or muggle!Harry, in which Harry Potter has no magic, etc.
} 
began questioning my motivations for writing such glaringly painful sexual experiences as happening to a character meant to represent myself. I was able to realize where my own particular proclivities lay without actually having to go through a humiliating real-life trial-anderror process.

Fanthropology community member Sunqist also posits that the Mary Sue can act as a sort of dressing-room try-out for a desired personality trait in a Suethor:

Mary Sues are an important part of identity development for the young women who write them... They serve as test balloons for the author's own identity. In creating these proto-identities, authors eventually discover that wellrounded characters are better received than idealized, hyper-feminine characters. As a result, they're less likely to want to incorporate that feminine ideal into their own personalities. The Mary Sue allows the author to distance herself emotionally from the personality traits she has tried, so it can be easier to discard them later. This leads to the development of well-rounded women, in addition to well-rounded characters (Sunquist).

I would say that this proposition is perhaps too blatant and simplistic; writing Mary Sues could possibly directly affect personality choices in the Suethor, but I will agree that the Mary Sue allows for the Suethor to inhabit their ideal personality and take it for a test drive, if only for the purpose of living a fantasy. I suggest that most fan crafter's entry into crafting was precipitated by an initial direct self-insertion fantasy, an 'I wish I could.' Whether or not this wish is translated into an actually written Mary Sue or remains purely daydream is up to the individual person, but I maintain that everyone has thought about it at least once, and that thought, the notion of altering a source text to make room for oneself, is the first step towards becoming a crafter. Once the desire to affect the source text has been acknowledged, the crafter is able to begin the process of creating fan crafts that suit their interests, kinks, choices, fantasies, and metas. They make room for themselves, and usually do so by inserting an avatar. The Mary 
Sue may act as a barrier between reader and the reader's fannish desires. Whether those desires are for more of a specific character or his/her development, or the universe of the canon, or simply for erotic literature featuring favourite characters, in inserting a Mary Sue into a story the Suethor creates a sort of chain link fence between themselves and the canon. This is my fantasy, the Mary Sue fence says, these are my desires. This canon, these people, are mine and you the reader cannot touch them. You can only watch. I want you to watch. Mary Sues, therefore, can also aid the realization of a voyeuristic/exhibitionist fantasy without the danger of legal repercussions.

"Pretty much all [Mary Sue fan fictions] are wish fulfillment of one sort or another" says Suethor Scribe. Penny Dreadful elucidates the point by adding that she enjoys "pretending to have a life with people [she] feel[s] comfortable with and being able to do things, see things [she] never [would] be able to in real life" (Penny Dreadful). Were lemur acknowledges that she has her "blind spots, [her] issues, and while [she tries] to keep them under control when [she's] writing either fanfic or orig[inal] fic, when [she's] in that id-vortex-y place to escape my situation, if only for the duration of the story; [she] want[s] to feel powerful and in control instead of overwhelmed. Maybe it's just an unorthodox form of journaling? ... Another form of writing which is definitely NOT for public consumption" (were lemur 2). While the last sentiment has been argued, that journals are indeed eventually meant for publication and that people do write them with audiences in mind, and doubly so for those journals and blogs which are online, the notion that a Mary Sue is meant to be a private fantasy that empowers and enables is an interesting allegory with personal sexual pleasure and evolution. Masturbation, too, is meant to be kept private, but is most titillating when shared - voyeuristically - with others. Mary 
Sues are voyeuristic literary pornography - erotic in the blatant display of Suethor's personal desires.

\section{c.iv: Forcing a Subject Position in an Otherwise Unaccommodating Text}

I strongly believe that the most powerful and most often-used incarnation of Mary Sue is, as Ika Willis argues, a way to force a discluded Subject Position within an otherwise unaccomodating text. That is, a Suethor will create a Mary Sue that resembles / represents their own marginalized subject position (person of colour, queer, non-American, female, various religions, etc) if and when said subject position fails to appear in a canon. Willis describes it as "not so much 'filling in the gaps' with a known unknown, but rather a way of negotiating the 'painful gaps' left in the encounter between a reader's 'felt desires' and the real world" (Willis 166). Fan crafting is "generated first of all by a practice of reading which, rather than expressing its latent meanings reorients a canonical text, opening its fictional world onto a set of demands determined by the individual reader and her knowledge of the (fictional and non-fictional) world(s)" (Willis 155). Willis explains that it is through the act of fan crafting in general, and writing as a Mary Sue in specific, that Suethors "make space for [their] own desires in a text which may not at first sight provide the resources to sustain them; and, secondly, recirculate the reoriented text among other fans without attempting to close the text on the 'truth' of her reading" (Willis 155). The Suethor then has the opportunity to attempt to 'fill in the gaps' "in canon. For these gaps may only become visible - may only, indeed, be gaps - when the text is read from a position that refuses the illusion of continuity" (Willis 158). But adding a Mary Sue to a text is not the same as "simply adding the final piece of a jigsaw ... rather, writing fan fiction first of all makes gaps in a text that the cultural code attempts to render continuous, and then, rather than filling them in, supplements these gaps with intertexts which are not docile, but which ... 'make 
the tacit things explicit"' (Willis 158). They "can be a site of resistance not only to the doxa which tries to govern the reading of a text, but also to the 'vengeful rigor' of academic discourse" (Willis 168). At its most basic, the Mary Sue addresses how a canon text 'hails' a reader and displays the dominant discourses on a subject or subject position. For example, as a Caucasian, single, short North American bilingual female, how does Stargate: Atlantis hail me? With characters Dr. Weir and Dr. Keller, I'm told that yes, I can have a position of power or be intelligent, but only a passive one, and my stories are not as worth telling as the men's, though it's entertaining when I go crazy. How does that as viewer/reader make me feel? Vaunted that I get to be the leader? Discouraged because I only get to talk - the only action/romance I get is when I'm taken over by a different consciousness, I'm held hostage, I'm duped by aliens or love potions, or my boyfriend dumps me.

As some groups of consumers may find themselves excluded, marginalized, or ought right offended by this canonical presentation of subjects and subject positions, some write fictional stories based on/in the canon which includes a self-representative character who stands in for both the author and the marginalized/ excluded subject position, to create a character or situation within the canon which (re-)includes and represents the Suethor/reader/viewer who feels excluded. Though, sometimes the subject position being represented is so narrow as to only represent the Suethor herself -or her idealized avatar - and therefore the Sue is simply a Sue as no other discluded readers can identify with him/her.

Many consider fan fiction as a manifestation of "the human impulse to discuss contrary ideas or a book or movie or TV show and to take the next step to imagine a further adventure." (Shelly) Willis is concerned with the necessity of creating space for queer interpretations within nominally heterosexual texts, explaining that "it is through writing fan fiction that a fan can, 
firstly, make space for her own desires in a text which may not at first sight provide the resources to sustain them; and, secondly, recirculate the reoriented text among other fans without attempting to close the text on the 'truth' of her reading." (Willis 155) Fan fiction exists to create a space in which a dialogue which is missing from the canon can be addressed. Make Mine Mary Sue Mailing List contributor Penny Dreadful explains that she finds "fan fiction fills a void most mainstreams $[\ldots]$ leave behind $[\ldots]$ it fills in the gaps $[\ldots]$ most fan fiction writers are not afraid to show the down and dirty or hot and exotic sides" of the fandoms (survey, 2005). Penny Dreadful explains that when she realizes that her own subject position has be excluded from a fandom, she feels the excluded subjects are left out of fandoms "so it wouldn't dirty the [creators'] pristine ideal" (ibid). For example, Scribe, as a self-described 'plump woman' often feels that "someone went through the world [that the fandoms] are showing and 'sanitized' it... that there are concentration camps somewhere, but instead of skeletal inmates, they're overweight" (Scribe, survey 2005). When asked whether she uses Mary Sues to reinstate the 'overweight' female subject position, she replied that she has "never taggetted [sic] a specific show for that. It's just that when [she] write[s] fan fiction, the men are a lot more likely to find a queen sized woman attractive" (ibid).

Willis, admits that it is "writing fan fiction which has made the complexities of [her own] subject position as a reader visible to [her]" (Willis, 166). Jenkins further explains that queer writers and viewers have long lamented the fact that although the future world suggested by Gene Roddenberry's Star Trek series is supposedly a utopia of tolerance and understanding, there has yet to be a fully or committed queer character featured on the show. Many queer fans ask themselves, 'If this is the perfect future, then where am I?' (Jenkins, "OOTC", 172) Many special-interest groups, such as the Gaylaxians, are petitioning for the creators to include a queer 
character in the next incarnation of Star Trek (Jenkins, "OOTC", 172). But Suethors have the ability to immediately affect change in the series by creating a fan craft that includes a queer character or relationship. What those petitioning the creators wish is accomplished within hours. Fan crafts allow the readers to find pleasure in the right to re-interpret, to negotiate readings of discourse

from a position of taking and giving pleasure: while academic discourse can also attempt to reorient texts, to open them onto knowledges of wider, brighter, queerer worlds, it always runs the risk of seeming to speak from a position of authority, of attempting to prove its reading of a text, rather than attempting simply to circulate it as one among many readings, taking pleasure in multiplicity itself (Willis 167).

Jenkins calls this push to be represented in a fandom where one's subject position is excluded "intervention analysis, [which] speaks from, about and for the margins of popular culture", and that "intervention analysis seeks not only to describe and explain existing [discourses] of knowledge, but also to change them." (Jenkins 2003, 172-3). Mary Sue fan fiction is a method of intervention analysis. "The producer's refusal to represent [marginal] characters [can] cut deeply," (Jenkins, 2003, 174) and order to remedy the isolation and marginalization the excluded readers feel, they are required to "create a context where fan politics may be acknowledged and accepted as a valid contribution to the debates about mass culture," (Jenkins 2003, 173) and this is most simply accomplished through the global and accessible Internet. The readers of a fan craft themselves now, like the yin-yang symbol which boasts a little bit of white (fan craft) in a field of black (canon), be unable to read the canon without remembering to some extent the fan fiction in which the marginalized Mary Sue exists. For example, once a reader has been exposed to a queering of canonical characters, they will always see the slash in canon, even if the character is proven to be totally heterosexual in the show. Fan crafting "is a way of taking 
pleasure in the truth - in the reorientation of a text away from the abusive false logic of the cultural code; a way, moreover, of taking pleasure in scandalously acting as if it were natural to do so, as if all readings (or at least all readings that can themselves become legible for other fans) were equally possible" (Willis 168). Thus, even though the canon itself may not include a subject with which the reader may identify, and may still fail to hail a marginalized reader, the marginalized reader may not feel as excluded if they consider the fan fiction in tandem with the canon. The excluded subject position now exists within the world of the canon for the Mary Sue author and reader. Fan fiction thus intertwines the pleasure one's subject position and desires with a "deeply political project of resistance and in-sistance that people must have the right to make and circulate meanings outside the circuit of ideologically or institutionally guaranteed transparency, provability, and ultimately, enforceability" (Willis 156).

But Almagor reminds us that "even when the [Suethors] readily find roles for their characters, they can't always make space for themselves" (Almagor 665), as their subject positions may be too complex or complicated, or their feeling about said subject positions too varied. "It may be, in fact, that it is writing fan fiction which has made the complexities of my subject position as a reader visible to me" (Willis 166). Almagor explains that, when she asks her students to write Mary Sue characters as a creative writing exercise in the class room

More often than not, my students choose fantasy and magic and adventure for this project; there's nothing exciting about pretending to live in a realistic story about regular kids. And more often than not, in this project, my black, Hispanic and Asian students' characters develop long blonde ringlets and sparkling violet eyes. They manage to leave those clichés behind when they write historical fiction and school stories, the genres in which we find more than a handful of non-white writers and non-white protagonists. But if they want to rescue their parents or travel through time or tame dragons or lead armies or quest for love or save the world, their only choice is to write themselves into 
stories that are exclusively, blindingly, obliviously white... racial difference becomes impossible within them (Almagor 665).

Thus, writing a Mary Sue story is "an opportunity to claim space for themselves even where the books they read have not made it readily available" (Almagor 665). It is interesting to note that while Mary Sue is concerned with centralization of the self, no matter what the Suethor's subject position, the stories themselves are marginalized by the fan community. 


\section{c.v: Meta Sue}

"Here's the way I look at it. We all have stories we tell ourselves, but when we them to other people we have an obligation to make them as good as we can. And that includes things that range from correct spelling to believable characters. I don't make fun of Mary Sues or stories with bad spelling. But I don't read them either.

--were_lemur

If Mary Sue has all this potential to be and do everything that I've noted above, then why is she still so often scorned, marginalized, mocked, and flamed? Most of this behaviour goes back, again, to Crites' notion of the embarrassment sparked by being reminded of one's own past behaviour, the exposing of one's fetishes and interests and opinions, one's subconscious desires, and the scorn that they had received for them in turn. However, when written with intent, a Mary Sue has the ability to break down walls, and question structural truths in narrative and media making. In actively engaging in a meta-Mary Sue mindset while writing, the resultant Mary Sue is a powerful being. In writing a Meta Sue one writes about oneself, and not about one's wishself. The Meta Sue is a fully rounded Original Character instead of a Mary Sue. She is aware of her own narrative power and makes choices that reflect that awareness; this Mary Sue uses her own inherent Sueness as a sort of super power. Perhaps she actively acts against her own Sueness, as my Marie Susan does in "Slipstream", or perhaps she shrugs and goes it, as Vega does in "Across Time", or maybe she's totally unaware of it, as Elana was in "A Deal With Dracula". Even if the Meta Sue isn't intimately aware of what makes a Mary Sue, per se, she can still act in ways that are converse to the established behavioural patterns of the universe in which she resides. She has the have the power to act, but also so critique as she acts, and critique as others react.

A Meta Sue is therefore a character who is aware of their own inherent character-ness and can use that to step partially or fully outside of the actions of their own story and analyze 
what occurs. New information communication technology has "led to the development of literacy and social practices that traverse traditional geographic, linguistic, and producerconsumer boundaries" (Black xiv) and as such pedagogy, counselling, sociology, and ESL instruction must change to accommodate this new generation of tech-savvy fan crafters in the class room. Black says that "there is a need for literacy educators to become acquainted with and potentially integrate elements of adolescent's out-of-school literature practices and existing technological competencies into classroom instruction and activity", to utilize to the greatest advantage the "informal learning and literacy practices that youth are engaging with in out-ofschool spaces" (Black xiv). Contemporary students are "entering classrooms with a mindset... organized around the production and distribution of information and various texts" (Black 1). Both Black and Almagor champion the use of fan crafting in the classroom as a means of inspiring creativity, coming to terms with difficult emotions or concepts evidenced in the studied text, analyzing the theme, characters, histories or precedents of the studied text, or with personal growth and self exploration. While the sexualized side of Mary Sue may be absent in classroom based interactions (though romantic elements may persist), the introduction to this method of textual and self exploration may continue with students outside of the classroom setting and far into adulthood. Consumers with an aptitude or affinity for tech gadgets are engaged in what Black calls "forms of semiotic engagement and symbolic manipulation of the media" (Black 1), calling for more engagement with fan crafting archives, what she calls "online affinity spaces" due to the friendly atmosphere in which fan crafters can explore and hone their skills and ideas, "as a formative part of their writing and literacy development" (Black 2008). In such affinity space and "through online discussions of fan writing, the teen writers develop a vocabulary for talking about writing and learn strategies for rewriting and improving their own work" (Jenkins, 
2004) and engage "in literate and analytical activities that they normally would not encounter and meaningfully engage with until college" (Black 16). Moreover, fan crafters also engage in research activities in order to make sure that their created worlds are as authentic and historically accurate as possible, learning research methodologies and skills that will be required for higher education far earlier in life. One of my personal earliest memories as a fan was reconstructing the Dracul family tree in order to accurately introduce characters into "A Deal With Dracula".

What develops, then, is the ability to question, critique, analyze, and create realistic selfportraits within a Mary Sue story. Of the Suethors working on a meta level "a significant minority see themselves as a liability to the mission... [they] cast themselves as bumbling comic sidekicks, annoying little sisters, and occasionally, love interests for male protagonists. Their avoidance of conventional heroic role produces the most intriguing endings, though anticlimaxes, disappointments, and dead ends" (Almagor 663) in stories that reflect the urbaneness or never-ending realities of real life, of true emotion and outcomes, of self analysis that leads to discovery and original characters whose inherent wonderfulness does not put off readers, a Mary Sue who is an effective place-holder for both the Suethor and the reader.

Thomas (2005) explores how young women utilize fan crafting to explore their sexuality, gender issues, and the pressures of society. Many Mary Sue fictions often depict violenceeither sexual or physical - towards women, and this, I believe is a direct result of the mixed messages that contemporary media and advertising bombards young women with. Insecure in their own bodies, objectified, and just discovering their sexuality, Suethors put their avatars through the worst possible abusive scenarios, deflecting the violence directed at them onto a doppelganger who, unlike the Suethor, has the ability to walk away from her traumas unscathed. 


\section{d: Why We Need Mary Sue}

There is an argument that fan crafting in general, and Mary Sue fan crafting in particular is merely a reflection of the current hyper-consumer mentality: crafters want certain things to occur within the canon and when they are not gratified, they create a means with which to achieve satisfaction, especially if they desire a self-reflexive mirror character. The concern is that fan crafting is merely a means of narcissistic gratification for consumers of canon texts which could possibly threaten the creation of any new canon text or endanger the histories of classical texts as readers become disinterested in that which holds no gratification. I do not disagree that for some fan crafters or consumers of fan crafts, this may be the case; however, I argue that there are many fan crafters for whom fan crafting is a method of engaging particularly with those texts that do not satisfy them in order to investigate and understand why motivations, characters, or stories are dissatisfying and appreciate the canonical text for that very divide. Inserting a Mary Sue into a story that is dissatisfying allows the crafter to inhabit the space of the text and appreciate the previously dissatisfying, create a means to being satisfied in the text. We have established that a well-wielded Mary Sue can shatter binaries, question inherent truths, deconstruct narrative clichés, and serve as self-(or sexual self-) exploration for the authors. Mary Sues can also

challenge a patriarchal, heterosexist, and racially stereotyped cultural landscape... [she can] rewrite the story to revalue [our] place in it... [Mary Sue] offers important epistemological interventions in the reigning discourse, confronting the traditional production of knowledge by reworking the canon [via] ... commodity resistance - a strategy of popular struggle through the resignification of common goods (Chander \& Sunder 601). 
The Mary Sue shakes up " the very concept of the social subject; the demands raised by a symbolically complex cultural environment... and the question of contextualizing the position of the mass media in a social world that can seem dominated by, or even reducible to, such media" (Bailey 5). Fan crafting is a valuable method of connecting personally with a fandom and finding a way to exercise active creativity in a predominantly passive consumer oriented medium.

\section{d.i: Pedagogical Applications in Narrative Structure and Story Making}

Almagor's The Mary Sue Project, a pedagogical project in which students are actively encouraged to write themselves into pre-existing works of fiction, explains that when people write fiction, "we almost always start with ourselves; not out own lives, necessarily, but our bodies, memories, dreams, desires... beginning to find the language for [our] sensations" (Almagor 661). It makes sense, then, especially when working with a group of young or new writers, to begin with the literal self as a template make a story self, and thus a story. Mary Sueing is actually very useful as a method of connecting personally with a text and finding a way to exercise active creativity in a predominantly passive consumer oriented medium. A Mary Sue story can be good and can do good things and can be meaningful and break down the walls of passive consumption or accepting inherent cultural binaries or self-exclusion, and make the reader think. Pflieger notes that, in regards to Mary Sues and agency, there is "a sense that young teenage girls now aren't as willing to abdicate their natural powers as were girls of previous generations; it's their right to be competent and strong, and to carry off the occasional prince over their shoulders. All power to them" (Pflieger 11).

Almagor's students "quickly discover that fitting a new character into the story means dismantling the original prose to see how it works" (Almagor 663). The exercise of consciously and deliberately creating a Mary Sue forces the Suethor to investigate the structure of the source 
text, educating the Suethor in the realms of narrative structure and style, intent, and character development. In order to write, the reader must first deconstruct before reconstructing. Then, as Ika Willis argues, the reconstruction can recirculate and affect the meaning inherent in the source text. "To the writers' surprise, adding the [extra] character seems to tip the narrative offbalance, so that the group almost never" achieves the climax of the plot in the source text in the same manner, if at all (Almagor 663). This allows for a study of the nature of narratives, why what happens when, where, and with whom that makes the story function. These neophyte authors will have a solid basis for character and plot development when they engage in their own original creative writing, due to their newfound ability to decipher cause and effect. While working on their Mary Sues, Almagor's students "can see themselves in the pages... my Plan B is for this writing project itself to spark literary activism; to ask students explicitly who gets to be in the original story, who's left out and why, and what we can do about it" (Almagor 665).

\section{d.ii: Self-Exploration and Expression}

Doctor Steven Bailey explains that "self-stability is achieved through symbolic anchoring... an essentially communicative process at the center of self-formulation" (Bailey 38). That is, in engaging in creating a Meta Sue, in "describing their own selves, or the story-selves they develop, proves their only reliable alternative to writing about the Planet of the Tall, Slender, Blonde and Incidentally Also Graduated from Harvard at Sixteen" (Almagor 661). Working with a Meta Sue offers Suethors the opportunity to self-examine, for "when they are the ... rewriters - then the power to question, subvert, and renovate their fiction is in their hands" (Almagor 665). Exploring oneself through the creation of a character based on oneself, though scorned in fan crafts, is the surest way to understand one's own desires, morals, aims, goals, and 
sexuality. Even if the wish-fulfilment aspect of the exercise is deliberate, the form in which those desires are illustrated may yet reveal subconscious preferences and beliefs. 


\section{5: The Project}

Your writing is good, but Ana is too much of a Mary Sue. It gets more and more obvious as the story progresses. It's a real shame - with your writing skills, this story could have been good. However, I can't take the Sue anymore, so I'm going to stop reading now.

--Review of JM Frey's "Harry Potter and the New Neighbour". 2009.

In an attempt to test my checklist and archetypes, to marry theory and practice, I created four Mary Sue stories in which I was able to engage, draw upon, play with, and critique the Mary Sue. A majority of these stories were based on actual, existing copyrighted television programs, books, and films in order to firmly categorize them as fan crafts and entrench my work within the same legal liminal space as those fan crafters whom I study. Each of these stories has been written on the assumption that a good Mary Sue story - well written, consciously plotted and with an emphasis of the potentially meta nature of the Mary Sue - can exist and can be meaningful and break down walls and make the reader think. Each of the four stories contains a Mary Sue who exhibits the Mary Sue Checklist requirements and demonstrates within prose some of the Faces of Mary Sue, and attempt to support my thesis that a Meta Sue is both possible and enjoyable.

In the first, a multi-fandom story titled "Slipstream", the Mary Sue is Marie, a direct reflection of myself and my graduate student status, who enters into a fandom-based adventure with full knowledge of who and what Mary Sues are. In the second, "Across Time", the Mary Sue is Vega, a young woman from reality who discovers that the world she inhabits is actually fictional. The third story, "The Dark Side of the Glass" does not feature a Mary Sue who is aware of the theory of Mary Sues, but is, however, intimately acquainted with the commercial and awkward world-building that often occurs in television program creation, as she works on the (made up) television show which she accidentally comes to inhabit, "City By Night". The fourth 
and last story is about a Mary Sue who is entirely obvious to her own Mary Sue nature, with a meta undercurrent within the plot about the construction of period romances. The fourth story is especially important to the project, as it is a standard commercial novel (whereas the first two are be fan fictions and the third an original short story) in the style of Maguire or Cross, and a retelling of Jane Austen's life and early novels. Titled "First Impressions" (the original title of Pride and Prejudice) it is a standard length novel about a Meta-Mary Sue who interacts with Austen and thus directly influences Austen's creation of Pride and Prejudice. This creates a tension that educates the reader in the present concerns in gender roles, and the flawed nature of specific, time-honoured interpretations of classical works, the canonical methodologies and the inherent binaries of understanding and meanings.

I have written more Mary Sue stories since 1991. However, I will focus on these particular stories due to their very deliberate and particular natures. Since 1991 the stories have grown more deliberate, more playful with the rules of Mary Suedom, more aware of their classification as such ("Ningen", set in Dragonball, "Spider" and "Wolf", set in Inu Yasha, and

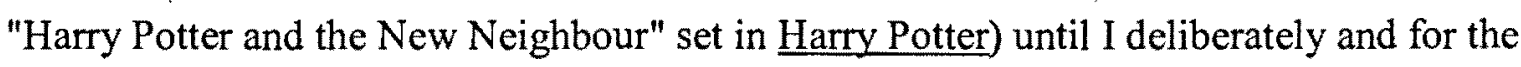
purpose of later reflection and study, began "Slipstream" in 2005.

\section{a: Across Time}

I took a deep breath and said, "No. No, I don't. The Gods of Ancient Greece were not real." His eyes widened fractionally, as if he didn't quite believe that I was speaking what he probably thought was the worst blasphemy -I was denying him his existence. "People worshipped anything and everything - streams, grove, trees, and even abstract ideas like War, Love, and Intelligence - because they didn't understand the science of why things worked the way they did. The only explanation they had was a higher power, and so worshipped it in fear of it taking its revenge. There is no such thing as Gods." -Across Time, Chapter 2

Fandom: Xena: Warrior Princess and Hercules: The Legendary Journeys

Length: Novel, 337 pages 
Aims: I decided with this fan fiction that I wanted to deliberately and literally, as Willis posits, 'fill in the gaps'. This particular pair of crossover media texts is filled with plot discontinuities, alternate universes, reincarnated characters, schizophrenic characterizations, and a distinct lack of female characters who were strong and capable without having to kick asses (non-warrior women were weak, chattel, raped, or innocent priestesses). To that end I created Vega, an intelligent character who starts scared and alone and grows into a meaningful, and agency wielding Mary Sue, a young woman from reality who discovers that the world from which she originates is actually fictional. I also made a point of including every point in the checklist, as either a major plot point or consequence without straying outside the realm of Original Character and into badly written Mary Sues. Vega was never intended to be a Meta Sue, deconstructing her own existence, or the existence and rational of the fictional worlds around her, yet, in filling the errors in canon continuity, she became one. She was instead meant to be both Literary Masturbation - fulfilling my own desire for a sexual and romantic relationship with the character Strife - and the Thief of Mythos, in that a prophecy originally written about the title character Xena was rerouted to be counteracted and then fulfilled by Vega.

Type of Mary Sue: Literary Masturbation; Thief of Mythos

Pedagogical Aim: This piece was intended, along with "Slipstream", to complete a sort of survey of what exactly makes a Mary Sue. While writing these two series, I was able to compile the Mary Sue checklist and at the same time, engage my readers in a discussion of what makes a Mary Sue via what my Mary Sue did and did not do, and how the actions both fulfilled the requirements of the checklist and the archetype while still retaining an element of surprise and originality, and how those actions were received and commented upon by readers. "Across Time" was my only true 'work in progress', where I actively sought feedback from readers as I 
posted the story chapter by chapter and then revised the plot depending on how the story was received and what sort of feedback I got.

\section{Checklist}

1) The Mary Sue character exists for the Suethor's wish fulfillment.

Vega exists to repair the discontinuities in the plots of both Xena and Hercules, which I had always greatly hoped would be fixed during the run of the programmes, but never were. Vega also ends up the lover/wife of my favourite character, Strife.

2) There is a sense or tone of whimsy and /or self depreciation in the text.

Vega begins the story with little self confidence and great confusion about how, exactly, she has managed to enter a fictional realm. Vega is insecure, and a great deal of luck - bad, for Vega, but good for Ares and Strife - propels the first half of the story. Vega only earns agency and takes control of the plot after she becomes a confident person, is comfortable with her own character, and accepts her destiny.

3) The Mary Sue's appearance and personality are often divulged within the exposition. I very purposefully wrote three pages of exposition in which Vega's individual traits are revealed from within a framework of her railing against the misuse of exposition found in the Mary Sue stories that she's read.

4) The Mary Sue is given a name with a hidden or relevant meaning.

My name is Vega (no, not really. But I am really dumb enough to use my real name here? Nuh-uh). Vega is the dominant star in the Libra Zodiac (my sign), and in about 3000 years will replace Polaris as the North Star.

I've always sort of liked that comparison.

I'm a Libra with a Libra Moon rising, so I'm as Libra as they come. Intelligent (top of my class, usually! Unless it's math... blah!), artistic (write, draw, sing, dance, act, do voice work...), balanced (mostly just by a hair), fair, and unfailingly organized. Also, one day I'll be famous, just you wait and see. And everyone will look to me, just as they look to Polaris.

(from Chapter 1) 
5) The Mary Sue is previously unrecognized, or drops in from 'reality' into the fandom. In the first half of the story, both Vega and the reader are convinced that Vega exists in the same reality as the reader. However, it is revealed later that Vega is actually a citizen of the pseudoreality established in the Hercules episode "Yes Virginia, There Is A Hercules" (aired Feb. 23, 1998) and the Xena episode "The Xena Scrolls" (aired Jan. 13, 1997), a reality where Hercules actor Kevin Sorbo is actually Hercules himself, and the programs are televised interpretations of the ancient poems of the character Gabrielle.

6) The Mary Sues' abilities outdo the canonical characters with no previous experience. Vega spends the first portion of the story convinced that she is human; however, when she embraces her divine heritage, she proves to be a more compassionate, and thus more powerful, divinity than the canonical gods.

7) The Mary Sue is immediately accepted into the inner circle of friends and confidants. Though the gods in both series were notoriously petty, over-sexualized, and selfish, Vega befriends - without a sexual act - the primary featured characters. She also immediately gains the friendship of Xena, Joxer, and Gabrielle, three very close knit comrades whose circle never expands during the run of the program.

8) The Mary Sue disrupts the canonical friendships, partnerships and romances. Vega's presence distracts Ares from his normal romantic pursuit - always unsuccessful - of Xena.

9) The characters are made to act out of character by the Mary Sue's presence. I chose to interpret this point as 'the Mary Sue inflicts character growth' rather than 'the Mary Sue inflicts character rape'. Vega's presence, and the action for which her presence is a catalyst, 
forces both Strife and Ares to grow into more stable, more mature, and more compassionate men. While they began the story with the characterization prevalent in the series - petty, mean, lustful, unbalanced - they end as responsible and trustworthy community leaders.

10) The Mary Sue robs the strong female characters of their rational agency. Having no desire to alienate my readership by making Xena and Gabrielle into unpleasant characters (and thus sabotaging my own attempt to create a Meta Sue), I nonetheless transferred Xena's plot-driving agency to Vega.

11) The Mary Sue is sexually attractive to all canon characters. The Greek gods are notoriously lust-driven, so this was a very easy point to fulfill.

12) The Mary Sue is ardently desired by the villain. Ares especially.

13) The Mary Sue is the reason for the main conflict in the plot and usurps destinies. Xena is the Godkiller, murdering the majority of the Olympian host and thus saving the world, who is also destined (in the $21^{\text {st }}$ century) to eventually bring back the gods, in the form of the television programs that play in the pseudo-reality. Vega usurps this destiny, exposing the programs in the pseudo-reality as being based on fact and revealing the Gods - whom she resurrects - to the pseudo-real people of the pseudo-reality, thus saving all of creation.

14) The Mary Sue's sense of humour is quite practiced and enjoyable. Vega's humour is very self depreciating and runs in the same vein as the program's usual tone, which I found to be one of my hardest challenges, as my own tone is very different than the series' when I write my own original fiction.

15) The Mary Sue is able to shift shapes, or has a friend / pet that can shift shapes. 
Vega is the Goddess of Pathways, and thus has the ability to change her appearance or be invisible.

16) The Mary Sue 'understands everything'.

Vega, as a citizen of the pseudo-reality, has, like the reader, an almost omnipotent understanding of the characters and worlds of the programs she has viewed; as the Goddess of Pathways, Vega has the ability to see into the future insofar as the result out of a particular life of choice.

17) The Mary Sue has a tragic past that precedes the story, that they 'get over' cheerily. In the first chapter, Vega is imprisoned, tortured, and nearly raped by Ares. Again, in constructing Vega as a Meta Sue rather than a Mary Sue, I made certain to take into account the trauma that such an experience would engender. Vega does not spend any time with Ares, even after his reform.

18) The Mary Sue is the centre of the plot, the only one who can 'save the day' . The plot centers on the Gods attempting to find a way to preserve their own lives and the world by making sure human kind continues to worship them. Vega, as the Goddess of Pathways, is the only God with the ability to retrieve them from Ashphodel after Xena murders them, and is the instigator of an alliance with the Christian Pantheon in order to return the Gods and their Worship to the world, thus preserving it from destruction.

18.5) And in doing so, the Mary Sue 'ties up loose ends'. Vega neatly fills in the gaps left by the glaring discontinuities in the programs, specifically that Strife is shown in season four as being alive in 1996 A.D., yet is later murdered in season five in approximately 300 B.C.E. Vega retrieves him from Ashphodel in 1995.

19) The Mary Sue character 'saves the day' in unlikely ways that leave the canon characters stunned and amazed. 
The citizens of the pseudo-reality are stunned to learn that the ancient Gods are real, and are back.

20) There is a happily ever after wherein the Sue and the Love Interest are united. Vega and Strife marry after Vega recovers from being gravely ill while in Ashphodel. They produce a son named Quest, the God of Adventures.

Feedback and Impact: An extremely well-received piece online, and especially liked for my solidification of the characterization of the canonical character Strife, whose writing often suffered from inconsistencies, and the repair of some major schisms in the time line of the show. Most reviewers mentioned that they were pleased to find that a Mary Sue could indeed be a fully rounded and successful reader-placeholder.

\section{b: Slipstream \& Slipstream: Quick To Say Yes}

If you were to fall into your favourite fandom, I mean, really do it, would you tell people? Would you be scared of that character that you are fond of, knowing that he or she really has the power to hurt you for real? Would you pursue the silly crush? Would you warn the heroes of the future? Would you even tell them who and what you are? Don't be so quick to say 'yes'.

-Slipstream, Chapter 1

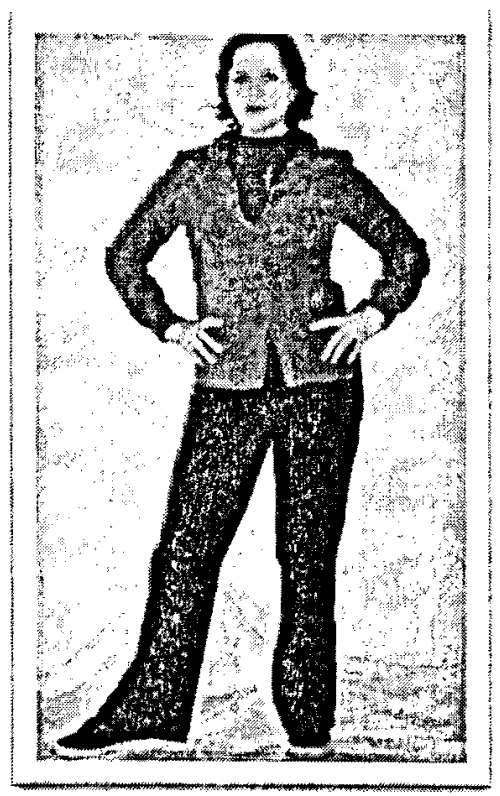

JM Frey dressed as Marie Susan in Chapter 1.

Fandom:

Slipstream: Dracula: The Series; Harry Potter; Anita Blake; Pirates of the Caribbean; The Phantom of the Opera; Labyrinth; Gundam Wing; Angel: The Series; The Lord of the Rings; Sailor Moon; Star Trek: The Next Generation; Tokyo Babylon; Pride and Prejudice; Highlander: The Series; Inu Yasha; Stargate: SG-1; Nightwalker; Xena: Warrior Princess; Neverwhere; RENT; Wicked: The Life and Times of the Wicked Witch of the West

Slipstream Quick To Say Yes: Gundam Wing; Harry Potter; Pirates of the Carribbean; Forever Knight (written and then removed: Saving Private Ryan; Thoughtcrimes) 
Length: Serialized Novels, 719 pages \& 94 pages

Aims: In this multi-fandom story, the Mary Sue is Marie, a direct reflection of myself and my graduate student status, who enters into a fandom-based adventure with full knowledge of who and what Mary Sues are due to her own academic investigations into the topic. I made a point of. making Marie as close to my own reactions and as less like an original character as I could get. Marie is thrown into a fictional world where she must learn to use her own Mary-Sue-ness as a sort of super power in order to save both the day and her own skin. She is accidentally, by virtue of a botched magical experiment, pulled into the fictional realm of Dracula: the series, and from there must travel from reality to reality searching for her home or a faster way to get there. Each of the realities that she passes through is one comprised of a canonical fictional work, and thus is Marie a living Mary Sue, with all the trappings that comes with that turkey of a title. However, to complicate things more, Marie is a self-aware Mary Sue, as she has studied fanfiction herself in her own university Literary Theory classes. I purposefully set the first chapter in Dracula: the

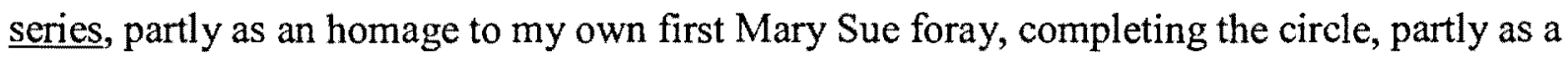
means of biting my thumb at those reviewers who were unkind to me on "A Deal With Dracula". Marie 'slips' between fandoms, forever searching for home and trying to weather the trials of being a Mary Sue. it also raises and addresses what are to me some of the key issues of fanfiction in general and Mary Sues in particular: What if there really was a way to traverse the realities? How would someone react to that ability? How would a real person handle the perpetual and plot-necessary extreme drama, danger, and romance of fictional environments? As a forewarned reader, would someone entering a familiar fandom violate Star Trek's Prime Directive and interfere? Would this real person reveal themselves to the main players? Divulge major plot points and secrets? Can you really change History? And if someone did reveal themselves and 
certain 'spoilers ${ }^{29}$, how would it affect the fictional reality they were currently in? Would it at all?

How would being a Mary Sue effect a person emotionally in a realistic manner? Mary Sues are often in danger or the centre of attention - how would this effect a person's psyche after a prolonged period of time? How would a person who is aware of the Mary Sue conventions and trappings react when ensnared inside them?

These are the realities that Marie Susan Brooke must face every day of her new life. She is fighting to get home, sliding from one fictional reality to the next, hoping each time that this new one will be her last. One by one, I confronted Marie with the harsh conventions of fan fiction and Mary Sueism, and forced her to deal with them in a realistic, humanistic.manner, and not that of a true Mary Sue. I'm going to spoil the ending and tell you that Marie gets home and in one piece, though much changed in temperament. But that's the point. Marie becomes a lot more closed off, irritable, stand-offish, and detached. Slipstream is my experiment in human behaviour and poor Marie my white mouse. I wanted to see what being a Mary Sue would really do to a person, and this is what I've concluded: basically, all that 'Slipping' between realities really robs one of one's humanity - survival becomes more important than compassion. One cuts oneself off, becomes detached. That's the reality of the Mary Sue.

Here is a full-grown woman who up until now has lived a pretty normal life. Suddenly she is thrust into a situation where nearly every choice she makes becomes life-or-death for her or someone else. When she's not constantly on the move or under some kind of mental, emotional, or physical attack, she's hiding and trying to recover from the last one. Marie is a Mary Sue who is aware of the very clichés and trappings of her own existence. She is a Mary

\footnotetext{
${ }^{29}$ A 'spoiler' is a bit of information in a summary or synopsis of a work which is generally thought to ruin the 'surprise' of, or give away, the ending.
} 
Sue who is completely self aware and self-reflexive, yet is a Mary Sue all the same and cannot escape the impedimenta she knows exist. She is slowly deconstructing her own existence as she batters her way through the Checklist, but where does that leave her? What's left when you deconstruct yourself? Is there anything left?

The one thing that Suethors in general seem to forget is the consequences, the results. All these things happen to and around Mary Sues, but few people address or take into account the real human reactions to these events. Culture-shock nothing. We're talking reality-shock. It's enough to make anyone bitter and self-isolating. Imagine what kind of life Mary Sues must endure: constantly pursued, constantly in danger, constantly substantially affecting the entire lives of people and constantly having the fate of one world or another in your hands. On top of that, Marie is constantly sliding to new realities, where it all just happens all over again. Now, image what kind of person you'd become if you were consistently subjected to that kind of life: weary, wary, always on the alert, always seeing alternate motives in everything everyone does. You'd never trust anyone. You'd avoid people and places just to keep everyone around you, and yourself, safe. Wherever you are, it's guaranteed by the rule of the Mary Sue to become a dangerous or overly-sexualized place - much better to withdraw, to hide yourself, protect the innocents from you and what will inevitably surround you. And better to protect your heart, too. One can only handle so much death and separation. If you make no friends, then it doesn't hurt to leave. If you don't fall in love, then longing can't touch you. Now, imagine living this way for years. Years. It's not healthy. It's not human.

And what happens when you go home? The place where you thought you would be safe, and warm, and yourself again... but you can never be yourself again. When you look at the faces around you, the faces you thought belonged to people who understood you, people who loved 
you, you realize that they nothing about what has happened to you, what you have experienced and how that has changed you. Imagine how lonely, how cold, how frustrated that would make you feel. And the only way to deal with it would be to shut down. Turn off all emotions. Stop caring. The Marie we see at the end of Slipstream is this person.

Type of Mary Sue: Meta Sue, Literary Masturbation

Pedagogical Aim: I wanted to know if I could really write a Mary Sue - a Mary Sue that ticks off every box on the checklist - and still have it be a good, educational, well-written, wellreceived, interesting story where the character reacts completely and totally like a human being would. I learned a lot about what sort of strength and stamina I believe I have, and what sort of trauma I perceived would be too much for myself. Was the Meta Sue actually possible? I also wanted to educate my readers as to what a Mary Sue really is, why she exists. I wanted to prove that Meta Sues could exist.

\section{Checklist:}

1) The Mary Sue character exists for the Suethor's wish fulfillment.

Marie exists to fulfill many of my personal and academic desires; through her I was able to revive my interest in Dracula: the series and in a sense revise Elana Seward into a Meta Sue, as Marie, like Elana, is deeply and intimately as accurate a representation of myself and my Teactions as I could convey; Marie was my most thorough and successful attempt at pushing my theory of the Meta Sue out of the purely theoretical sphere and into practice, as well as into fandom where it was received very well by its readers. Lastly, Marie, in slipping through many fandoms, has the chance to interact (both platonically and romantically / sexually) with all of my favourite characters from all of my favourite fandoms. "Slipstream" is very much a survey of my most loved media texts. 
2) There is a sense or tone of whimsy and /or self depreciation in the text.

Marie derides herself for being too much a scholar, living too much in her head rather than experiencing the worlds through which she is travelling. While the overall tone of "Slipstream" is far darker than the conventional Mary Sue, a sense of Marie's self-doubt remains a prominent feature of her characterization until the fourth instalment of the series, "Slipstream: Down Once More". Because Marie is forcefully propelled from one highly stressful, high adrenaline situation to another by virtue of her very black-hole-of-plot-ness, there is much chance and little personal agency that Marie can exert, except in the way in which she reacts to particular situations which, again conventionally, most Mary Sues react to in an opposite fashion. For example, when Spike, the 'bad boy' vampire of Angel: The Series makes sexual advances at Marie, she flees and protests, where most Mary Sues would gladly capitulate.

3) The Mary Sue's appearance and personality are often divulged within the exposition. I described Marie wearing exactly what I had on the day I began writing. Not only that, I went home and had the outfit photographed (see above image). I have made a very specific attempt to convey in Marie the most honest and blatant recreation of my 'self', even down to her appearance.

4) The Mary Sue is given a name with a hidden or relevant meaning. Marie Susan Brooke = Mary Sue Book.

5) The Mary Sue is previously unrecognized, or drops in from 'reality' into the fandom. Marie drops in from our reality, with nearly full knowledge of the media text, or at least previous passing acquaintance.

6) The Mary Sue's abilities outdo the canonical characters with no previous experience. 
For Marie to survive Slipping, and repeated exposure to the sorts of traumas and plot climaxes that Mary Sues suffered, I determined early that the only way she could live through the experience was if she was granted some sort of extra-normal powers which would work to full capacity no matter which media text she was interacting with. Marie would need: immortality, to survive all of the death scenes; magical powers to defend herself against urbane and occult weapons alike: strength, speed and stamina to win each fight; and of course the meta-knowledge of Mary Sues which she could exploit to her advantage. To that end, Marie was immediately turned into a vampire, learned Harry Potter-style duelling magic from Professor Flitwick, gained martial training from a variety of her lovers - Legolas the elf from Lord of the Rings, Methos the immortal from Highlander: The Series, and Miroku the monk from Inu Yasha, among others.

7) The Mary Sue is immediately accepted into the inner circle of friends and confidants. Marie took for granted that she would be accepted, and so often elbowed her way in. Whether this is the Mary Sue at work, or just self-fulfilling prophecy is left up to the reader to decide.

8) The Mary Sue disrupts the canonical friendships, partnerships and romances. This was one aspect of the Mary Sue that my research taught me was absolutely unforgiveable in any sort of fan craft that a reader would tolerate. It is one of the few traits that absolutely must be absent from a Mary Sue story for any reader to accept it. As "Slipstream", along with "Across Time" is a flagrant attempt at promoting the theories of the Meta Sue, it was one that had to be discluded from both crafts in any serious form. The trait is, however, satirized in both stories.

9) The characters are made to act out of character by the Mary Sue's presence. This is the other trait that readers will not tolerate.

10) The Mary Sue robs the strong female characters of their rational agency. 
Again, as with Vega, Marie often usurps the surrounding female characters of their agency in the plot by usurping their roles, but she does not usurp their rationality for fear of committing 'character rape'.

11) The Mary Sue is sexually attractive to all canon characters.

This was a trait that I will admit to having a great deal of fun exploring. Marie was made to be ridiculously attractive despite her very plainness and unwillingness to enter into any sexual relationships. Marie was pursued by suitors from every fandom to the point of ridiculousness, and to her own complete and utter exasperation.

12) The Mary Sue is ardently desired by the villain.

See above.

13) The Mary Sue is the reason for the main conflict in the plot and usurps destinies. As Mary Sues are the reason the story is being told, I made certain to put Marie through a full climaxing narrative in each reality, with little rest between the last resolution and the next commencement. This was in large part my attempt to force Marie to a breaking point, where the attraction of being a Mary Sue, of being the centre of everything is shown in a stark light as unhealthy, wearying, and traumatizing.

14) The Mary Sue's sense of humour is quite practiced and enjoyable. Marie's signature quote is "Are you deaf? Or just stupid?", an insipid and silly line that was popular in the schoolyard in my youth, flagrantly offensive and juvenile.

15) The Mary Sue is able to shift shapes, or has a friend / pet that can shift shapes. Marie, as a vampire, can become a bat. She is aware of her ability to become a wolf or mist, but has had no desire or chance to attempt the former, and admits that the latter terrifies her, that she is scared that once she becomes incorporeal, she will fade to nothingness. 
16) The Mary Sue 'understands everything'.

Marie is an avid consumer of many of the fandoms into which she slips, and does spend a great deal of time offering small tidbits of advice to the characters of which she is fond. She retrieves Sirius Black from beyond The Veil, and soothes the egos or assuages the guilt of many of the other characters who are going through a difficult stage of character growth in the media text.

17) The Mary Sue has a tragic past that precedes the story, that they 'get over' cheerily. The very point of writing so realistic a Mary Sue is to test how much a real human being could go through before they snapped. (For Marie it was about ten fandoms; I can only hope that the real me would last that long). Many readers expressed genuine shock that my Mary Sue had a realistic and complete mental breakdown mid-story. With counselling and renewed determination, Marie works through her traumas and arrives out the other side a stronger and more compassionate person. Her scar from her first death and resultant transformation into a vampire is described thus:

Of course, the cold wasn't the only reason I wore the turtleneck. Like Remus had warned, my neck bore a puffed, white ridge of scar tissue. It was in the shape of Lucard's upper jaw, bisected by a line that I assumed was torn when he thrust his tongue into my flesh (Chapter 6).

17.5) Long-term guilt or pain is rare in a Sue.

Marie suffers from severe night terrors after being raped by Alexander Lucard, and held hostage by Jean-Claude of the Anita Blake ${ }^{30}$ series.

18) The Mary Sue is the centre of the plot, the only one who can 'save the day'.

\footnotetext{
${ }^{30} \mathrm{I}$ feel compelled here to point out that Laurell $\mathrm{K}$. Hamilton, author of the series, has requested publicly that fans refrain from creating fan crafts about her work. Other such authors are Anne Rice, Terry Prachett, and P.N. Elrod. Most fan crafters comply with such author requests (and there are other authors who take the opposite tack - J.K. Rowling, Anne McCaffrey, and Tanya Huff for example). I chose to ignore this request to deliberately court the dangers of copyright infringement that fan crafting infringes upon, and to firmly entrench myself with Willis when she says that I, as reader, have the Barthesian immortal right to do what I will with art.
} 
Marie's unique nature - a spell-wielding kung-fu vampire with the ability to manipulate the circumstances of her own existence - was often the very key to saving the world and characters from destruction. I wanted to be clear that the day was not saved by Marie because she was just any old Mary Sue, but because she was Marie Susan Brooke with her own particular skill set.

18.5) And in doing so, the Mary Sue 'ties up loose ends'.

Marie sometimes slipped into the media text after the conclusion of the series. In those cases she was able to provide an ending for the characters that I personally found more satisfying. Other times, she, like Vega, was able to clear up plot inconsistencies, or comment on those aspects of the canon that I found unsatisfactory. In each instance, she leaves the world of the media text -at least on the surface - relatively unscathed. I made a deliberate choice that Marie's actions would not, in the end, much alter the canon. The idea being that Marie is something that happens in the background of the canonical action, or during the commercial break, or in between episodes or volumes. Marie was meant to flit in the corners of canon, unseen by readers but acknowledged as present, a reflection of fan crafter's own desires to connect with, to 'be in' the canon.

19) The Mary Sue character 'saves the day' in unlikely ways that leave the canon characters stunned and amazed.

Most characters were very stunned to see magic or vampirism in their worlds, where neither canonically exists.

20) There is a happily ever after wherein the Sue and the Love Interest are united. Marie's overarching love interest - Ares, God of War from Xena: Warrior Princess - is lost at the end of the first novel, and in fact will not be achieved until the end of the fourth. Her desire to be reunited with Ares, and to complete her familial cluster in finding the vampire son that she births 
and rejects in the middle of the first novel, is the motivation for her to continue Slipping through

the three sequel stories.

20.5) Unless the Mary Sue dies, in which case her death is tragic, meaningful, and beautiful.

Marie is unable to perish permanently, but it often occurs at the end of a particular action plot in order to 'tidy up' the world for a return to regularity, to offer Marie a chance to Slip to the next world in privacy, or to leave a moral or memento for the heroes left behind.

Feedback and Impact: Is a Meta Sue actually possible? Can she exist? Yes. The feedback for this story has been entirely positive and I have received letters stating that people have revised their own Mary Sue stories or begun their own based on what they learned from Slipstream. Based on reader feedback and requests to clarify Marie's character journey, plot points, or specific inquiries into the definition of a Mary Sue, the story was expanded to include a second set of stories wherein Marie returns to slipping in order to retrieve the son she accidentally created in the first story. ${ }^{31}$

\section{c: The Dark Side of The Glass}

Mary thinks 'love' is a bit of a strong adjective for a feeling towards a fictional character, and then reconsiders. She works to bring him to life, she faithfully watches every episode and updates the Wikipedia article page and reads his fan fiction. She attends the conventions and creates meaningful works or art centered on him, thinks about and analyzes his motivations and gestures and verbal tics. She knows what he is and that makes him more special to her, not less. Love is exactly what it is.

\section{-The Dark Side of The Glass}

31 At the time of publication, a secondary author - Cat Latin - has agreed to write a novella about Marie in a fandom of her choosing with almost no feedback from me. The question I asked myself for this Slipstream was this: Is it still a Mary Sue if she's authored by more than one writer? Can - could - Marie remain my particular Mary Sue if she is adopted by another fan crafter and written as a fan crafter would to a media text's canonic characters. As Cat Latin has not completed the story as of yet, I cannot report on its success, but our dialogue this far has been encouraging. Cat Latin says: "I usually avoid MS fictions. I'm fascinated by what [JM]'s been up to, creating a selfaware MS, who uses the usual MS tropes as "powers."” 
Fandom: A fictional vampire detective television program titled "City by Night", an homage to and amalgamation of Dracula: The Series, Forever Knight, Angel: The Series, True Blood, Blood Ties and Nightwalker. The title of the story comes from a song on the Forever Knight soundtrack of the same name.

Length: Novella, 37 pages

Aims: Meant to be read in the same vein as Bookwierd or Inkheart, I created a fictional realm within a fictional realm for my characters to inhabit. This was done to both streamline the interpretations of the vampire crime drama genre into a single entity, and also so that I may later publish the story and further the spread of the Meta Sue into the professional realm ${ }^{32}$, as I intend to do with "First Impressions". This story does not feature a Mary Sue who is aware of the theory of Mary Sues, but is, however, intimately acquainted with the very commercial and awkward world-building that often occurs in television program creation, as she works on the (made up) television show which she accidentally comes to inhabit. This last story is the only one about a Mary Sue who is entirely obvious to her own Mary Sue nature, and the only one without a metalevel of which the Mary Sue is conscious within the plot.

Type of Mary Sue: Commenter on Narrative Convention and Deconstructer of 'Inherent Truth' Pedagogical Aim: I intend readers to become aware of the bizarre half-world building that creators of television programs engage in and liken the Mary Sue to filling in the gaps in the narrative.

\section{Checklist}

1) The Mary Sue character exists for the Suethor's wish fulfillment.

\footnotetext{
${ }^{32}$ As of completion of this project, "The Dark Side of The Glass" has been picked up for a sci-fi/fantasy anthology titled RE:'versed, a collection that investigates the clichés of the genre. Publication date is estimated at March 2010.
} 
I love vampire cop shows, and I have the clichés that are inherent in their construction, narratives, characters, and plots. I've always wanted to poke holes in those clichés and highlight the gaps.

2) There is a sense or tone of whimsy and /or self depreciation in the text. Mary was designed deliberately to be socially awkward, pathetic, obsessive and the typical stereotype of the typical media fan in order to rouse the sympathy of the reader. Eventually Mary evolves into a more sure and rounded person, but in the end chooses to live in a fantasy world than the real one.

3) The Mary Sue's appearance and personality are often divulged within the exposition. I deliberately did not physically describe Mary so that the reader may utilize her like the place holder of the romantic fiction genre. As Mary's personality and preferences is so rigorously documented - the first page is a summary of Mary's typical work day - I wanted to leave a deliberate opening for the imagination of the reader, and the opportunity for self-insertion.

4) The Mary Sue is given a name with a hidden or relevant meaning. Mary has no last name, but was named obviously. Her 'Mary Sue' other, a character created in the television program "City By Night" is named Mary Trinity in homage to the author one of the first Mary Sue stories I ever read - SSJ Trinity aka Trin-san - and because it sounds so perfectly Mary Sue. Mary's Mary Sue is more Mary Sue than she is, even though she is the protagonist Mary Sue of the tale.

5) The Mary Sue is previously unrecognized, or drops in from 'reality' into the fandom. Mary is a PA on the production crew of "City By Night". She is hit by a catering van and wakes up in 'Night City', a place where the show she helps to create is real, and all the inhabitants talk and act like the characters, guest characters, or background extras they are. 
6) The Mary Sues' abilities outdo the canonical characters with no previous experience. Mary remains depressingly normal throughout the story, but her Mary Sue is a very agile and powerful vampire.

7) The Mary Sue is immediately accepted into the inner circle of friends and confidants. Richmond du Noir, the hero of "City By Night" forms a fast and strong romantic relationship with Mary, at the same pace as the character would if the story had only a 48 minute episode in which to introduce the girl-of-the-week, prove her connection with the hero, and then portray her noble and meaningful death or self-sacrifice.

8) The Mary Sue disrupts the canonical friendships, partnerships and romances. Sherri, a street urchin friend of Richmond's, is blocked from Richmond because his focus is diverted to Mary. Sherri desires a romantic relationship with Richmond, Richmond believes their relationship is paternal, and Mary is the competition who wins out against young and inexperienced Sherri.

9) The characters are made to act out of character by the Mary Sue's presence. Sherri is deliberately hostile towards Mary, and Mary, who is familiar with "City By Night" is confused by the teenager's reaction.

10) The Mary Sue robs the strong female characters of their rational agency.

See above.

11) The Mary Sue is sexually attractive to all canon characters. Richmond is sexually attracted to Mary and instigates a romantic relationship immediately.

12) The Mary Sue is ardently desired by the villain.

Antonio, Richmond's maker, seeks to use Mary as a tool to force Richmond back to his evil roots (another standard cliché of the vampire cop show). He is irresistibly pulled to Mary because of 
the influence she has over Richmond. Antonio repeatedly forces her into allowing him to drink her blood, which is in this instance, akin to repeated rapes, in order to undermine Richmond's confidence and independence.

13) The Mary Sue is the reason for the main conflict in the plot and usurps destinies. Mary's presence gives Antonio just the situation he requires to attempt to force Richmond back into the fold. Without Mary's presence, the plot would not be occurring.

14) The Mary Sue's sense of humour is quite practiced and enjoyable.

Mary is a fan of "City By Night" and a fan crafter herself who is intimately aware of the tone and patter of the show.

15) The Mary Sue is able to shift shapes, or has a friend / pet that can shift shapes. Mary cannot shift shapes; however, she does shift into a Mary Sue at the end, and that Mary Sue can shift shapes according to standard vampire lore.

16) The Mary Sue 'understands everything'.

Mary is a convention-attending die-hard fan of "City by Night" as well as a member of the production crew, and a fan crafter who works with the "City by Night" fandom. She is familiar with both the final processes and the behind-the-scenes work that goes into the program, though she is still somehow continually surprised by how flat the characters she interacts with are, or how adherent to standard vampire cop show clichés the plots are.

17) The Mary Sue has a tragic past that proceeds the story, that they 'get over' cheerily. Before Mary falls into "City By Night", she overheard herself being mocked by the series' lead actor and producer. Her mortification does not last long, however, as soon she is caught up in the series itself.

18) The Mary Sue is the centre of the plot, the only one who can 'save the day' . 
In this case, I refrained from 'ending' the story conventionally, instead completing the narrative before the say required saving or major battle occurred. Mary returns to her own reality in what would be the mid-season break, while "City By Night" gears up for the end of season climax. Desperate not to miss the climax, Mary attempts to return to the world of the program. I finish the narrative before the reader is informed whether Mary is successful or not in the hope that the reader will then imagine the afterlife of the story for themselves, fantasizing with Mary as if their own Mary Sue.

19) The Mary Sue character 'saves the day' in unlikely ways that leave the canon characters stunned and amazed.

Mary's presence in the world of "City By Night" skyrockets the ratings of the previously faltering program, saving it from cancellation. The character Mary Trinityds a fan favourite.

20) There is a happily ever after wherein the Sue and the Love Interest are united.

See point 18.

20.5) Unless the Mary Sue dies, in which case her death is tragic, meaningful, and beautiful.

To return to her own reality, Mary is hit by a car a second time, this one driven by Antonio. It is this final act of cruelty that makes Richmond determined never to rejoin Antonio and to forever defy him.

\section{d: First Impressions}

I gained new respect for my female predecessors.

I might posses the almost manic co-ordination it may take to steer and press the gas pedal and shift gears of a car, or to type whole documents without looking at the movement of my fingers, or to even button mash on a fighter video game, but remembering all those dance steps and which order they came in for half-africkin-hour was just amazing. And there were dozens of these different dances hundreds, maybe, and each of them with their subtle but important differences that I couldn't even begin to fathom. 
Fandom: The life of Jane Austen (which technically is not a fandom in that it is not a complete, solitary fictional world. It is, however, the focus of devoted Janeites with a film - Becoming Jane - and several hundred books, essays, articles, stories, and speculations within its purview).

Length: Novel, 200 pages

Aims: The only novel written specifically and entirely for this project, "First Impressions" is about a Meta-Mary Sue who interacts with Austen and thus directly influences Austen's creation of Pride and Prejudice. However, as many fan crafters do with other narratives, I centralize the previously marginalized tension of queerness that runs as an undercurrent throughout the source text and Austen's life by introducing Jessie Ferris (who later becomes Austen's long-time friend Martha Lloyd through a marriage and an identity swap), thus making the text address my own socio-political concerns as well as Austen's. Austen's books are always very concerned with the roles of women in the household and the socio-political sphere, and are always pointing out the flaws inherent in the Regency English social and moral systems (Ray, 2006). I added another layer of critique to Austen's books by putting the Regency attitude in direct juxtaposition (and contact) with the current one. The main character, Jessie Ferris, is a bisexual, self-employed single woman in possession of a great fortune (comparatively), and in want of a wife. She is everything treasured by the mamas of the Ton in Austen's books, yet female. The book also critiques the clichés of the modern period romance genre, as Jessie questions her own romantic involvement with her rescuer in terms of Stockholm Syndrome and Post Traumatic Stress Disorder.

Type of Mary Sue: Forcing a Subject Position in an Otherwise Unaccommodating Text 
Pedagogical Aim: This exploration of the undercurrent of queerness creates a tension that educates the reader in the present concerns in gender roles, and the flawed nature of specific, time-honoured interpretations of classical works, the canonical methodologies and the inherent binaries of understanding and meaning. Jessie is also the person on whom Jane's three earlier heroines - Maryanne Dashwood, Elizabeth Bennet, and Fanny Price - are based. Jessie is the woman who loves desperately and futilely, who walks through the rain in despair, who loves to tease and have a laugh, who comes around to accepting her new love and admitting to her own stubbornness in the end, who teaches Jane that there are graver and more sullen things in the world than ill-matching ribbons, who questions authority and tradition, who shows Jane that the world must, inevitably change. Jessie becomes the prototype for Jane's own feminist prototype, Fanny Price, guided by her own inner moral compass despite the influences of the people around her, clinging to a world that's been lost to her while in a world in which she's lost.

\section{Checklist:}

1) The Mary Sue character exists for the Suethor's wish fulfillment. I was surprised to discover, however, that while I personally preferred Jane as Jessie's romantic partner, Jessie fought long and hard with me to stay with Jane's brother Francis, her rescuer, due to her PTSD. In the end we came to a truce, and through a series of events Jessie's name is changed to Martha Llyod. Martha was the long time friend and house-mate of the Austen women, and after Jane's death, she was Francis Austen's second wife.

2) There is a sense or tone of whimsy and /or self depreciation in the text. In keeping with the attempt to write a professional publishable quality novel, I have limited the tentative self-depreciation and instead focussed on self-deception; Jessie, rationally, does not believe in time travel and therefore doubts her own sanity highly. This does give an air of self 
doubt. The plot occurrences, while still relying heavily on chance as a catalyst, are most often the result of Jessie's agency rather than universal karma.

3) The Mary Sue's appearance and personality are often divulged within the exposition. Very deliberately, as with Mary in "The Dark Side of the Glass", I have chosen not to describe Jessie in any elaborate detail, instead using the opening exposition to infer her personality; this is done so that Jessie may be a more tolerable place holder for the reader.

4) The Mary Sue is given a name with a hidden or relevant meaning. Jessica Anne Ferris; Jessica, after myself, Anne because it is a common twenty-first century middle name, and Ferris to allude to Austen's character Edward Ferrars. Both are awkward and undemonstrative, both are promised elsewhere (Edward, in an engagement, and Jessie in the twenty first century), and both arrive seemingly out of the blue to capture the heart and interest of the protagonist.

5) The Mary Sue is previously unrecognized, or drops in from 'reality' into the fandom. Jessie is a citizen of our reality, thrown back in time into what is perceived to be our reality still.

6) The Mary Sues' abilities outdo the canonical characters with no previous experience. Jessie proves to be very good at storytelling, though less successful than Austen at writing it down.

7) The Mary Sue is immediately accepted into the inner circle of friends and confidants. Due to Francis Austen's patronage, Jessie is introduced to the Austen women and becomes a close friend of all, confidant and confider to Jane, and Jane's lover.

8) The Mary Sue disnupts the canonical friendships, partnerships and romances. When Cassandra Austen discovers Jane and Jessie's relationship, she disavows her sisterly affection for Jane and has Jessie sent away, causing uproar in the Chawton Cottage house. 
9) The characters are made to act out of character by the Mary Sue's presence.

Jane Austen becomes a lesbian. Francis Austen becomes an adulterer.

10) The Mary Sue robs the strong female characters of their rational agency.

As I mentioned before, this is one point that I am hesitant to fill in order to ensure that the characterization of the canon characters remains appealing and does not put off my readers.

11) The Mary Sue is sexually attractive to all canon characters.

Jessie attracts Francis and Jane Austen, but also a serving girl named Miss Martin, a neer-dowell rogue named Mr. Cullin, and her eventual husband, Mr. Lloyd - though their marriage is a social contract and not anything to do with love.

12) The Mary Sue is ardently desired by the villain.

Mr. Cullin peruses Jessie for her oddness and strange intelligence, and to revenge himself upon her for humiliating him publically.

13) The Mary Sue is the reason for the main conflict in the plot and usurps destinies. It is Jessie's idea to revise Jane's novel into Pride and Prejudice, and accidently names the novel as well. Jessie spends a great deal of time with Jane while Jane is revising the novel, and therefore has a great impact on the final product. Jessie is also the prototype of Fanny Price of Mansfield Park.

14) The Mary Sue's sense of humour is quite practiced and enjoyable.

Jessie speaks as a twenty-first century woman does, making her speech patterns incomprehensible and amusing to her companions.

15) The Mary Sue is able to shift shapes, or has a friend / pet that can shift shapes. Jessie has a fluid sexuality, liking either sex equally.

16) The Mary Sue 'understands everything'. 
Jessie has the privilege of knowing that Jane Austen will eventually become a celebrated author, though she is not intimately aware of all the details of Jane's life.

17) The Mary Sue has a tragic past that precedes the story, that they 'get over' cheerily. Jessie, due to an accident and later a sword fight, looses the mobility and use of her right hand. I inflicted this injury on Jessie purposefully so that it is clear that she is could not possibly be Jane Austen's ghost writer.

18) The Mary Sue is the centre of the plot, the only one who can 'save the day' . Jessie is the one who helps Jane finally come to accept her own queerness.

19) The Mary Sue character 'saves the day' in unlikely ways that leave the canon characters stunned and amazed.

Only in that Jessie teaches Jane to be happy.

20) There is a happily ever after wherein the Sue and the Love Interest are united. Jessie, as Martha Lloyd, remains Jane's long time friend and secret lover until Jane's death. At which point, Martha then marries Francis Austen - Jessie gets to be the lover of both treasured siblings.

20.5) Unless the Mary Sue dies, in which case her death is tragic, meaningful, and beautiful.

The last paragraph of the novel throws the entire plot into question; did Jessie really go back in time and become the lover of Jane Austen? Or has it all been a hallucination that occurs while Jessie is drowning to death in the twenty first century after a plane crash? 


\section{6: $\underline{\text { Conclusions }}$}

\section{a: Answering the Research Question}

The dominant question guiding this research asks if writing a Mary Sue that is not rejected by the fan community is possible. Before I could attempt to answer by writing Mary Sues that could possibly be accepted, I had to define what a Mary Sue was. To do so, I integrated the information about Mary Sues, fan crafters, reading communities, and Mary Sue writers acquired through surveys, online discussions, and content analysis of existing Mary Sue stories and communities with the limited academic inquiries on the topic into a singular, definitive definition. This definition addressed what a Mary Sue is, how she is perceived by fan readers (either singularly, or due to peer-influencing stereotypical reaction to the trope, inside or outside of fan communities), and why she is perceived in that manner, why she provokes that particular response.

I was then able to move on and determine what must be done in regards to deploying and manipulating the trope in order to redeem both Mary Sue and my young self as a Suethor. The answer to all these questions lies in the Meta Sue, a new evolution of the Mary Sue that I invented for this MA Project to speak on behalf of Mary Sues and Suethors alike. It was through identifying the characteristics of the Mary Sue, and capsize them, that I was thus able to create the Meta Sue. Meta Sue gives authors a chance to seriously engage in self exploration and investigation into narrative structure without the negative reader reaction that most Mary Sues garner because of the premeditation inherent in the character archetype. Mary Sues are inherently dualistic, but the Meta Sue provides a different mode of writing and a different mode of reading wherein the negative aspects are denied through a sense of prophylactic irony and deliberate awareness, that Meta Sue is a serviceable reader placeholder. 
In creating these Mary Sues of my own, as I illustrated so thoroughly in the previous chapter, I have proven that a Meta Sue was possible, that in understanding the tropes well, a Suethor can invert the clichés, and play with them in a very intentional way. This project is relevant because it proves that the Meta Sue can exist and successfully function. I also wrote these four stories - two fan crafts and two professional fictions - to determine that a Meta Sue is not a singular, particular phenomenon, but as a repeatable narrative choice that influences other writers into creating their own Meta Sues. Fan crafter Cat Latin has picked up Marie Susan and is currently writing a third story for the 'Slipstream' series, and other fan crafters have been in contact with me since the publication of 'Slipstream' to aid in the construction of a fourth, hyperaware multi-author Meta Sue story which addresses the question of whether a Mary Sue can remain as one if she is authored by someone who is not the originating Suethor. Prior to this, fan readers and crafters were investing in the negative stereotypes of the Mary Sue; my work asks them, forces them to engage on a different, positive, analytical level. I, like Lelac Almagor, seek to encourage other fan crafts to reclaim the Mary Sue for the purpose of exploring their own sexuality or subject position and /or in pedagogy as a method of deconstructing narrative and character.

\section{b: Weaknesses}

While I did have access to earlier conversations and questionnaires I distributed to Mary Sue communities, my own particular survey, which I created for this project, was largely unanswered by any participants. The population sample was so small that I had to treat the resultant data as content analysis rather than compile the percentages and averages that I had hoped for. I was relying on the online communities of which I am a member to allow me to distribute the survey, which I largely was not. Another weakness this built into the research was 
an inability to also use the survey as a method of determining the age and gender demographic of the Mary Sue writers that answered. I failed to ask age and gender questions in the survey, as I was focussed more on the writing portions, and combined with the lack of respondents, the survey did not offer an opportunity to determine the Suethor age and gender demographic. I therefore had to rely on the assumption made in Black, among the online communities, and in other research, that Suethors are usually aged 13-18 and female, and Meta-Sue authors are aged $19+$ and female. Now that I have defined the Mary Sue, further research into the topic must focus on an attempt to understand the Suethor, her / his demographic, and motivations. I also began, and could not complete, a Mary Sue story in which my character was male. This Marty Stu agent Fitzwilliam Greene, a steampunk-inspired tinkerer who loves to travel but gets seasick was to feature in a tale based on Doctor Who. However, it was difficult to write from the male perspective, something I do only rarely in my own professional fiction, and decided to discontinue the attempt and focus my attention on "First Impressions" instead. The story, titled "Madmen and Blackflies", ${ }^{33}$ has since been revised into a speculative script for the Doctor Who television program and is being looked at by a screen writing agency. My Marty Stu has not died, merely switched mediums.

\section{c: Strengths}

The primary goal, and indeed, reason for existence of this paper is to finally, and definitively, offer a definition of what exactly a Mary Sue is, why people write, love, and hate her, and in what ways she can become a useful, informative tool for the fan crafting community as a Meta Sue. In compiling this definition, in provoking interest in the Meta Sue archetype and providing four examples of how the ideal of the Meta Sue can be achieved, I inspired other potential Suethors into delving further into the genre and use the Meta Sue as a tool for self

\footnotetext{
${ }^{33}$ See appendix $\mathrm{F}$ for an excerpt.
} 
examination and to act as a means of effacing the gaps in subject and subject positions which are centralized or marginalized in media texts. I researched and created the Mary Sue Checklist and the Five Faces of Mary Sue, and this information allows other Suethors to determine the primary motivations of why Suethors write Mary Sues, and why readers do or do not hate them, and thus begin to understand how to create their own Meta Sues. Meta Sue provides the chance to illustrate or explore a concept without the, as Willis calls it, 'vengeful rigor' of academia; fan crafting can be an edu-tainment approach to typically difficult topics such as race and gender inequality, colonialism, sexual orientation, or family dynamics (these being but a handful of topics for which I can off hand name at least a dozen fan crafts that explore them in a compassionate, thoughtful, and thorough manner), "a deliberate, politically loaded, practice of recontextualization that reorients a text in order to demonstrate that it bears the trace of a desiring structure not wholly congruent with the most literal (which is to say, the most ideologically obedient) reading" (Willis 156 ). Fan crafting therefore intertwines pleasure with the "deeply political project of resistance and in-sistence that people must have the right to make and circulate meanings outside the circuit of ideologically or institutionally guaranteed transparency, provability, and, ultimate, enforceability" (Willis 156). A Mary Sue can act as a way for people to begin to explore a budding creativity or unfamiliar self-identified subject position, or as a way to critique choices made by production teams, writers, actors, or even the very structures and clichés of the media text itself. By inserting a new person into a place where she clearly doesn't belong, the writer rips a hole into the fabric of the universe, letting in the water, submerging all the aspects of a media text except those which the Suethor wishes to address, which float to the surface; human reaction, self identity, community building, awareness, constructive critique, and the simple visceral or physical pleasures that are oft times denied in media texts. Meta Sues 
cause a flood, and sometimes the media text, the art, and the Mary Sue just has to drown in order for the baby to live. 


\section{7: Bibliography and Works Cited}

Almagor, Lelac."The Mary Sue Project". The Horn Book Magazine, November/December 2006. Boston; The Horn Book Inc, 2006. (pp 661-665)

Almagor, Lelac. E-mail Correspondence. February, 2009.

Bailey, Steven. Media Audiences and Identity: Self Construction in the Fan Experience. New York; Palgrave MacMillan, 2005.

Balenoptera. "Comment." History's Reflections (Livejournal). Available $<$ http://losyark.livejournal.com/89653.html> Accessed: September $26^{\text {th }}, 2006$.

Bacon-Smith, Camille. Enterprising Women. Philadelphia: U of Pennsylvania Press, 1992.

Bastion of Questionable Sanity. "The Mary Sue Report." Moderator: Unknown. Available: $<$ http://www.livejournal.com/community/marysues/ $>$ Accessed: February $25^{\text {th }}, 2005$, 9:27am

Beeler, Stan \& Lisa Dickson, eds. Reading Stargate SG-1. New York: I.B. Tauris and Co, 2006.

Bedard, Phil \&Larry Lalonde. Dracula: the series (series). Dir. Joe Dea. Bernard Behrens, Geordie Johnson. Cinexus/Famous Players, 1990-1991.

Blair, Gavin. "Lecture Notes - ReBooting ReBoot" FanExpo Sci-Fi Comics Convention. Metro Toronto Convention Centre, August $26^{\text {th }}, 2007$.

Black, Rebecca W. Adolescents and Online Fan Fiction. New York, NY: Peter Lang Publishing Inc., 2008.

Brayton, Jennifer. "Fic Frodo Slash Frodo: Fandoms and The Lord of the Rings." From Hobbits to Hollywood: Essays on Peter Jackson's Lord of the Rings. New York: Rodopi, 2006. p 137-153.

Burnett, Robert \& P. David Marshall. Web Theory. London; Routledge, 2003.

Busse \& Hellekson, "Introduction: Work in Progress." Fan fiction and Fan Communities in the Age of the Internet. eds. Busse, Kristina and Hellekson, Karen. Jefferson, North Carolina: McFarland \& Company, 2006.

Barthes, Roland. "Myth" Performance Analysis. trans. Annaette Lavers, 1972. Eds: Council, Colin \& Wolf, Laurie. London, England: Routledge, 2001.

Brooker, Will and Deborah Jermyn, eds. The Audience Studies Reader. New York: Routledge, 2003. 
Brooker, Peter. A Glossary of Cultural Theory, $2^{\text {nd }}$ Ed. London; Amold, 2003.

Caddell, Bud. In "Going 'Mad' Creating Fan Fiction 140 Characters At A Time." Confessions of an Aca-Fan. Mod. Henry Jenkins. Available.

$<\mathrm{http}: /$ henryjenkins.org $/ 2009 / 01 / \mathrm{mad}$ men_twitter_and_the_future_1.html $>$ Accessed: February 2, 2009.

Caras galadhon (Galadriel). "The Public Mary Sue (I've Got a Theory)". The Heart of the Golden Wood (Livejournal). Available: <http://caras-

galadhon.livejournal.com/100236.html> Accessed: October 23, 2006.

Caras_galadhon (Galadriel). "Some Fierce Maenads: Revisiting Mary Sue, Picture Comms, \& Claims on Fannish Objects". The Heart of the Golden Wood (Livejournal). Available: <http://caras-galadhon.livejournal.com/290070.html> Accessed: October 23, 2006.

Connell, Yvonne. The Ultimate Mary Sue. Available: $<$ http://www.lcfanfic.com/stories/2004/altimary.txt > Accessed March 9, 2008.

Coppa, Francesca. "Writing Bodies in Space: Media Fan fiction as Theatrical Performance." Fan fiction and Fan Communities in the Age of the Internet. eds. Busse, Kristina and Hellekson, Karen. Jefferson, North Carolina: McFarland \& Company, 2006.

Crites, Susan. Portrait of the Artist as a Young Fan. Available: $<$ http://www.subreality.com/marysue/portrait.htm> Accessed: February 18, 2009.

Cross, Liz. "Peter Pan In Scarlet". Peter Pan In Scarlet: The Official Website. Available: $<$ www.peterpaninscarlet.com> Accessed: November 27, 2006

Culler, Jonathan. Literary Theory: A Very Short Introduction. New York: Oxford University Press, 2000.

Chapman, Heather \& Truman, Cheryl. "Amateur Hour." The Columbus Dispatch. Available: $<$ http://www.dispatch.com/features-stort.php?story=dispatch/2006/10/15/20061015-D100.html> Accessed: October 19, 2006.

Chander, Anupam \& Madhavi Sunder. "Everyone's a Superhero: A Cultural Theory of 'Mary Sue' Fan Fiction as Fair Use". California Law Review, Vol. 95:597. California; University of California Press, 2007.

Dempsey, Shawna \& Lorri Milan. "Object / Subject of Desire." Canadian Theatre Review. Fall, 1997. pp 17-18.

Dempsey, Shawna \& Lorri Milan. "Radical (Self-) Direction and the Body: Shawna Dempsy and Lorri Milan's Performance Art." Canadian Theatre Review - vol. 76. Fall, 1993. pp 37 41. 
Destina. "FAQs: Frequently Asked Questions". The Fan fiction Primer. Available: $<$ http://www.lyricalmagic.com/fanficFAQ.html> Accessed: April 20, 2005.

Dougherty, Micheal \& Dan Harris. Superman Returns. Dir. Bryan Singer. Brandon Routh, Kate Bosworth. Warner Brothers; Legendary Pictures, 2006.

Dorfman, Elena. Fandomania: characters \& cosplay. New York: Aperture Inc., 2007

Durham, Meenakshi Gigi \& Douglas M. Kellner. Media and Cultural Studies Key Works, revisd Ed. Malden, MA: Blackwell Publishing, 2006

Eagleton, Terry. "Post Structuralism". DART 4F90 Coursepack. Ed. David Fancy. St. Catharines, Ontario: Brock University, 2004.

Egon G. Guba \& Yvonna Lincon. "Major Paradigms and Perspectives, Competing Paradigms in Qualitative Research". The Landscape of Qualitative Research: theories and issues. Thousand Oaks: Sage Publications, 1998. pp 185-219.

Elrod, P.N. "FAQs on Writing". Vamp-Writer-Dot-Com. Available: $<$ http://vampwriter.com/FAQ-WRITING.htm> Accessed: February 2, 2009.

Encyclopedia Dramatica. "Mary Sue". Encyclopedia Dramatica. Available: $<$ http://encyclopediadramatica.com/index.php/Mary_Sue"> Accessed: March 9, 2008.

Fiske, J. Understanding Popular Culture. London; Routledge, 1989.

Fiske, J. "The Cultural Economy of Fandom." The Adoring Audience: Fan Culture and Popular Media. Ed. L. Lewis. New York, Routledge, 1992. pp 33-49.

Frey, JM. "A Deal With Dracula". Fanfiction.net. Available: $<$ http://www.fanfiction.net/s/63365/1/A_Deal_With_Dracula > Accessed: February 19, 2009.

Frey, JM. "Across Time". History's Mirror (Livejournal). Available: <http://losyark.livejournal.com/229635.html> Accessed: February 4, 2009.

Frey, JM. First Impressions. Unpublished.

Frey, JM. "Slipstream". History's Mirror (Livejournal). Available: $<$ http://losyark.livejournal.com/227741.html> Accessed: February 4, 2009.

Frey, JM. "Slipstream II: Quick To Say Yes". History's Mirror (Livejournal). Available: <http://losyark.livejournal.com/234604.html> Accessed: February 4, 2009.

Frey, JM. "Slipstream III". History's Mirror (Livejournal). Available: <URL> Accessed: DATE. 
Frey, JM. "Slipstream IV: Down Once More". History's Mirror (Livejournal). Publication Forthcoming.

Frey, JM. The Dark Side of The Glass. 2008. Publication Forthcoming.

Frey, JM. Whose Doctor? 2008. Publication Forthcoming.

Freud, Sigmund. Beyond the Pleasure Principal. Trans. James Strachey. London: Hogarth Press, 1950.

Freud, Sigmund. The Ego and the Id. Trans, Joan Riviere. London: Hogarth Press, 1927.

Glennon, Paul. Bookweird. Toronto; Canada, 2008.

Gobsmaked. "What Exactly Makes People Dislike MarySues so Much?" Fandom Discussions. Available: <http://www.journalfen.net/community/fandom_discuss/57939.html> Accessed: March 18, 2009.

Hall, Stuart. "Encoding/Decoding" (1980), Centre for Contemporary Studies (ed. By:) Culture, Media, Language: Working Papers in Cultural Studies, 1972-79. London: Hutchison, pp 128-138

Hayden, Teresa Neilsen. "Namarie Sue". Making Light. Available: <http://nielsenhayden.com/makinglight/archives/004188.html> Accessed March 9, 2009.

Hellekson, Kristina \& Karen Busse, eds. Fan Fiction and Fan Communities in the Age of the Internet. London, England: MacFarlane and Company Inc, 2007.

Herman, Andrew and Thomas Swiss, eds. The World Wide Web and Contemporary Cultural Theory. New York: Routledge, 2000

Hewlett, David. A Dog's Breakfast. Dir. D. Hewlett. David Hewlett, Kate Hewlett, Paul McGillian. Kibble Productions, 2007.

Hill, Matt. Fan Cultures. London, England: Routledge, 2002.

Hill, Logan. "The Vidder". New York Magazine. November 12, 2007. Available: $<$ http://nymag.com/movies/features/videos/40622/> Accessed February 20, 2009.

IMDB. "Snakes on a Plane". The Internet Movie Database. Available:

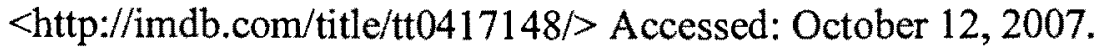

Jenkins, Henry. Fans, Bloggers, and Gamers: Exploring Participatory Culture. New York: New York University Press, 2006. 
Jenkins, Henry. "Out of the Closet and Into the Universe: Queers and Star Trek". The Audience Studies Reader.eds. Booker, Will \& Jermyn, Deborah. New York: Routledge, 2003.

Jenkins, Henry. Textual Poachers: Television Fans \& Participatory Culture. New York:

Routledge, 1992.

Jergensen, John. "Rewriting the Rules of Fiction." The Wall Street Journal Online. Available $<$ http://online.wsj.com/public/article/SB115836001321164886-

Y0O1DfzuHNEO_UgGUIHFskuFTzM_20061015.html?mod=tff_main_tff_top> Accessed: September 16, 2006.

Jowet, Garth \& Ian C. Jarvie \& Kathryn A. Fuller. Children and the Movies: Media Influence and the Payne Controversies. Cambridge: Cambridge University Press, 1996. 92-121.

Katekat1010. "Comments." Fanthropology (Livejournal Community). Available: $<$ http://community.livejournal.com/fanthropology/274912.html> Accessed: September 27,2006

Kaplan, Deborah. "Construction of Fan fiction Character Through Narrative". Fan fiction and Fan Communities in the Age of the Internet. eds. Busse, Kristina and Hellekson, Karen. Jefferson, North Carolina: McFarland \& Company, 2006.

Katz, Elihu. "The Two-Step Flow of Communication." Public Opinion Quarterly 21,1 (1957). 61-78.

Katz, Elihu \& Jay Blumer, \& Michael Gurevitch. "Utilization of Mass Communication by the Individual." The Uses of Mass Communication: Current Perspectives on Gratifications Research. Beverly Hills: Sage, 1974. 19-32.

Katz, Elihu \& John Durham Peters \& Tamar Miebes \& Avril Orloff. Canonic Texts in Media Research: Are There Any? Should There Be? How About These?. Cambridge UK; Polity Press, 2003.

Keen, Andrew. The Cult of the Amateur: how today's Internet is killing our culture. New York: Doubleday, 2007.

Lacan, J. Ecrits: A Selection. New York; Norton, 1977.

Lasswell, Harold D. The Structure and Function of Communication in Society. Ed. L. Bryson. New York: Harper \& Co. 1953.

Lewis, Lisa A. ed. The Adoring Audience: Fan Culture and Popular Media. London, England: Routledge, 1992.

MacDonald, Anne-Marie. Goodnight Desdemona (Goodmorning Juliet). 1988. United States of America: Vintage Canada, 1998. 
Make Mine Mary Sue Mailing List. "Messages" Yahoo! Groups. Moderator: Scribe (Fannie Feazel) Available: <http://groups.yahoo.com/group/makeminemarysue/> Accessed: February 25, 2005.

Masaki, Lyle. "Six Gay Geeks Who've Improved the Pop Culture Landscape". AfterElton.com. Available: $<$ http://www.afterelton.com/blog/lylemasaki/six-gay-geeks $>$ Accessed February 20, 2009.

McCaffrey, Anne. "Fan Fiction Rules". The Worlds of Anne McCaffery. Available: $<$ http://annemccaffrey.net/index.php?page_id=20> Accessed: February 2, 2009.

McCormick, Carlos. "Becoming". Fandomania: characters \& cosplay. New York: Aperture Inc., 2007

Merton, Robert K. "The Focussed Interview and Focus Groups: Continuties and Discontinuities". The Public Opinion Quarterly, Vol 51, No. 4 (Winder, 1987). Oxford University Press. pp.550-566.

Meyer, Stephanie. Twilight. New York; Little, Brown and Company, 2005.

Miller, Mark Crispin. Boxed In: The Culture of TV. Evanston, IL; Northwest University Press, 1988.

Missy, Merlin. "The (Original) Mary Sue Litmus Test". Firefox News. Available: < http:/firefox.org/news/articles/651/1/The-Original-Mary-Sue-Litmus-Test/Page1.html> Accessed: March 9, 2008.

Morely, D. Television, Audiences, and Cultural Studies. London; Routledge, 1992.

Octal. "Comments." Fanthropology (Livejournal Community). Available: $<$ http://community.livejournal.com/fanthropology/274912.html> Accessed: September 27,2006

Ong, Walter J. Orality and Literacy: The Technologizing of the Word. London: Methuen, 1982.

Opera. "Comments." Fanthropology (Livejournal Community). Available: $<$ http://community.livejournal.com/fanthropology/274912.html > Accessed: September 27,2006

Parry, Micheal. Ed. The Rivals of Dracula - A Century of Vampire Fiction. Surrey; Severn House Publishing, 1978.

Paperclipchains. "Mary Sue Witch Hunt". Fanficrants (Livejournal Community). Available: $<$ http://community.livejournal.com/fanficrants/7307648.html> Accessed: September 19, 2008. 
Penny Dreadful. Questionnaire. March $17^{\text {th }}, 2005$. Available:

$<$ http://groups.yahoo.com/group/makeminemarysue/message/4532> Accessed: April 20, 2005.

Pennley, Constance. "Brownian Motion: Women, Tactics, and Technology." Technoculture. Eds.

C. Pennley \& A. Ross. Minneapolis, MN; U of Minnesota Press, 1991. pp135-161.

Pflieger, Pat. Too Good To Be True: 150 Years of Mary Sue. Presented at the American Culture Association Conference, March 311999 and revised in 2001. Available $<$ http://www.merrycoz.org/papers/MARYSUE.HTM> Accessed: March 9, 2008.

Queenitsy. "Comments." Fanthropology (Livejournal Community). Available:

$<\mathrm{http}$ :/community.livejournal.com/fanthropology/274912.html> Accessed: September $27^{\text {th }}, 2006$

Ray, Joan Klingel. Jane Austen for Dummies. Hoboken, New Jersey; Wiley Publishing Inc., 2006.

Rice, Anne. Interview With The Vampire. Dir. Neil Jordan. Brad Pitt, Tom Cruise. Warner Bros., 1994.

Roddenberry, Gene. Star Trek: The Next Generation (series). Patrick Stewart, Jonathan Frakes. Paramount Pictures, 1987.

Rowling, J.K. Harry Potter and the Philosopher's Stone. Vancouver; Raincoast Books, 1997.

Rowling, J.K. Harry Potter and the Chamber of Secrets. Vancouver; Raincoast Books, 1998.

Rowling, J.K. Harry Potter and the Prisoner of Azkaban. Vancouver; Raincoast Books, 1999.

Rowling, J.K. Harry Potter and the Goblet of Fire. Vancouver; Raincoast Books, 2000.

Rowling, J.K. Harry Potter and the Order of the Phoenix. Vancouver; Raincoast Books, 2003.

Rowling, J.K. Harry Potter and the Half-Blood Prince. Vancouver; Raincoast Books, 2005.

Rowling, J.K. Harry Potter and the Deathly Hallows. Vancouver; Raincoast Books, 2007.

Rubess, Banuta. "Introduction" Goodnight Desdemona (Goodmorning Juliet). 1988. United States of America: Vintage Canada, 1998.

Rudnick, Brent. "An Interview with Robert Tapert". WHOOSH! Magazine, Issue 52, Jan 2001. Available: < http://www.whoosh.org/issue52/itapert1.html> Accessed February 20, 2008.

Ryan, Brittney. Holly Claus The Christmas Princess. New York; Harper Collins, 2007. 
Sanders, Joe, ed. The Sandman Papers: An Exploration of the Sandman Mythology. Seattle: Fanatagraphics Books, 2006.

Scribe. "Stranger in a Strange Land". Scribe's Scribbles. Available $<$ http://www.angelfire.com/grrl/scribescribbles/strangercontents.htm> Accessed: April $20,2005$.

Scribe. Questionnaire. March $17^{\text {th }}, 2005$ Available:

$<$ http://groups.yahoo.com/group/makeminemarysue/message/4529> Accessed: April 20, 2005

Schezar, Xellos Azalyn. "Comments." Fanthropology (Livejournal Community). Available: $<$ http://community.livejournal.com/fanthropology/274912.html> Accessed: September 27,2006

sDragon. "Comments." Fanthropology (Livejournal Community). Available: $<$ http://community.livejournal.com/fanthropology/274912.html> Accessed: September 27,2006

Seshat. "So what is BLAZES is a Mary Sue?" Seshat's Online Library. Available: $<$ http://www.geocities.com/sheshat/fanfic1/marysue.htm> Accessed: February 21, 2005.

Shelly. "In Defence of Fanfic, part 1". Shelly Writes Stuff. Available $<$ http://www.shellywritestuff.blogspot.com/2006/10/in-defense-of-fanfic-part-1.html > Accessed: December 29, 2006.

Smith, Paula. A Trekkie's Tale. 1973. Available: $<$ http://www.fortunecity.com/rivendell/dark/1000/marysue.htm > Accessed February 20, 2009.

Soldurios. "Here's A Fandom That Rarely Gets Any Credit". Mary Sue (Livejournal Community). Available: <http://community.livejournal.com/marysues/1748483.html> Accessed: February 19, 2009.

Springwoof. "SGA 519: Vegas -- Review and Episode Tag" Going to the Dogs! (Livejournal). Available: $<$ http://springwoof.livejournal.com/37542.html\#cutid l > Accessed: January 18, 2009.

Stareyes, Becca. "Comments." Fanthropology (Livejournal Community). Available: $<\mathrm{http} / /$ community.livejournal.com/fanthropology/274912.html $>$ Accessed: September 27,2006

Takahashi, Rumiko. Inu Yasha vols 1-7. 1997. Trans: Mari Morimoto. San Francisco, CA: Viz Communications, 2003 
Television Tropes \& Idioms. "Mary Sue". Television Tropes \& Idioms. Available:

$<$ http://tvtropes.org/pmwiki/pmwiki.php/Main/MarySue> Accessed March 9, 2008.

Trin-san. "Mary Sue's Private Hell" SaN: Stuff and Nonsense. Available:

$<$ http://trinsan.com/personal/marysue.html> Accessed: April 20, 2005.

Urban Dictionary. "Mary Sue". Urban Dictionary. Available:

$<\mathrm{http}: / /$ www.urbandictionary.com/define.php?term=Mary_Sue $>$ Accessed March 9, 2008.

Various. "What's a 'Mary Sue' fic?" Lois \& Clark Fanfiction Message Boards. Available: $<$ http://www.lcficmbs.com/cgi-

bin/boards/ultimatebb.cgi?ubb=get_topic; $f=5 ; t=001255 ; p>$ Accessed" March 9, 2008.

Walter, Natasha. "Works In Progress". The Guardian. Available:

$<$ http://books.guardian.co.uk/news/articles/0,6109,1336775,00.html> Accessed: October $27,2004$.

Weadon, Joss. Buffy: The Vampire Slayer (series). Sarah Michelle Geller, Nicholas Brenden, Alyson Hannigan, Antony Stewart Head. Twentieth Century Fox; Mutant Enemy, 1999.

Weed, Vulgar. "Comments." Fanthropology (Livejoumal Community). Available: $<$ http://community.livejournal.com/fanthropology/274912.html> Accessed: September 27,2006

Wedding, Ken. "Fan Fiction Comes Home To Roost". Reading On The Web. Available: $<$ http:/home.globaleyes.net/ken/fanfic.html> Accessed: January 19, 2009.

Westcott, Grace. "Friction over Fan Fiction". Literary Review of Canada July/August 2008. Available: $<$ http://1rc.reviewcanada.ca/index.php?page=Friction-over-Fan-Fiction $>$. Accessed: August 18, 2008.

Whitfield, Kit. "Snappy Sue: Mary Sue Gets Mean" Kit Whitfield's Blog. Available: $<$ http://www.kitwhitfield.com/2006/09/mary-sue-gets-mean.html> Accessed November $3,2008$.

Wikipedia. "The Book of A Thousand and One Nights". Wikipedia, the Free Encyclopedia. Available: $<$ http://en.wikipedia.org/wiki/A_thousand_and_one_nights $>$ Accessed: February 4, 2009.

Wikipedia. "ReBoot: Revival". Wikipedia, the Free Encyclopaedia. Available: $<$ http://en.wikipedia.org/wiki/ReBoot\#Revival> Accessed: October 12, 2007.

Wikipedia. "Mary Sue". Wikipedia, the Free Encyclopaedia. Available: $<$ http://en.wikipedia.org/wiki/Mary_Sue> Accessed: November 27, 2006. 
Wikipedia. "Snakes on a Plane". Wikipedia, the Free Encyclopaedia. Available: <http://en.wikipedia.org/wiki/Snakes_on_a_Plane> Accessed: October 12, 2007.

Willis, Ika. "Keeping Promises to Queer Children: Making Space (for Mary Sue) at Hogwarts". Fan fiction and Fan Communities in the Age of the Internet. eds. Busse, Kristina and Hellekson, Karen. Jefferson, North Carolina: McFarland \& Company, 2006. 


\section{7: Appendices}

\section{Appendix A}

The Mary Sue Checklist

1) The Mary Sue character exists for the Suethor's wish fulfillment. The Sue looks like the author wishes she looked, acts like the way she wishes she could, says what the author wishes she could say, and creates an environment within the canon in which things that the Suethor wishes would have happened in the canon, does. The Mary Sue is sometimes the gender or sexual orientation which the author wishes (s)he was, or feels is fashionable.

2) There is a sense or tone of whimsy and /or self depreciation in the text.

3) The Mary Sue's appearance, personality, and even scent are often divulged in detail within the exposition of the story; Mary Sues often have physical traits that are a biological impossibility, such as eyes that are violet or shift colour, pointed ears, the limbs or ears of an animal, or hair colour that is not within the normal spectrum of shades.

4) The Mary Sue often was given a name with a hidden or relevant meaning, or that simply "sounds cool", with no regard for ethnic tradition or likelihood.

5) The Mary Sue is a character either previously unrecognized by the fandom's central protagonists and antagonists before the commencement of the story, or drops in from 'reality' into the fandom.

6) The Mary Sues' abilities / magical powers / skills / talents not only outdo the canonical characters (even if, or especially if, the canonical characters are the most powerful / talented / skilled at this particular ability) but often eclipse them. The Mary Sue directly copies the skill and is better at it. The Mary Sue is adept at any sort of fighting or magic wielded by the canonical characters, often surpassing the canonical characters in ability with little to no practice or previous experience.

7) The Mary Sue is immediately accepted into the canonical character's inner circle of friends and confidants, no matter how unsociable or closely guarded said circle of friends is in the canon.

7.5) If the Mary Sue is related to a major character that is not the romantic interest, then said relation is often used as a haphazard excuse to introduce the Sue to the canonical characters/ future romantic interest.

8) The Mary Sue acquires friends or romantic interests / partners among the canon characters, blocking or disrupting the canonical friendships, partnerships and romantic relationships within the canon.

9) The surrounding canon characters are made to act out of character by the Mary Sue's presence. 
10) The Mary Sue robs the strong female characters of their rational agency, turning them into catty bitches.

11) The Mary Sue is sexually attractive to all canon characters, regardless of their sexual orientation or availability.

12) The Mary Sue is often ardently desired by the villain despite there being no advantage or reason for the villain to want said Mary Sue.

13) The Mary Sue is often the reason for the main conflict in the plot, whether inadvertently or as a central figure. Any special destiny, quest, or plot arc possessed by the central character of the canon is often usurped by the Mary Sue.

14) The Mary Sue is witty and snarkish, and no matter how lame said witticisms are, the canonical characters akin the Sue's sense of humour to that which is quite practiced and enjoyable.

15) The Mary Sue is often able to shift shapes, or has a friend or magical pet that can shift shapes.

16) As the Mary Sue is the author's avatar, the Mary Sue enters the world of canon with the same understanding of character, plot, and universe as the Suethor; the Mary Sue therefore has incredible insight into the lives and workings, the desires and dreams and fears, of the characters with which she is interacting and often serves as a conduit for advice that the Suethor wishes to impart on the characters. The Mary Sue 'understands everything'. The advice considered, the canon characters often behaviour is often altered to accommodate the Suethor's desired changes.

17) The Mary Sue has a tragic past that precedes the story, or something traumatic and mentally scarring occurs mid-story that they 'get over' cheerily, suffering neither post-traumatic stress, Stockholm syndrome, or other disorders or phobias brought on by their past experiences. Any scars or marks that result from the trauma are 'cool', or are interesting places or shapes, and are often aesthetically tasteful. Sues are rarely ashamed by said scars or marks, or associate them only lightly with the trauma.

17.5) Mary Sues mope, brood, or pout, but only for as long as it takes for the canonical characters to distract her. Long-term guilt or pain is rare in a Sue.

18) The Mary Sue is the centre of the plot, the key player in any battle, and is the only one who can 'save the day' by virtue of her wonderfulness.

18.5) And in doing so, the Mary Sue 'ties up loose ends', filling in plot holes from canon, getting characters who the Suethor believes are romantically destined for one another together, or forces an ending to the major plot arc from canon in a satisfying (to the Suethor) and happy way. 
19) Somehow the Mary Sue character 'saves the day' in unlikely ways that leave the canon characters stunned and amazed, often at the cost of her own life / health / magic powers / happiness / love / ability to stay with the characters or in the fandom.

20) Yet somehow there is a happily ever after wherein the Sue and the Love Interest are reunited, often affirming their relationship through marriage and procreation, therefore supporting the patriarchal hegemony that a powerful female character like a Mary Sue could otherwise challenge.

20.5) Unless the Mary Sue dies, in which case her death is tragic, meaningful, beautiful, and offers the characters that the Suethor is most directly interested from the canon a lesson / morale / memento to take with them. 


\section{Appendix B}

"A Trekkie's Tale" by Paula Smith

"Gee, golly, gosh, gloriosky," thought Mary Sue as she stepped on the bridge of the Enterprise. "Here I am, the youngest lieutenant in the fleet - only fifteen and a half years old."

Captain Kirk came up to her.

"Oh, Lieutenant, I love you madly. Will you come to bed with me?"

"Captain! I am not that kind of girl!"

"You're right, and I respect you for it. Here, take over the ship for a minute while I go get some coffee for us."

Mr. Spock came onto the bridge. "What are you doing in the command seat, Lieutenant?"

"The Captain told me to."

"Flawlessly logical. I admire your mind."

Captain Kirk, Mr. Spock, Dr. McCoy and Mr. Scott beamed down with Lt. Mary Sue to Rigel XXXVII. They were attacked by green androids and thrown into prison. In a moment of weakness Lt. Mary Sue revealed to Mr. Spock that she too was half Vulcan. Recovering quickly, she sprung the lock with her hairpin and they all got away back to the ship.

But back on board, Dr. McCoy and Lt. Mary Sue found out that the men who had beamed down were seriously stricken by the jumping cold robbies, Mary Sue less so. While the four officers languished in Sick Bay, Lt. Mary Sue ran the ship, and ran it so well she received the Nobel Peace Prize, the Vulcan Order of Gallantry and the Tralfamadorian Order of Good Guyhood.

However the disease finally got to her and she fell fatally ill. In the Sick Bay as she breathed her last, she was surrounded by Captain Kirk, Mr. Spock, Dr. McCoy, and Mr. Scott, all weeping unashamedly at the loss of her beautiful youth and youthful beauty, intelligence, capability and all around niceness. Even to this day her birthday is a national holiday of the Enterprise. 


\section{Appendix C}

"The Mary Sue Alphabet" by Irony-Chan

A's for Amanda

Our hero's twin sister

Got lost as a baby

And gosh, how he missed her

He always suspected

He had a half lacking

He set off to find her

By magical tracking

So now they're together

And smiling a lot

Too bad that the story's

Got no trace of plot

$B$ is for Bridget

Who's named for the author

She could have been subtle

But just didn't bother

Yet somehow I doubt

That the writer's a d-cup

Or sings like an angel

With nary a hiccup

Or doesn't need glasses

Or looks like a hottie

Or ever will earn

Her black belt in karate

C is for Clementine

Good on a broom

The fastest of flyers

Just look at her zoom!

The new school all-star

She aims like a dream

They haven't lost once yet

Since Clem made the team!

But the other side's jealous

And might not play fair

Will they cheat 'til she loses?

... does anyone care?
D's for Diana

Her story's a wreck!

With no sign of grammar

Or any spell-check

The readers sent email

To justly complain

But all of their efforts

Turned out to be vain

The author replied with:

"Who cares how it's written?

"It's only a fanfic!

"You're mean, and kick kittens!"

\section{E is for Elwen}

An elf in her glory!

Who seems unware

That she's in the wrong story

Like all of her people

She's comely and wise

The hardest heart melts

At her come-hither eyes

But how did she get here?

There aren't any clues

And the author won't tell

'Til she gets more reviews

\section{F for Furiko}

Who came from the East

Her father's a magical

Shrinekeeper priest

She brought her katana

And swings it with ease

And she'll say 'onegai'

Instead of just 'please'

Each chapter begins with

A guide to the phrases

And thanks the reviewers

For singing her praises 
$G$ is for Georgia

Likes watching TV

Replaying the movie Upon DVD

'Til one day by magic

The screen opened wide

Before Georgia knew it

It sucked her inside!

Now she'll save the hero

By hook or by crook

She knows all the future

'Cause she's read the book

H starts the name

Of a girl called Heather

An element witch

Who can magic the weather

A sunshiny day

Means she's merry and glad

But thunder and snowstorms

Show up when she's mad

And should she be sleeping

And having strange dreams...

I suppose that might be why

It's raining sardines<smiles>[131I-]</smiles>

\section{I for Isolda}

Who's nasty and mean

The worst evil sorceress

You've ever seen

The Dark Lord is naught but

Her grovelling bitch

No-one out-evils

This black little witch!

It runs in her family

Right down in her roots

But without a good beta

Her plots become ploots
$\mathbf{J}$ is for Janviere

Frozen and cold

A silent immortal

A thousand years old

Ever since she discovered

The Sorcerer's Stone

There have been none to love her

She wanders alone

Her tale is tragic

With no-one to tell

Where she hid the body

Of Nicolas Flamel

$K$ is for Kimberly

Nothing but trouble

There's chaos a boiling

In her cauldron's bubble

The girl's a genius

Her pranks are the best!

But all of the teachers

They think she's a pest

Four times in a row

She's been kicked out of school

To let her in here

The headmaster's a fool

\section{$L$ for Lorraina}

The heir to three thrones

She dresses in ballgowns

And wears precious stones

But deep in her heart

She's so royally lonely

She longs for a prince

To love her and her only

She wants to be treated

Like all other girls

Perhaps if she'd dump

The tiara and pearls 
$\mathbf{M}$ is for Madysonne

Fresh from the states!

Like totally awesome

This chica, she rates!

She brought with her all of

Her favourite CD's

And might let you listen

If you just say please

She's spreading the music

As far as she can

And somehow I'm guessing

The author's a fan

$\mathrm{N}$ is for Naoko

In space she has dwelt

Her real name's Sailor

Asteroid Belt

A student by day

Vigilante by night

A short-skirted soldier

In crimson and white!

But what will she do when

Her secret's discovered?

Why, sex up the hero

And make him her lover!

\section{O for Ophelia}

The evil guy's daughter

Her life is so awful

Her tears flow like water

Her husband's been chosen

By father and mother

But her heart already

Belongs to another

Oh woe! And oh angst!

Yeah, it's piled on thick

And most of the readers

Are gonna be sick
$\mathbf{P}$ is for Paris

Just swimming in prose!

Her lips weren't pink only

They bloomed like a rose!

Like wheat in the sunshine

The gold of her hair

Her eyes, how they sparkled

As clear as the air!

Her skin was as white

As the robe of a saint

And it's that lack of iron

Keeps making her faint

\section{$\mathbf{Q}$ is for Qing}

She's the Chinese exchange

Her manners are foreign

Her habits are strange

She's odd and exotic

She dresses in silk

Eats rice for her breakfast

And never drinks milk

A stereotype walking

On feet bound up small

The author did clearly

No research at all

\section{$\mathbf{R}$ for Rhiannon}

Got brought up by a pack

Of wolves in the wild

One would think that she'd lack

For poise and good manners

But she's got 'em in spades

Perhaps that is how

Every she-wolf behaves

There's only one chapter

But quite clear to see

That poor helpless werewolf

Will get paired with she 
$\mathbf{S}$ for Serena

Who changes her form

When she wants she can become

A white unicorn

Both tigers and eagles

Are shapes she can take

A big golden dragon

A small silver snake

A galloping mustang

A peacock of blue

The woman's a one-person

Portable zoo

$T$ is for Tracey

The coolest of cool

Most popular chick

At her old wizard school

But here things are different

She's all but unseen

The others don't like her

And everyone's mean

It's all 'bout the in-crowd

And the reader infers

That in the end Trace

Will say vengeance is hers

$\mathbf{U}$ is for Umbra

Which isn't a name

But in the end really

There's worse stuff to blame:

Her surname is either

'MacKay' or 'MacBride'

The story says both

It can't seem to decide

That's about as much sense

As this fic ever makes

Especially since it lacks

Paragraph breaks
$V$ for 'Virginia'

Who used to be canon

Til one day along came

A writer named Shannon

Now Gin's into cutting

And punk-rocker bands

And writes poems bout the pain

That no-one understands

But her parents don't worry

To any degree

Because just like their daughter

They're both OOC

\section{W stands for \\ One Wendover Sable}

She started off Sue-some

Right out of the cradle

The poor foundling baby

Was given a home

By snobby, rich wizards

Brought her up like their own

And should any point out

That this ain't realistic

Just watch as the author

Goes fully ballistic

\section{$X$ is for Xanthe \\ Who isn't a Sue}

Like any good character

She's got flaws, too

Her hair isn't curly!

Her nails she bites!

She's scared of the dark

When she turns out the lights!

So many things

That could get in the way... But they'll never stop Xanthe

From saving the day
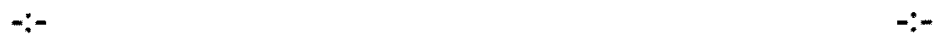
$\mathbf{Y}$ is for Yarrow

Who's better than teacher

At seeing tomorrow

In every small feature

In fact, she's so good

That she tutors the classes

And with her instructing

All students get passes

Yet when she predicts ruin

Woe is her - no one hears!

So much for the love

And respect of her peers

\section{$\mathrm{Z}$ is for Zuli \\ Her name is Zuliekha}

But she keeps it short 'cause

That's tough on the speaker

She sings and she dances!

She's mastered disguise!

She chit-chats with snakes!

She makes Julienne fries!

The reader is torn

Between laughter and gaping

Spoofs shouldn't be worse

Than the things that they're aping 


\section{Appendix D}

$\underline{\text { Survey Questionnaire }}$

1) Why do you write fan fiction?

2) Why do you write Mary Sue fan fiction?

3) Why do you read fan fiction?

4) Why do you read Mary Sue fan fiction?

5) Have you ever felt that the way a TV show/movie/book treats people like you is ridiculous? Wrong? Biased?

6) Have you ever felt that a TV show/movie/book has EXCLUDED people like you?

7) How did these representations (or lack thereof) make you feel about the show/book/movie?

8) Have you written a fan fiction to fix the way the way the show treats people like you?

9) Have you written a Mary Sue fan fiction to fix the way the show treats people like you?

10) Have you written a Mary Sue for the sole purpose of wish fulfilment?

11) Would you consider yourself a Mary Sue Author? Or just a Fan fiction author? Would you consider yourself an author at all?

12) What is your favourite fandom to read/write in? Why?

13) Summarize your perfect Mary Sue: hair and eye colour, body shape, special powers, fandom, etc.

14) What is your favourite Mary Sue fiction? Author?

15) Anything else you'd like to say in defence of/about/bashing Mary Sues?

16) Why did you choose your online handle and why do you think it represents you? Are you the same person as your Internet personality? Why or why not?

17) Have you ever written a story with a character that you later realized was a Mary Sue? 


\section{Appendix E}

Excerpt from "Madmen and Blackflies" by JM Frey

Chapter One: Blackflies

Quebec City, the Dominion of Canada

The Year of Our Lord, $189 X$

Master Fitzwilliam Greene, nephew of the dearly missed Lord MacLeish and lately of St. Catherine's Glen, Scotland, had an absolutely abysmal inability to travel without getting miserably ill. Which made standing on the wharf in Quebec City, orders already in hand demanding his journey now continue on to Cooper's Wharf in the town of York, upriver, singularly horrifying.

Greene supposed that this was the moment when a man was meant to screw up his courage, or stiffen his upper lip, lift his chin, and all manner of other clichés that existed to help a man bare through an odious ordeal. Instead, he swallowed heavily, took a deep breath of the saltand-fish-innards wharf air, and re-read the letter of command in the desperate hope that the words had changed.

Master Greene worked for Torchwood, a secret agency operating under the direct purview of the Royal Eye, and which existed to protect the Great British Empire from those rogue elements from beyond the shores of God's understood reality. It was entirely possible, therefore, that the words could change.

Yet, no.

They still read:

Agent Greene:

Congratulations on your new appointment. We know that you will uphold your proud family legacy. Upon arrival in the province of Quebec, take passage up river to the town of York in the province of Ontario, on the northern coast of the Lake of the same name. Property at the edge of the city on Younge Street has been purchased by Torchwood and will serve as the Hub for Torchwood 4, Canadian Colony.

First Mission: Discover what the Indian heathens worship at Niagara Falls and determine if it is a threat to the Empire. Capture, Study or Terminate, at your discretion. Agent recruitment is your prerogative.

Sir Stephan Davies, Director, Torchwood London.

October 8th, 189X

The seal, red wax imprinted with the stylized " $T$ " shaped hive that represented the compartmentalized agency under the command of their Queen, was broken clean in half. Greene wished - again, with the hope that only a Torchwood Agent could have, knowing that the mere wishing itself might actually make it come to pass through some outside power - that he had never broken the seal at all.

In fact, he stole a small, indulgent moment to wish quite fervorently that he had never agreed to travel to Canada, that he had never sworn an oath to the Torchwood Agency, that his Uncle had never been murdered by the wolf, that Queen Victoria (long may she reign) had never 
visited the Torchwood Estate, that the Lycanthrope had not crashed its vessel in St. Catharine's glen, that the Enemy had not ever visited the Empire from the strange and awful place from which he hailed.

Greene cracked open one eyelid. No. Still on the dock.

Drat.

Greene, like his great-uncle, the previous Lord MacLeish before his father's brother, was a bit of a mechanical dabbler. He was perhaps altogether too interested in springs and gears and lenses, in steam power and this new electricity, in rails and cables and blades and rivets for the young nephew of a country Lord.

Of course, his great-uncle had started it.

It had been him who had first introduced Greene, as a young boy, to the wonders of science. First to let a toddling youngster rife with genuine curiosity sit on his knee as he carefully deconstructed a stalled pocket watch, then put it back together spring by spring, gear by gear, and snapped the back cover on. He let Greene's fat child fingers wind the watch back into ticking life. It had constituted the start of a lifelong addiction.

Greene would have been perfectly content to remain in the workshop out the back of his father's rambling and slightly neglected estate for the rest of his life, the forgotten youngest son. He wanted nothing more than to tinker, to read the latest announcements in the science journals, to correspond (when he got the chance to write, and the courage) with Thomas Edison and George Armstrong, Donat Banki, Alexander Bell; men, like him - tinkerers.

But then his uncle had died, heirless, and rather than continuing the family succession, Uncle Robert's wife sold the lands, the house, the title and the whole of the estate to the Queen herself (long may she reign). Ninnian Greene, his older brother, hadn't much minded. His brain was set too much on the fancy of America, the women of France, the wine of Spain, the freedom to go where he liked with whom he liked; not stepping up to inherit the title of Lord MacLeish suited Ninnian just fine. As long as he got his money - and he had - Ninnian was just as pleased as punch to scarper off to the Continent.

Then the Queen (long may she... oh, hang it) began filling the house with secrets.

Greene hadn't meant to pry.

It was just that he had heard such fantastical clankings in the dead of the night, the sounds of workshops and the smells of smouldering irons, drifting down from the house. His imagination supplied him with thoughts of the Queen's wonderful new creations, inventions to make the locomotive go faster, to make boats unsinkable, to feed all of her hungry children, sparkling under the starlight.

Greene wanted to believe the Queen was noble.

He wanted to see her great and glorious works. Perhaps, maybe, even, just a little, he wanted to help. Instead, when he had made his quiet and rather timid way around the curving, overgrown garden path at the back of the estate that he knew was hidden from view through any of the back windows due to many instances of trial and error and mischief as a little boy, and peered into the carriage sheds and over the yard walls, he instead saw strange half-dismantled vessels, light-throwing shotguns, corpses on the surgery tables that were not, could not be of God's world.

And they weren't. 
Caught embarrassingly easily, but not before he had seen and comprehended far too much - if Fitzwilliam Greene was anything, it was not stupid - Greene had been forcibly recruited into the newly created Torchwood Agency. At first Greene was delighted; the laboratories were more advanced than anything his own father's money could provide, that his own meagre portion could furnish. They were greater, perhaps, than even those of the great American inventors. He had access to every tool, every latest discovery, every theoretical paper, every alloy he could possibly wish for. He invented seven new ways to improve the British Rail system within his first week.

And it seemed that the Torchwood Institute did not discern between rank or colour. Greene, who had always secretly thought that the inclusion of all levels of society ought to be the particular provenance of the Queen (long may she reign), was pleased. Employed along side of him were Chinese herbalists and Eastern mystiks, and negro mathematicians from every title and level of wealth; the only prejudicial treatment any one received was due to one's skills and the performance thereof.

After that, he was considerably less contented.

"Stop working on trains and hatch doors and elevators," his team leader said. "Apply your skills to the vessel that washed up on the Isle of White. Reverse engineer some of those weapons the crew had in their holsters."

"Weapons will hardly do much towards improving our Empire," Green protested, goggles pushed up on his forehead, hair headed in approximately thirteen different directions at once, and a long black smear of mechanical oil starting to dry, and itch, on his right cheek.

"They will do," his team leader said with a frown that suggested that Greene focus his efforts or else. It was never quite clear what the or else entailed, exactly, only that the team mates that suffered through an or else returned to work diligent and white-faced.

Greene switched teams instead.

He found himself in the Mistletoe Library, pouring over blueprints for what his new coworkers dubbed "The Hubs"; great underground train stations that would both connect the three great regions of the main island of the United Kingdom - one in London, England, one in Cardiff, Wales, and one in Glasgow, Scotland - with the Torchwood Estate, and act as the main centre of investigative activity for each area. The Hubs were filled with comfortable barracks for the agents that would man it, great bathing suites and kitchens, armouries and practice ranges, laboratories and experiment hangars and places to store their vehicles, relaxation lounges, libraries, archival warehouses, anything and everything, and all underground, hidden from the populous, safe from the people that it would serve to keep safe in return. There was even talk of utilizing Edison's new light bulbs to act as surrogate suns for underground gardens.

Greene's work on hydraulics and hatches was soon incorporated and the Queen had been so impressed with this new and fantastical bunker that she had deemed that Greene, with his particular mechanical expertise, was the only person fit to oversee their construction.

Greene spent the next three years flitting from building site to building site, digging in the mud and the permafrost, dictating, double-checking, and oft times just wading right in with blowtorch and gloves to fix the error when the blue prints were simply too complicated for the workers to follow. It was a good three years. At least the parts where he was able to travel by means of his own two feet - his perpetual travel sickness made every carriage ride, every handsom cab, every train an utter misery and he spent more than a little time in the sweet throes of oblivion that only carefully regulated opiates and sleeping draughts could provide. He dosed himself quite precisely, having no desire to lose his mind to the Chinese Poison. 
Yes, it was a happy three years. And Greene was content, when he could walk, as long as he dodged the mandatory weapon's training, as long as he skipped as many of the psychic training sessions as he could without reprimand, and avoided any sort of fantasmagoric or otherworldly aspect of the whole wretched business; as long as he could keep building Torchwood's underground railways, and not their weapons.

But then the time came, the time that he dreaded: the hubs were nearing the level of completion where Greene and his blueprints would no longer be needed. Greene was about to become superfluous, which meant an imminent transfer back to one of the research and development sectors. When the Queen called him to a private council in London, he went with shaking hands and knees. A hundred thousand terrible thoughts swarmed through his mind and set his stomach roiling; she was going to make him build her a horrid new war machine, she wanted a flying device, she wanted a better gun. Being in her mere presence was awe-inspiring and nerve-shaking enough, but the horrid concerns made him all the more anxious about the conversation that was to come.

It turned out to be mercifully brief. That was the only merciful thing about it.

The Queen gave him a medal for his services to the Crown, and a large purse to match, in a secret ceremony witnessed by no one beyond herself and the head of the Agency, Master Davies, in a secreted room so far back in the palace Greene wondered if they'd walked into another county. And then she told him that when he returned home, a knighthood would be waiting for him.

"When I return... I beg your pardon, ma'am?" he asked, unable to raise his eyes or body from where he knelt to receive the medal, fear and boldness making his knuckles white on his knees. The hair on the nape of his neck pricked upwards, even as a flash of heat swept down his spine.

"The Torchwood Institute exists to protect the British Empire, Mister Greene," the Queen had replied primly. "You did not think that I would not extend its protection beyond these singular shores?" It was a question for the sake of politesse. Greene took it for the reprimand it was meant to be.

"Of course not, ma'am," he whispered. "If I may ask...?"

"You may."

"To where...?" He gorge rose at the mere thought of having to step foot on any sort of sailing ship, cutting off his inquiry.

"The Dominion of Canada," the Queen replied, seemingly unperturbed by his incomplete phrases. "It is a land of trees and redskin heathens, but our great allies in the American War, and the location of some of the Empire's greatest natural resources. We must maintain its security."

She seemed to think this was explanation enough and stopped there.

Davies handed him his orders, bid him take a fortnight to collect whatever kit he felt would be necessary and make provisions for his travel. The rest - lodgings, acquiring land for a new Hub, and the labour to build it - had already been taken care of in advance of this private conference.

Greene was sorely tempted to make a note of the fact that he had not, in actuality, agreed to the venture. One look at the expression on Master Davies' face convinced him to hold his tongue. 
The journey to Cooper's Wharf had been completed in under a week, and with the weather still fine and sunny this time of year, Greene exited the ship with far more buoyed spirits than he had embarked upon it. This ship had not been the heady sailing rig with the pregnant white sails that had dragged him across the Atlantic, but a lower-prowed cargo vessel that moved slowly and steadily down the relatively calm waters of the wide St. Lawrence River. The days spent carefully navigating the Thousand Isles area had almost been pleasant; at least, what Greene had seen from the deck between heaves.

The Hudson's Bay Company and the generations of settlers from France and Great Britain alike - as well as many other European nations - had long since civilized the area on either side of the river, though to the south the land had been ceded to the Americans after their dreadful bloody war nearly a century prior.

Standing at last on solid ground, Greene gave into the temptation to sink down onto the steamer trunk he had brought off of the ship with him. The rest was being delivered by unhappy seamen even as he pressed the soles of his boots ever more firmly against the still and comforting ground. All full, of course, of those gadgets and inventions and necessary tools that he couldn't bare to leave behind. Greene lifted his walking stick, placed it between his legs, folded his hands over its topper, and lay his forehead upon his knuckles, near to shaking with relief. It was, of course, not at all the pose of a proper young British gentleman so it was to his great chagrin that it was in that very pose that Judge Levius P. Sherwood found him.

It was not exactly the sort of impression that he had hoped to make upon his arrival in the Dominion of Canada.

"Lord MacLeish, I presume?" Sherwood asked, tipping his hat at the young aristocrat surrounded by a pile of steamer trunks. Greene knew he must look a bit of a fool, mostly by the sly curve of the other man's lips, hidden only marginally by the outer fringes of his hearty moustache.

Greene hastily gained his feet, patting the dust off of his lapels as he did so. "Then you must be Judge Sherwood," Greene said. He'd received another letter on board the ship explaining who his contact in the Dominion would be; a portly old Judge in charge of maintaining the peace and order in York, though not a man to be initiated into the Institute. "And please, just Mister Greene is fine. My uncle was the Lord MacLeish, not I, and the title died with him, I'm afraid."

"Ah, quite," the Judge said. "Welcome to the Dominion of Canada, sir, and my mighty beautiful town of York."

Greene accepted the welcome and the handshake that accompanied it, and wondered at how quickly a regional accent can change in such a short amount of time. The voice might have held the race of a British accent a generation ago, but now it was level and vowel-less, only a few round 'o's clinging stubbornly where they it could. Judge Sherwood, surely, if not second or third generation of European born to these shores, couldn't have been in Canada for so very long. He spoke in the same flattened vowels and soft consonants of all the men around him, though with a decidedly more cultured air. Greene wondered what they must think of his own, somewhat rural, Scottish brogue, nearly musical compared to the evenness of the colonial cadance.

"If all your luggage is accounted for, sir," Sherwood said, "I'll have it sent 'round to the boarding house. My wife had to find it for me, of course. She says they have the best laundress in the whole block, though breakfast there ain't what it should be. Don't know nothing about a good boarding house myself, of course. Mrs. Sherwood spoils me rotten, she does, and she'll spoil you 
too, if you'll come 'round for dinner this evening. Do say yes, she's been frantic over it for a week."

"Then of course my answer is yes, sir," Greene said with a carefully practiced smile, though his stomach rolled at the thought of putting anything into it just yet.

The Judge looked over his shoulder at a man waiting at the side of an empty horse-drawn cart. He flicked his fingers and within moments there was a gang of strapping young men heaving Greene's trunks into the back of the cart and galloping off towards... well, the boarding house, Greene hoped. Greene had only just managed to save his own battered carpet bag of most treasured tools - the watch tools given to him in the will from his great uncle - and clean garments from being hoisted into the back of the cart along with everything else.

"And for you and I," the Judge said, patting his rotund belly, "dinner! My home is this way, and I'm certain you're not opposed to a bit of brisk exercise to warm up the blood and prepare the appetite?"

"If you please," Greene said, "I would like to go survey the property before hand."

"Survey the...?" The Judge repeated, and then trailed off. "It's naught but a mud pile this time of year, Mister Greene. The snow has barely melted."

"All the same, Judge, I am dreadfully curious."

The Judge frowned, but flicked his hand again, and a stocky man driving an open phaeton that barely looked sturdy enough to weather the deep ruts of the dirt roads around them swung up. Greene stared at the contraption - for it could hardly be called a carriage - in mild horror. It was barely a phaeton at all. The word was far too elegant for so basic a hack.

"Need a lift, guv?" the driver asked, and his accent was still pure Cheapside.

"What?" Greene squawked, before he could reign himself in. "In that?"

"'s safe, I swears," the driver said with a yellow grin. The Judge was already hoisting his considerable amount of self inside.

"God in heaven. This is a country of madmen!" Greene said, but did his best to scramble up onto the poorly sprung plyboard bench beside the Judge without smearing mud up the side of his pant leg from the spokes of the vehicle.

"Madmen and blackflies, sir!" the driver shouted cheerily. He stirred up his horse with a theatrical flick of his whip and an arching snap of the reigns. The phaeton surged forward and Greene dug his fingers into the inadequate upholstery and cursed Torchwood roundly but silently.

The driver laughed again and said: "Madmen and blackflies!" Chapter Two: Madmen

The Doctor was not sulking.

He was brooding; reflecting; meditating; digesting; percolating; pondering; and all perhaps a bit morosely, but he certainly was not sulking. Time Lords did not sulk. It was not... Time Lordy.

The Doctor toed off his Converses. He never wore socks under them, it disrupted his ability to feel the ground under the soles, muffled the warmth and texture of the crusts of each of the planets he stepped foot on, new and wonderful each and every time, no matter how many instances he returned. No person could have possibly stepped on each and every single square centimeter of a planet. Even if they tried, it would all be different by the time he was done. The Doctor liked to think this way, liked to know that he hadn't seen all of Earth yet, not yet, that there was still more to see, to do, more ground to walk upon. 
The Doctor leaned back on the ratty sofa in his control room - his only comfortable piece of furniture in the new design - and scooted his bum forward to the very edge. Head back, neck resting on the curve of the foam, he stretched out long legs and propped up his heels on the ledge of the TARDIS control console. He flexed, spreading out long toes. It's been a few regenerations since he'd been so lean and gawky; his fifth form had been tallish, thinish, but this was the reediest he'd been yet. Every other form had been stockier, shorter or rounder or more barrelchested. And far too much frothy curly hair.

He really did want to be ginger, just the once.

The Doctor thought of Jackson Lake and a small smile tugged at the corner of his mouth. Jackson had made quite an adequate Doctor, for not being a Time Lord, even if he hadn't been ginger either. The Doctor had been impersonated before, of course, by disreputable people and scam artists trying to trade in on his reputation, the legend of who he was.

His reputation.

The Oncoming Storm, the Star at the Heart of Forever, the Destroyer.

The Doctor's little smile sunk into a frown. He sighed heavily, brushing his fingers through the flop of brown hair hanging over his forehead.

His hearts hurt.

From somewhere under his feet, the TARDIS gave a sort of shrill beeping cry, a warning that she had locked on a distress signal. "I'm tired."

"Not today, old girl," the Doctor said, flicking the switch for silent mode with his big toe.

The hack stopped with a jaw-shuddering jolt next to a field of mud that was indistinguishable from any other, except that it had a fence surrounding it on three sides. The forth was open to the road and it was here that the hack parked. The fence was new, the wood still golden and wet looking. In time it would age and buckle, turning white and bubbled as it dried out. For now, it was straight and fresh.

Judge Sherwood was quite content to remain in his seat, and Greene was quite content to leave him there. Greene dismounted quickly, rubbing a hand over his stomach discretely, praying that he didn't embarrass himself further by emptying what meagre portion of sea biscuit he had managed to keep down that morning into the gutter.

Taking a few deep gulps of air, Greene straightened and shook himself all over once. Then he narrowed his eyes and stared at the field. It was half the size of a city block, just the right amount of room for a new Hub, but the wetness of the field had him anxious.

"The snow just finished melting, you said, Judge?" Greene asked over his shoulder; seeking clarification. "It's gone March; surely you can't have had snow all the way through Easter?"

The Judge smiled ruefully. "Canada is, I am afraid, a very cold place. We get buried in every year. Some days I think I should call in the militia just to dig out the roads for us."

Greene folded his hands behind his back and surveyed the plot of nothing and scrub. He scowled. This put his plans back at least another month. He would have to wait for the field to dry out before he could even begin to conceive of digging. He could waste a few days in building a fourth side to the fence, high and wide to discourage prying passersby, and a few more in building a quick shed to store the tools and materials that he would begin to accumulate, but beyond that no work on the actual Hub itself could proceed. 
Judge Sherwood, shimmying across the seat in a most ungainly manner so as to be nearer, called out to Greene: "As I am the person from whom you've just bought this strip of nothing land. I must admit, I am very curious about this particular arrangement..."

He trailed off there with a sideways glance at the hack driver, which more than anything communicated to the interested man that the business dealings of Greene and Sherwood were not for his ears.

Greene scowled harder, marching back to the hack, splashing wet brown mud up the sides of his boots and whispered into the Judge's face, hat in hand and held to the side to shield the driver's ears from his words and eyes from the movement of his lips when he retorted, "I believe the letter of purchase was quite clear."

Sherwood frowned and leaned in to match Greene's surreptious secrecy. "But all the land under the lot, sir?"

"Yes."

"But... not above sir?"

"No."

Sherwood paused, a shrewd light coming into his gaze. "So, for mining then, sir?" Greene sighed and shook his head. Already he could plot the course that this conversation was likely to take and quickly tired of it. He'd had the same conversation three times over with the three separate property owners of the lands in Glasgow, Cardiff, and London from whom Torchwood had procured land for its Hubs.

"No," Greene said in a curt tone which indicated that the topic was closed.

Or rather, would have indicated it for anyone with any sense. Judge Sherwood, it seemed, had more curiosity than sense however and so continued with "Then for-"

And Greene, who wasn't often given over to being rude, but had just completed the most uncomfortable and exhausting voyage of his life and longer for nothing more than a dry, warm, unmoving bed and a hot, simple meal, snapped, "Judge Sherwood, if I wanted you to know for what I was going to use the land, do you think I would not have told you already?"

The Judge, chastened, sucked on his moustache and said nothing. Greene sighed and scrubbed his free hand through his hair. It was dirty and oily and was sure smelled just as unpleasant as the rest of him. A bath, oh, what Greene wouldn't give for a bath. Though he wasn't about to get one if he remained at odds with the one man who was, at present his only ally and benefactor, as well as acquaintance, in York.

"Judge Sherwood..." he began, but the other man shook his head.

"No, no, of course, sir, I understand. What you choose to do with your own property is of course none of my concern. But, ah, just one further point of clarification?"

Greene closed his eyes very tightly for a brief second, just to help fend off the urge to roll them. "Yes?"

"I'm free to sell the land above your piece when you're... finished?"

"Yes. I expect to be finished in a year, if the weather stays fine over the fall - I will of course be erecting a fence to discourage gawking passersby. And you, of course, as per our agreement, will tell no one of our arrangement."

"Yes, but... sir, the work team you requested - now, sir, I really must intervene here, they're all the worst sort of thugs..." "And all the sort of thugs I need." Greene did not know the men who'd been arranged to perform his menial labour specifically, but he knew the type that Torchwood preferred; strong, stupid, and able to keep secrets. And dispensable and unmissed by society, should one choose to open his mouth. 
Sherwood sucked on his moustache again and seemed to resolve himself towards a decision to speak. "You won't be making any trouble in my town, sir. Business acquaintance or not, if any thuggery or trouble-"

Greene held up a forestalling hand. "I assure you, Judge Sherwood, that there will be no trouble. Absolutely none." Greene turned away to survey the land one more time, and under his breath muttered: "Not the sort you'll be prosecuting at any rate, Judge."

Then he dropped his hand, placed his hat back on his head, and nodded firmly. "Now, shall we to your industrious wife's table before our supper goes cold?"

Judge Sherwood, back in the realm of a topic he could better understand and appreciate, smiled and nodded and slid sideways on the hack so as to allow Greene access to his seat.

"Ah," Greene said, eyeing the contraption distrustfully. "Believe me when I say, Judge," Greene said, desperate to reassure. "If you want me have any sort of appetite at all for your wife's fine cooking, that we ought to walk."

He'd secretly taken to calling the other Doctor, the clone from-his-hand Doctor, "Handy". It was short, apt, and above all, filled with the sort of quick self-depreciation that he had recently surprised himself by admitting to.

Rude, not-ginger, and self-loathing.

Fantastic.

The Doctor lifted his tea cup to his lips, and frowned when the liquid that sloshed against his mouth was cold. He frowned and glared down at the cup; how long ago had it been since he'd reheated it the last time? Three pages? Ten? He set aside the book - Agatha Christie's The Wasp - tented face-down on his knee to save his spot, and retrieved the sonic screwdriver from his shirt pocket. Pointing it at the cup, he flicked the switch for a few seconds. The tea burbled and came to an almost immediate boil. Satisfied, he put away the screwdriver, picked up the book again, and held onto the cup carefully, so as not to burn the backs of his knuckles on the side of it.

The Doctor hadn't been fond of tea in his youth; back on Gallifrey, his father had drunk it every morning, wheaty-tasting and thick black. The Doctor hadn't liked tea, even Chinese or Japanese clear teas, until he'd visited England. The subtle flavour or Orange Peakoe, the sweet nip of Earl Grey, all a cloudy milky delight... that was tea that the Doctor enjoyed.

He tried to concentrate on that, on the scent carried throughout the control room by the steam, on the warmth radiating from the cup. He did not imagine the comforting glug of tea chugging out of a fallen thermos, spilling through the grille next to his own slack face, onto the Heart of the TARDIS. He did not, did not replay the image of Handy and Rose smooching on the beach in his mind. He did not think of Donna, brilliant shining Donna Noble, hurling the glowing red necklace into the lake, of the angry Vespifore diving down into its own doom after it.

The Doctor picked up his novel. He glared at the book in his hand, (both of them his, not belonging to someone else, not attached to someone else's arm, not resting on Roses' shoulder as she pushed her face up against his) reading and rereading the same sentence over and over before he had even registered that he'd done so.

Anger, swift and startling, washed over him.

The Doctor threw his tea cup hard at the wall. 
It shattered, steaming tea and stained white porcelain spraying outwards in a beautiful display of applied physics. He stared at the dripping stain on the wall of the TARDIS, then at his own shaking hands, in horror. In all his nine hundred and five years, the Doctor couldn't recall ever getting angry enough to chuck a tea cup against a wall. What on ... on Earth was wrong?

Clambering to his feet, relishing the cold bite of the grille against his bare soles, the Doctor stood beside the control console and threw the novel back down onto the sofa. He couldn't...he couldn't think. He couldn't concentrate on anything.

Persistent, and perhaps as an attempt to draw him out of his moody funk, the TARDIS' signal locator started sounding off again, shrill and just that side of grating to shove the Doctor's distracted mood into downright crankiness.

"No," he said, flicked the switch back to silent again, and stomped out of the control room as best as able in bare feet. 